$\frac{10}{6 / 16 / 9}=9 m(1)$
Orm

$\rightarrow$ OAK RIDGE
NATIONAL
LABORATORY

MARTIN MARUETRA

ORNL/TM-11887

\title{
The Oxidation of Type 310S Stainless Steel in Mixed Gases at Elevated Temperatures
}

\author{
J. S. Wolf \\ O. B. Cavin \\ J. H. DeVan
}

\section{MANAGED BY}

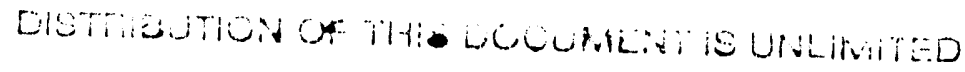

MABTIM MARIETTA ENERGY SYSTEMS, INC.

FOR THE UNITEO STATES

oferantranerit of caurngy 
This report has been reproduced directly from the best available copy.

Available to DOE and DOE contractors trom the Office of Scientific and Technt cal Information, P.O. Box 62, Oak Ridge, TN 37831; prices avallable from (515) 576-8401, FTS 626-8401.

Ayailable to the public from the National Technical Information Service, U.S. Department of Commerce, 5285 Port Royal Rd., Springtield, VA 22.161;

This report was prepared as an account of work sponsored by an agency of the United States Government. Neither the United States Goveriment nor any agency thereot, nor any of their employees, makes any warranty, express or implled, or assumes any legal liablity or responsibillty for the accuracy, com. pleteness, or usofulness of any information, apparatus, product, or process dieclosed, or represents that its use would not infringe privately owned rights. Reference herein to any specific commercial product, process, or service by trade name, trademark, manufacturer, or otherwise, does not necesearly consth tute or imply its endor sement, recommendation, or favoring by the United States Government or any agency thereor. The viows and opinions of euthors expressed herein do not necesserily state or reflect those of the United States Government or any agency thereof. 
ORNL/TM--11887

DE92 014941

Metals and Ceramics Division

THE OXIDATION OF TYPE 310S STAINLESS STEEL

IN MIXED GASES AT ELEVATED TEMPERATURES

\author{
J. S. Wolf \\ O. B. Cavin \\ J. H. DeVan
}

Date Published: April 1992

Prepared for the

DOE Office of Transportation Systems

EE 0600000

Prepared by the

OAK RIDGE NATIONAL LABORATORY

Oak Ridge, Tennessee 37831-6285

managed by

MARTIN MARIETTA ENERGY SYSTEMS, INC.

for the

U.S. DEPARTMENT OF ENERGY

MASTER under contract DE-AC05-84OR21400 


\section{CONTENTS}

LIST OF TABL

LIST OF FIGURES $\ldots \ldots \ldots \ldots \ldots \ldots \ldots \ldots \ldots \ldots \ldots \ldots \ldots \ldots \ldots \ldots \ldots \ldots$

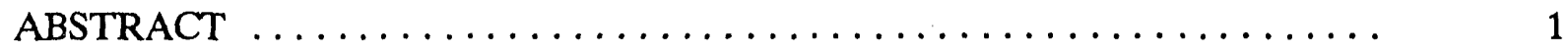

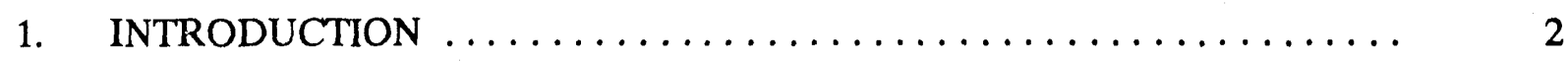

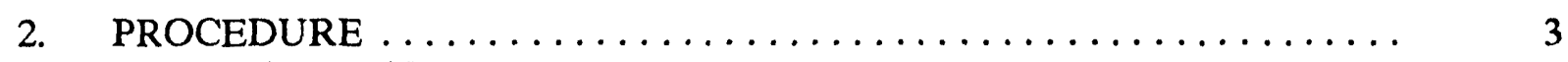

$2.1 \quad$ MATERIALS . . . . . . . . . . . . $\ldots \ldots \ldots \ldots \ldots \ldots \ldots$

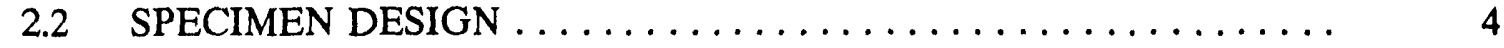

2.3 SPECIMEN PREPARATION $\ldots \ldots \ldots \ldots \ldots \ldots \ldots \ldots \ldots \ldots \ldots \ldots$

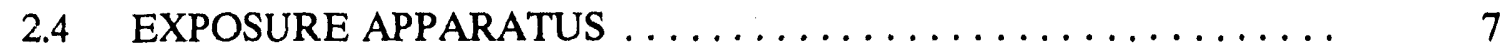

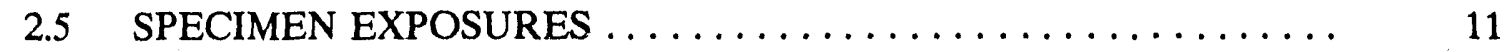

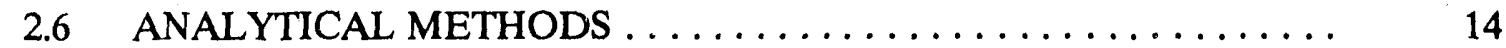

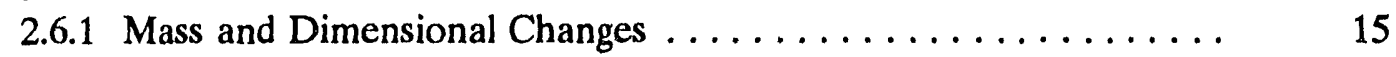

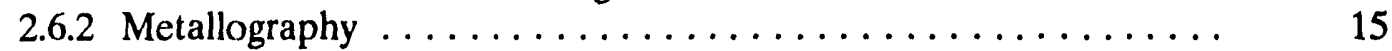

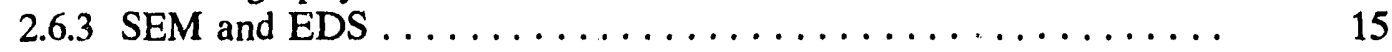

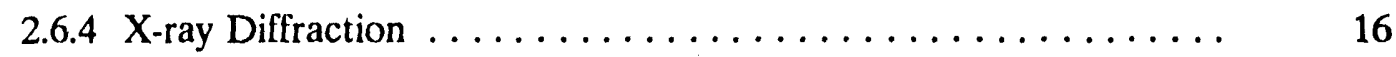

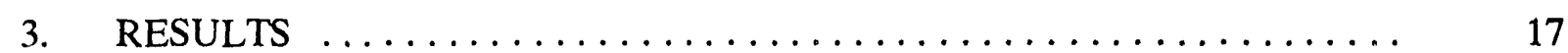

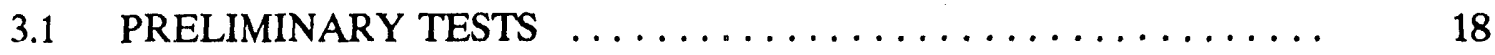

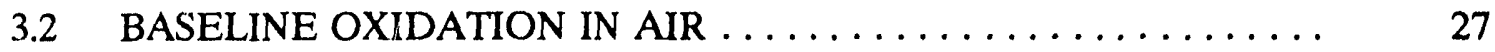

3.3 "LEAN" SULFIDIZING ATMOSPHERES $\ldots \ldots \ldots \ldots \ldots \ldots \ldots \ldots . \ldots \ldots$

3.4 "RICH" SULFIDIZING ATMOSPHERES $\ldots \ldots \ldots \ldots \ldots \ldots \ldots \ldots .50$

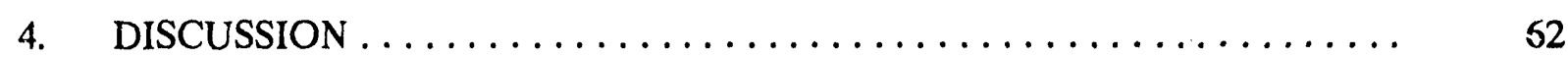

4.1 THERMOCHEMICAL CONSIDERATIONS $\ldots \ldots \ldots \ldots \ldots \ldots \ldots$

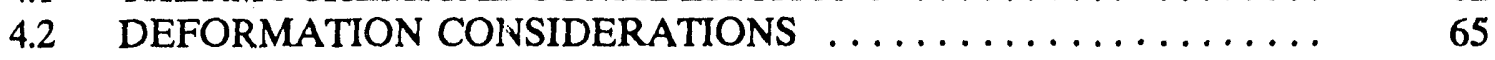

4.3 STRUCTURAL AND KINETIC CONSIDERATIONS $\ldots \ldots \ldots \ldots \ldots .67$

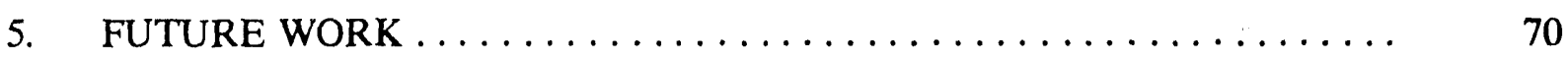

6. CONCLUSIONS $\ldots \ldots \ldots \ldots \ldots \ldots \ldots \ldots \ldots \ldots \ldots \ldots \ldots \ldots \ldots \ldots \ldots$

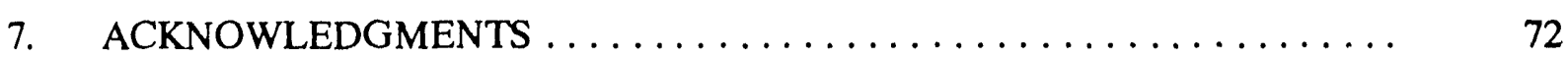

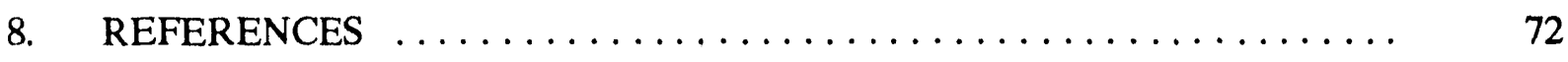

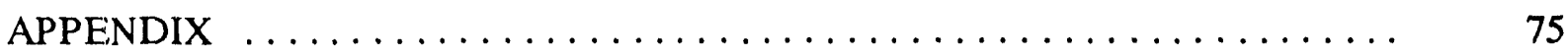




\section{LIST OF TABLES}

2. Electropolishing conditions for Type 310 S specimen blanks . . . . . . . . 6

3. Exposure conditions for $310 \mathrm{~S}$ specimens $\ldots \ldots \ldots \ldots \ldots \ldots \ldots \ldots$

4. Deformation of ell-shaped specimens in air at 800 and $900^{\circ} \mathrm{C} \ldots \ldots \ldots \ldots$

5. X-ray diffraction data for specimen AR7; alloy $310 \mathrm{~S}$ before

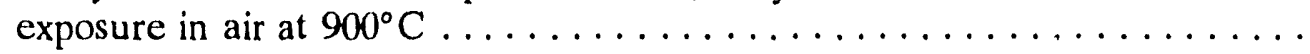

6. Qualitative EDS analyses for specimen E1R3 after 120-h exposure in air at $900^{\circ} \mathrm{C}$ (summary of relative elemental

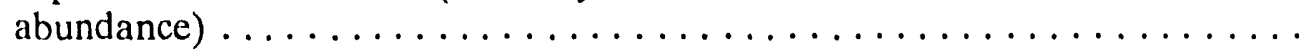

7. Room-temperature X-ray diffraction data for specimen AR7 after 5 -h exposure in air at $900^{\circ} \mathrm{C} \ldots \ldots \ldots \ldots \ldots \ldots \ldots \ldots$

8. Qualitative EDS analyses for specimen AR1 after 24-h exposure in air at $900^{\circ} \mathrm{C}$ (summary of relative

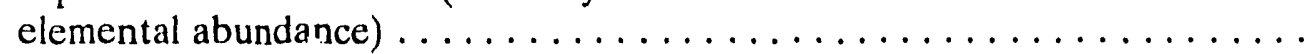

9. X-ray diffraction data for specimen AR1 after 24-h exposure

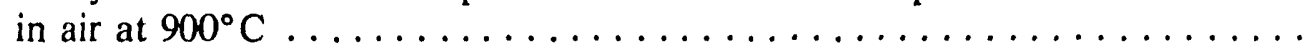

10. Qualitative EDS analyses for specimen AR4 after 216-h exposure

in air at $900^{\circ} \mathrm{C}$ (summary of relative elemental abundance) $\ldots \ldots \ldots \ldots$

11. Qualitative EDS analyses for specimen AR4 after 216-h exposure in air at $900^{\circ} \mathrm{C}$ (summary of relative elemental

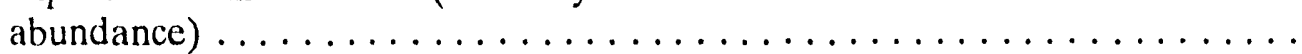

12. X-ray diffraction data for specimen AR6 after 384-h exposure in air at $900^{\circ} \mathrm{C}$ (File CT357C) $\ldots \ldots \ldots \ldots \ldots \ldots \ldots \ldots \ldots \ldots \ldots$

13. Deformation of ell-shaped specimens in the "lean" sulfidizing atmosphere at $900^{\circ} \mathrm{C} \ldots \ldots \ldots \ldots \ldots \ldots$

14. Qualitative EDS analyses for specimens E1R4, E1R5, and AR8 after 24-h exposure in the "lean" sulfidizing atmosphere (summary of relative elemental abundance) $\ldots \ldots \ldots \ldots \ldots \ldots \ldots$

15. Qualitative EDS analyses for specimen AR8 after 24-h

exposure in the "lean" sulfidizing atmosphere at $1000^{\circ} \mathrm{C}$ (summary of relative elemental abundance) 
16. X-ray diffraction data for specimen E1R5 after $24-\mathrm{h}$

17. Qualitative EDS analyses for specimen E1R6 after 216-h exposure in the "lean" sulfidizing atmospnere at $900^{\circ} \mathrm{C}$ (summary of relative abundance) $\ldots \ldots \ldots \ldots \ldots \ldots$

18. Qualitative EDS analyses for specimen E1R8 after 216-h exposure in the "rich" sulfidizing atmosphere at $900^{\circ} \mathrm{C}$ (summary of relative elemental abundance) $\ldots \ldots \ldots \ldots \ldots \ldots$

19. Qualitative EDS analyses for specimen E1R8 after 216-h exposure in the "rich" sulfidizing atmosphere at $900^{\circ} \mathrm{C}$ (summary of relative abundance) $\ldots \ldots \ldots \ldots \ldots \ldots \ldots \ldots \ldots$

20. Qualitative EDS analyses for specimen AR11 after 2-h exposure in the "rich" sulfidizing atmosphere at $900^{\circ} \mathrm{C}$ (summary of relative elemental abundance) $\ldots \ldots \ldots \ldots \ldots \ldots$

21. X-ray diffraction data for specimen AR11 after 2-h exposure in "lean" sulfidizing atmosphere at $900^{\circ} \mathrm{C} \ldots \ldots \ldots \ldots \ldots$

22. Melting temperatures of selected metal sulfides and cutectic temperatures $^{13} \ldots \ldots \ldots \ldots \ldots \ldots \ldots \ldots \ldots \ldots \ldots \ldots \ldots$

23. Relative sulfur abundance in special $\mathrm{CaSO}_{4}$ lot 


\section{LIST OF FIGURES}

1. Typical "flat" and "ell"-shaped $310 \mathrm{~S}$ specimens prior

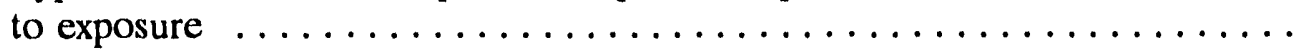

2. Mandrel used to bend "ell"-shaped specimens in a consistent

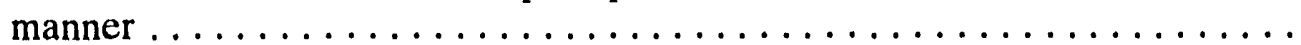

3. Typical quartz vessel used in the air oxidation of flat specimens

4. Furnace fixture used in the air oxidation of flat specimens $\ldots \ldots \ldots \ldots \ldots$

5. Quartz capsule used in the exposure of specimens to sulfidizing gases (shown prior to the loading and re-fusing operations)

6. Quartz capsule used in the exposure of specimens to

sulfidizing jases (shown after the final sealing operation) $\ldots \ldots \ldots \ldots \ldots$

7. Photomicrograph of a transverse section of specimen E1R3

after 120 -h expusure in air at $900^{\circ} \mathrm{C}$ (glyceregia etch) $\ldots \ldots \ldots \ldots \ldots$

8. Electron micrograph showing the transverse scale structure of specimen E1R3 after 120-h exposure in air at $900^{\circ} \mathrm{C}$

9. Changes in the interplanar spacing of scale compounds

on specimen AR7 during its early exposure in air at $900^{\circ} \mathrm{C}$.

10. Square of specific mass gain as a function of time for specimens exposed in air at $900^{\circ} \mathrm{C} \ldots \ldots \ldots \ldots \ldots \ldots \ldots \ldots$

11. Electron micrographs showing the scale structure of specimen AF1 after 24 -h exposure in air at $900^{\circ} \mathrm{C}$

12. Photomicrograph of a transverse section of etched specimen AR4 after 216 -h exposure in air at $900^{\circ} \mathrm{C}$

13. Electron micrographs showing the scale structure of specimens AR4 and AR5 after exposure in air at $900^{\circ} \mathrm{C}$

14. Square of specific mass gain as a function of time for specimens exposed in the "lean" sulfidizing atmosphere at $900^{\circ} \mathrm{C}$ 
15. Electron micrographs showing the scale structure of specimens E1R4 and AR8 after exposure in the "lean"

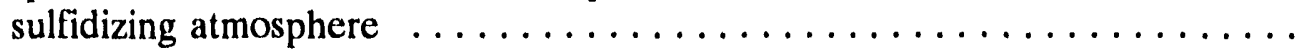

16. Electron micrographs showing the scale structure of specimens E1R5 and E1R7 after exposures in the "lean" sulfidizing atmosphere at $900^{\circ} \mathrm{C} \ldots \ldots \ldots \ldots \ldots \ldots \ldots$

17. Micrographs of the transverse scale structure of specimen E1R6 after 216-h exposure in the "lean" sulfidizing atmosphere at $900^{\circ} \mathrm{C}$

18. Square of specific mass gain as a function of time for specimens exposed in the "rich" sulfidizing atmosphere

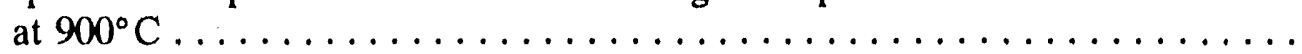

19. Photomicrograph of a transverse section of specimen AR11 after 2 -h exposure at $900^{\circ} \mathrm{C}$ in the "rich" sulfidizing

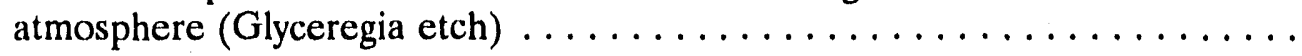

20. Photomicrograph of as-polished transverse section of specimen AR11 after 2-h exposure at $900^{\circ} \mathrm{C}$ in the "rich"

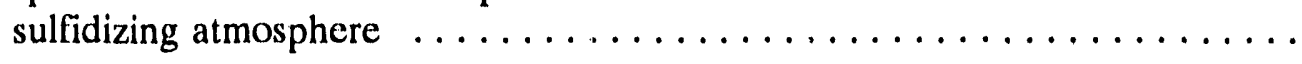

21. Photomicrograph of etched transverse section of specimen E1R8 after $24-\mathrm{h}$ exposure at $900^{\circ} \mathrm{C}$ in the "rich"

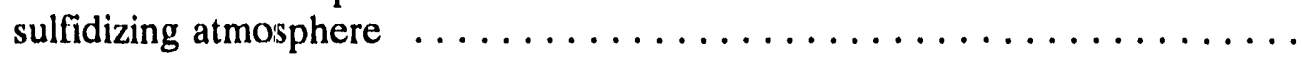

22. Electron micrographs of the scale structure of specimen E1R8 after 24-h exposure in the "rich" sulfidizing

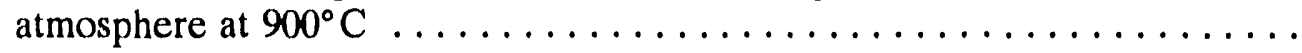

23. Electron micrographs of the scale structure of specimen AR11 after 2-h exposure in the "rich" sulfidizing

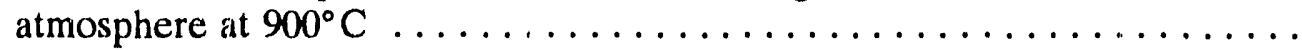

24. Thermochernical diagram at $9100^{\circ} \mathrm{C}$ for the constituents of $310 \mathrm{~S}$ illustrating their critical oxygen and sulfur potentials, the atmospheres used in the research, and the gas potentials, associated with the coal gasification

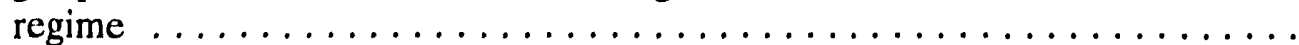




\title{
THE OXIDATION OF ' TYPE 31OS STAINLESS STEEL IN MIXED GASES AT ELEVATED TEMPERATURES*
}

\author{
James S. Wolft, O. Burl Cavin, and J. H. DeVan
}

\begin{abstract}
Sheet specimens of Type 310 S stainless steel were exposed to air as well as to "lean" and "rich" sulfidizing atmospheres at temperatures near $900^{\circ} \mathrm{C}$ to determine the relationships that exist between the scale structure, the rate of reaction, and the stresses generated during exposure. One goal of this experimental research program was to examine how these factors might be related to the breakdown of protective scales in sulfidizing atmospheres.

It was found that the scales formed in air and the "lean" atmosphere are protective and non-spalling while those formed in the "rich" atmosphere spall, initially react at rates 1,000 times greater than their counterparts in less aggressive atmospheres, and later exhibit a "breakaway"-type rapid reaction. Only those scales formed in air provide the cooperative, tractive interfacial forces required to produce uniform dilatation and deformation of the substrate. However, evidence exists for at least localized stresses in all of the scales examined.

The two-layer scales formed both in air and in the "lean" atmosphere exhibit an inner sesquioxide and an outer spinel layer; however, the crystalline nature and surface topography of the scales formed in these two atmospheres is grossly different which may, in part, account for the observed differences in macroscopic specimen deformation. Metallic particles found embedded in the scale layers of specimens exposed to the "lean" sulfidizing atmosphere may be indicative of a stage in scale evolution, which is a precursor to the breakdown process of the protective scale. In contrast, scales formed in the "rich" atmosphere are very complex, having a minimum of six scale layers as well as subscale product formation. Liquid sulfides are present at $900^{\circ} \mathrm{C}$ and may permeate the inner suite of layers via a vein-like network.

It was concluded that the transport of sulfur through scale layers is an issue that has a strong bearing upon the micro-structure, the state of stress, the barrier quality, and ultimately the potential for breakdown of scales formed in sulfidizing atmospheres. It is, therefore, suggested that the control of oxide grain size may prove to be a fruitful approach in the future development of sulfidation-resistant alloys, and a tentative experimental plan to probe the basis of that possibility is outlined.
\end{abstract}

*Research sponsored by the U.S. Department of Energy, Assistant Secretary for Conservation and Renewable Energy, Office of Transportation Technologies, as part of the High Temperature Materials Laboratory User Program, and Office of Fossil Energy, A Anced Research and Technology Development (AR\&TD) Materials Program, under contract DE-AC(0)584 OR21400 with Martin Marietta Energy Systems, Inc.

tProfessor of Metallurgy, Department of Mechanical Enginecring, Clemson Universily, Clemson, S.C. 


\section{INTRODUCTION}

It has been pointed out that the economy of our country is closely tied to its energy reserves, foreign and domestic, and to the technical methodology that we employ to drive the machinery of our economy. Recently, it has been strongly suggested that we keep our energy-production options open by using our tremendous coal reserve in preference to oil and gas. ${ }^{1}$ One major problem in coal utilization is the selection of materials of construction for long-term applications. A common requirement is the need for components to operate in the presence of both oxygen- and sulfur-bearing gases at elevated temperatures where metallic materials are subject to deterioration. An often-cited mode of deterioration is the loss of an initially protective quality of the scales formed upon metallic surfaces under such conditions-a phenomenon termed "breakaway" corrosion. This phenomenon is especially prevalent for those alloys that depend upon the establishment of chromium-rich scales for their protection at high temperatures. Many engineering and some scientific studies have been made; however, a recent review of the breakaway phenomenon indicates that we still know little about its origin, except that it may possibly be associated with stress development in scale layers. ${ }^{2}$

It is well known that if any metal or alloy is to display outstanding corrosion resistance in a particular environment, then that material must either be noble or it must develop a stable barrier film in that environment. The purpose of the barrier film or scale is, of course, to isolate and insulate the metallic component from the aggressive environment. Some of the methods for producing barrier layers on alloys have recently been summarized and, among those methods, the development of alloys with self-building alumina, chromia, or silica barrier layers is of particular interest. $^{3}$ Thus, it appears that, in order to design barriers of superior quality, we must comprehend the details of their formation and structure so that we can control the transport of material through them. An obvious point at which to start this process of understanding is to examine the naturally formed barrier layers as they are produced upon commercial alloys and in environments of interest to those engaged in the development of economic energy systems.

The purpose of this investigation was to examine the structure of naturally formed scales on one alloy steel and to monitor its reaction kinetics with special reference to the breakaway phenomenon. One thesis of this work was that breakaway may be caused by the natural generation and relaxation of stresses in the scale when alloys are subjected to mixed oxidants at elevated temperature. Type $310 \mathrm{~S}$ stainless steel was selected as the test material for this study on the basis that it is: (1) representative of potential alloys for the coal gasification environment, 
(2) readily fabricable and readily available, and (3) it was initially compounded for hightemperature heat and cyclic oxidation resistance. ${ }^{4}$ Thus, future alloy development programs for coal utilization may well adapt compositions of this type as a starting point.

The behavior of Type $310 \mathrm{~S}$ stainless steel was investigated at temperatures near $900^{\circ} \mathrm{C}$, both in air and in simplified sulfidizing atmospheres that bracket the extremes of those atmospheres associated with the coal gasification regime. The initial focus of this program involved the determination of the rates of chemical reaction, the deformation suffered by the steel due to its high-temperature exposure, and the chemical nature of the reaction products that formed, as well as their crystallography and geometric disposition, upon the metallic substrate. From such knowledge, it was hoped to gain some understanding of the problem of scale breakdown.

\section{PROCEDURE}

In this section of the report are listed the details of this experimental program including the material investigated, its fabrication into specimens, the exposure of those specimens to oxidizing/sulfidizing conditions, and the methods of analysis employed in the examination of specimens. Four general types of specimen exposures were utilized: (1) exploratory tests, (2) baseline oxidation tests in air, (3) exposures in "lean" sulfidizing atmospheres, and (4) exposures in "rich" sulfidizing atmospheres.

\subsection{MATERIALS}

The single metallic specimen material selected for this study was Type 310S stainless steel. Among the relatively formable austenitic stainless steels, this grade is known for its resistance to high-temperature oxidizing environments, which results primarily from its high chromium and nickel content. ${ }^{5}$ Both the nominal and actual compositions sit this alloy are detailed in Table 1. It is noted that the actual composition of this alloy is within the nominal analysis with one exception, the presence of the reactive element titanium. The presence of titanium was verified by independent means (energy-dispersive spectroscopy analyses discussed later).

Tests conducted in air required no special oxidizing reagents, while those conducted in the "lean" simulated sulfidizing atmosphere utilized a technical grade of calcium sulfate in order to generate the reactive gaseous atmosphere. The $\mathrm{CaSO}_{4}$ used here was a 10 to 20 mesh size fraction 
Table 1. Nominal and actual composition of Type $310 \mathrm{~S}$ stainless stecl

\begin{tabular}{llc}
\hline & \multicolumn{2}{c}{ Weight percentage } \\
\cline { 2 - 3 } Element & Nominal $^{5}$ & Test alloy $^{6}$ \\
\hline Chromium & 24 to 26 & 25.0 \\
Nickel & 19 to 22 & 20.0 \\
Manganese & $2.0 \max$ & 1.8 \\
Silicon & $1.50 \max$ & 0.47 \\
Carbon & 0.08 max & 0.062 \\
Titanium & 0.00 & 0.05 \\
Phosphorous & $0.045 \max$ & 0.044 \\
Sulfur & 0.03 max & 0.007 \\
Iron & Balance & Balance \\
\hline
\end{tabular}

of the commercial product known as Drierite. For tests conductea in the "rich" sulfidizing atmosphere, a mixture of $\mathrm{CaSO}_{4}$ and triple-distilled elemental sulfur was used, the mixture being stoichiometric with respect to the production of $\mathrm{SO}_{2}$ by complete reaction. A discussion of the reactive atmospheres produced by these techniques is presented in the Appendix.

\subsection{SPECIMEN DESIGN}

Two different specimen geometries were used in this program: a "flat" specimen (designated as the AR series) and an "ell"-shaped specimen (designated as the E1R series). Both geometries are illustrated in Fig. 1. The flat specimens had a single hole at one end for suspension purposes, while the "ell" specimens had a similar hole for suspension at one end and, additionally, two holes at the opposite end for the purpose of determining dilatation. These two types of specimens were intended for two different purposes. The primary use of the flat specimens was to secure kinetic and microstructural data related to the oxidation and sulfidation of the $310 \mathrm{~S}$ material. The "ell"-shaped specimens were designed to secure strain-related as well as kinetic and microstructural data.

The "ell"-type specimens were designed to sense strain in two ways. First, the convex and concave surfaces of an "ell-shaped" specimen are of difrerent length; thus, reactions dependent upon the extent of interfacial area may generate stresses of sufficient magnitude to cause "ell" 
YP5353

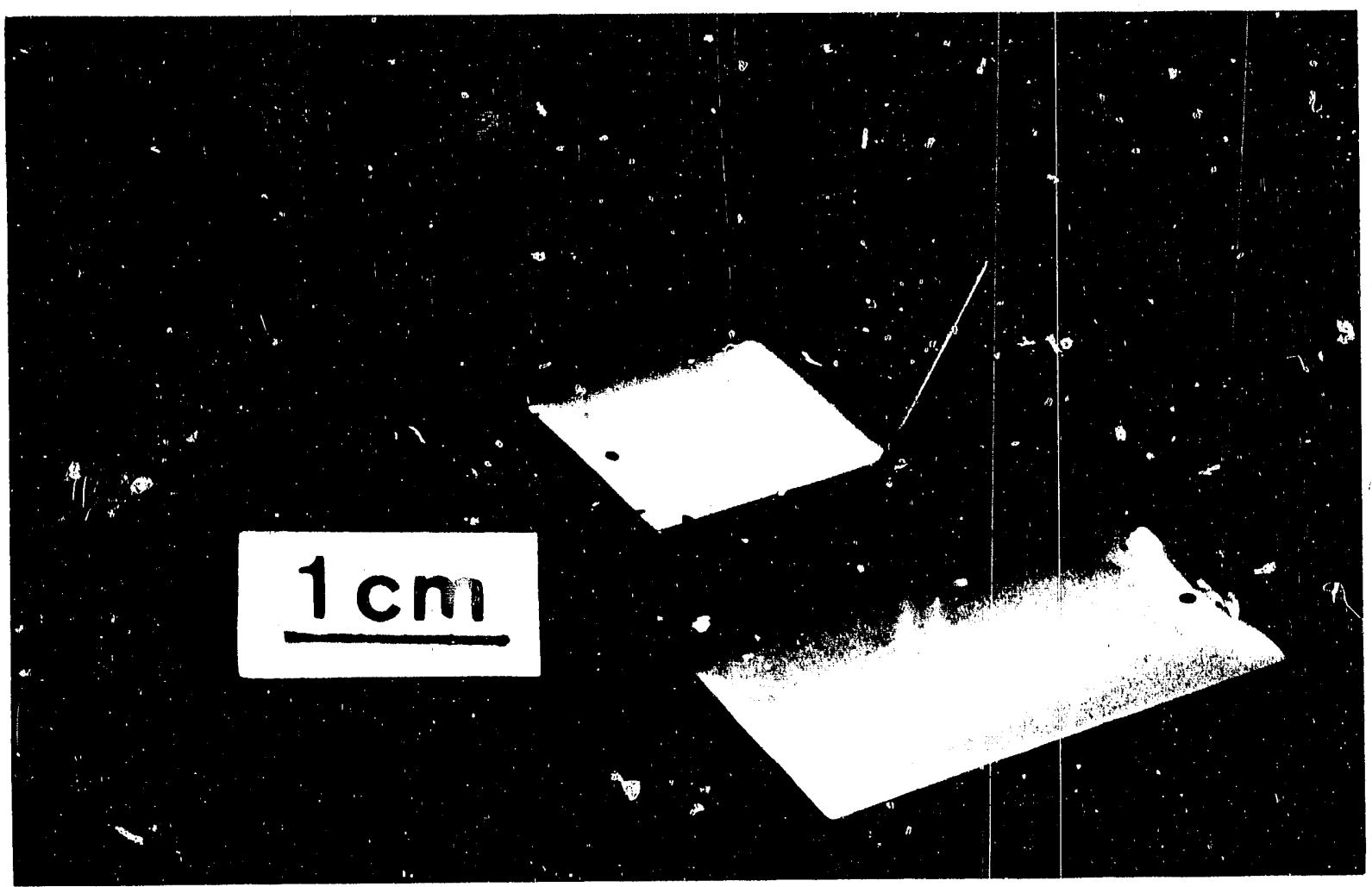

Fig. 1. Typical "flat and "ell"-shaped 310S specimens prior to exposure.

closure during exposure. ${ }^{7}$ Second, the two fiducial holes located near the end "ells" may be used to determine the planar dilatation of the thin-sheei specimens if one monitors the separation of their centers as a result of exposure. ${ }^{7}$ The primary assumptions for this case are: (1) that the out-of-plane warp is negligible and (2) that the hole edges are symmetrically altered as a result of exposure.

\section{SPECIMEN PREPARATION}

All specimens for this program were fabricated from the same lot of material, a portion of $310 \mathrm{~S}$ plate stock having the dimensions $12 \times 1.5 \times 0.063$ in." This material was cold rolled

*Althragh the policy of the Oak Ridge National Laboratory is to report its work in SI units, primarily customary units are used in this report. The engincering industry and the X-ray diffraction community presently use the customary units. The usage of the SI units would limit the usefulness of this report to the primary readership. 
to a thickness of 0.013 in., hydrogen annealed at $900^{\circ} \mathrm{C}$ for $15 \mathrm{~min}$, and then fiuish rolled to 0.010 gage. Specimen blanks, nominally 1 by 0.5 in., were sheared from this stock with the 1 -in. dimension being parallel to the rolling direction.

Subsequent to drilling the 1/32-in.-diam suspension and fiducial holes, the flat faces of the specimens were manually ground on 600 -grit $\mathrm{SiC}$ metallographic paper using double-sided tape to fix them to a backing block. Each blank was then electropolished under the conditions shown in Table 2.

Table 2 Electropolishing conditions for Type 310 specimen blanks

\begin{tabular}{ll}
\hline Electrolyte: & $45 \%$ phosphoric acid $\left(\mathrm{H}_{3} \mathrm{PO}_{4}\right)$ \\
& $40 \%$ sulfuric acid $\left(\mathrm{H}_{2} \mathrm{SO}_{4}\right)$ \\
& $15 \%$ distilled water $\left(\mathrm{H}_{2} \mathrm{O}\right)$ \\
Temperature: & Room temperature $\left(25^{\circ} \mathrm{C}\right.$ nominal) \\
Cathode: & 3 -in.-diam perforated stainless steel \\
Anode: & $310 \mathrm{~S}$ specimen blank \\
Potential: & $24 \mathrm{~V}$, closed circuit \\
Current: & $27 \mathrm{~A}$ (nominal); $\mathrm{CD}=27 \mathrm{~A} /$ in. $^{2}$ \\
Duration: & 15 (nominal) \\
\hline
\end{tabular}

After electropolishing, the specimens were rinsed in distilled water to remove the residual electrolyte, and the lengths of those specimens to be formed into "ells" were measured. The electropolishing operation was found to remove approximately 0.0002 in. of material from each face of the specimen. In order to produce "ells" of a consistent shape, a mandrel with a cylindrical radius of $1 / 8$ in. was fabricated for the purpose of bending the flat sheet; this device is illustrated in Fig. 2. The specimens were then placed in an alumina boat, in groups of seven or eight, and were provided a stress-relief anneal in flowing hydrogen for a period of $5 \mathrm{~min}$ at $900^{\circ} \mathrm{C}$. As this process produced a very thin tarnish layer, the specimens were subsequently re-electropolished to a bright finish using the procedure outlined above.

At this point, the mass of each specimen was determined using a five-place Mettler Model AE 240 analytical balance. The major dimensions of the specimens were determined to the nearest 0.0001 in. using vernier calipers, and the diameters of all holes, including the center-tocenter separations of the fiducial holes for the "ell" specimens, were determined to the same accuracy using a Nikon Measurescope Model II equipped with electronic readout. In addition, 
YP5352

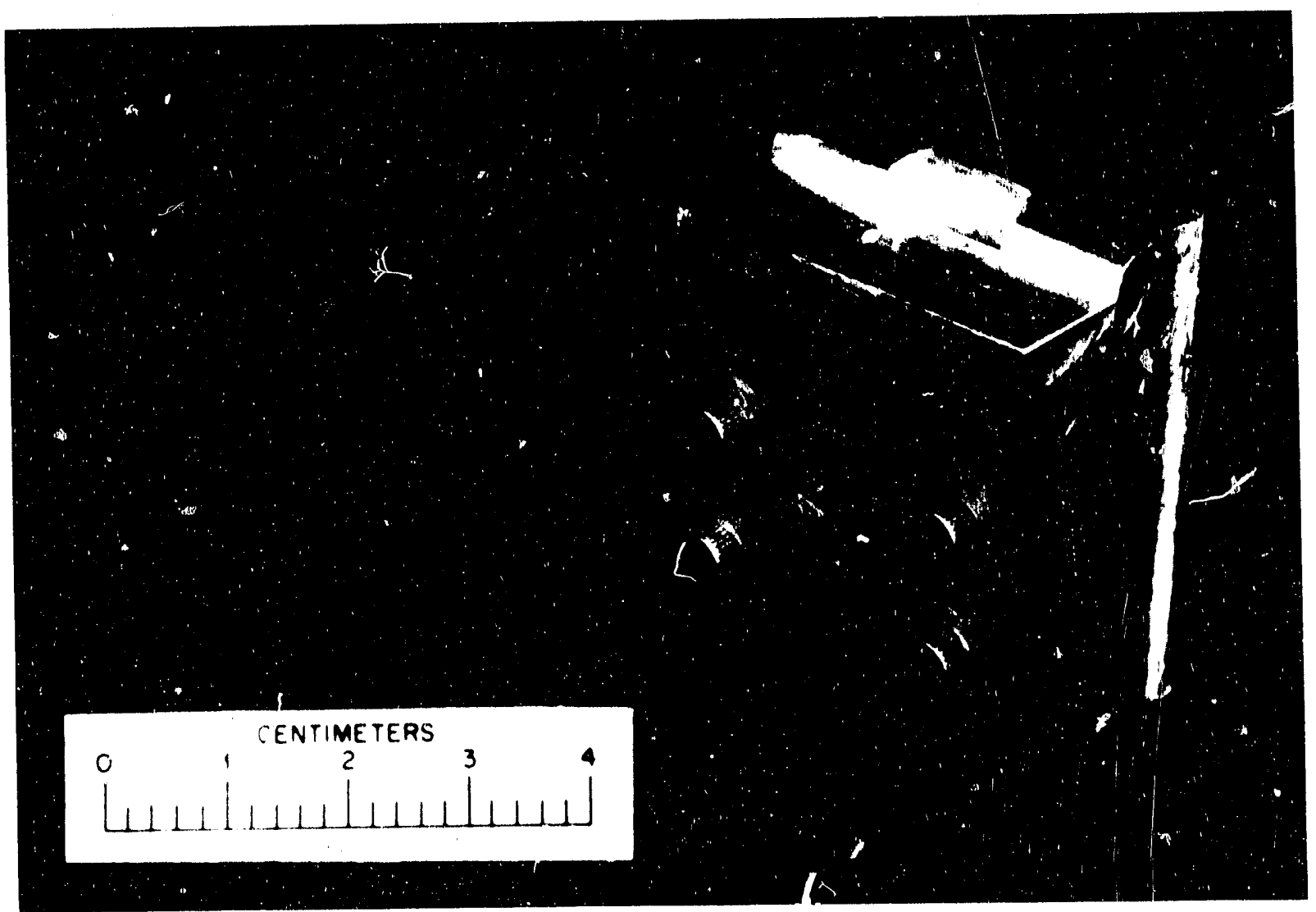

Fig. 2. Mandrel used to bend "ell"-shaped specimens in a consistent manner.

the bend arigles for the annealed "ell" specimens were determined to the nearest $0.5^{\circ}$ using a protractor method. The finished specimens were stored in capped, glass vials prior to their exposure.

\subsection{EXPOSURE APPARA'TUS}

Two different approaches were used in the conduct of these experiments, both of which involved the exposure of specimens in vertical muffle furnaces. In the first, specimens were exposed to air, while in the second, they were encapsulated in quartz also containing either $\mathrm{CaSO}_{4}$ alone or admixed with elemental sulfur and exposed to the resulting gaseous dissociation products. For all tests, the upper surfaces of the furnaces were covered with a blanket of Fiberfrax insulation in order to both maintain constant temperature and to throttle the air flow through the furnace. In most instances, temperatures were controlled to within $1^{\circ} \mathrm{C}$. 
In preliminary exposures in air, "ell"-shaped specimens were hung in the hot zone of the furnace with Nichrome wires. Laier exposures in air employed open quartz vessels within which flat specimens were suspended by platinum wires during oxidation (see Fig. 3). The purposes of these vessels were to retain any scale spall, which might occur at temperature or during subsequent cooling, and to minimize contamination during exposure. In order to maintain their alignment within the bore of the vertical furnace during oxidation, these vessels were, in turn, hung by Nichrome wires from the stainless steel furnace fixture illustrated in Fig. 4. This technique permitted the removal of individual specimens after a series of predeternined exposure times.

Those specimens to be exposed to sulfidizing atmospheres were mounted individually in specially designed quartz capsules prior to their exposure at elevated temperature. The capsules were fabricated from $25-\mathrm{mm}$ CD quartz tubing as follows. A small quartz hook was installed approximately 4 in. from one end of the tubing, and the other end was subsequently closed to form the hemispherical capsule bottom. Approximately 4 in. above the hook, the tubing was constricted to a diameter of approximately $15 \mathrm{~mm}$ in order to facilitate a later sealing operation; the 12-in. section below the restriction was maintained at a diameter of $25 \mathrm{~mm}$. The tubing was then cut radially with an abrasive saw to permit emplacement of the specimen. The resulting capsule configuration, prior to loading, is shown in Fig. 5.

YP5146

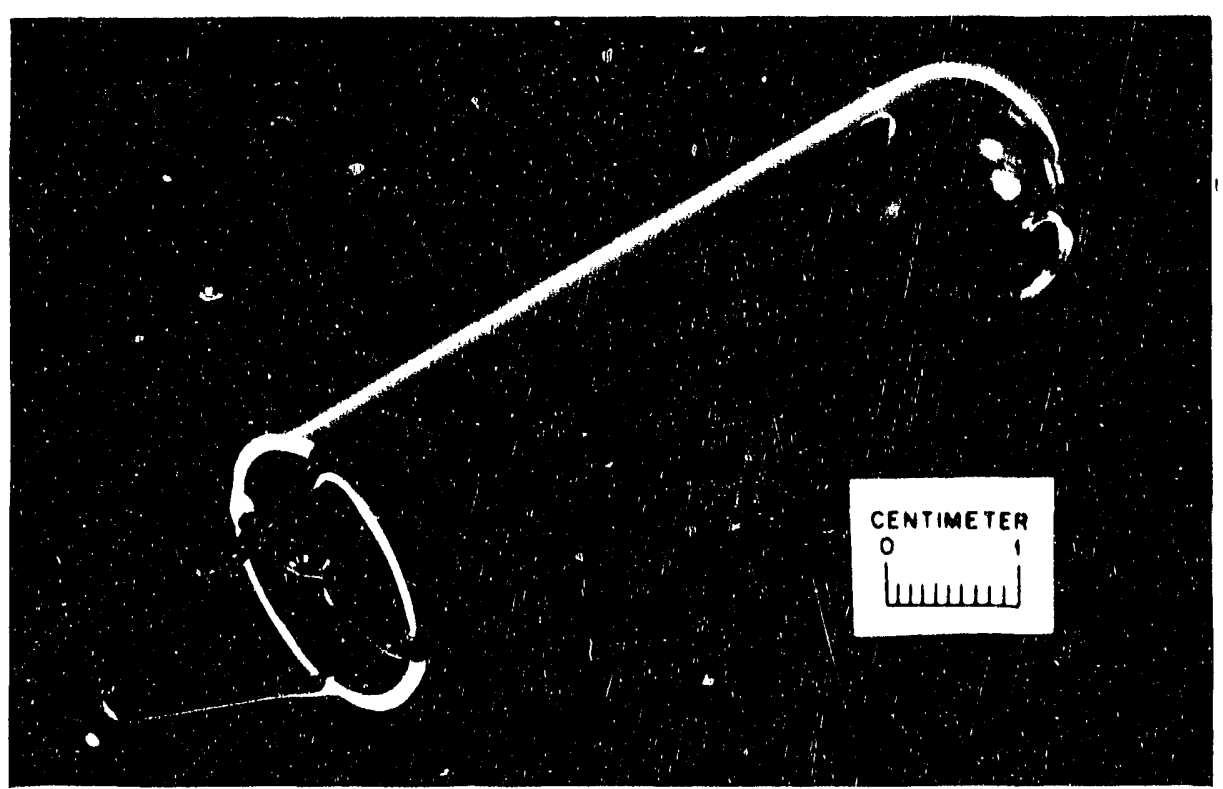

Fig. 3. Typical quartz vessel used in the air oxidation of flat specimens. 
YP5181

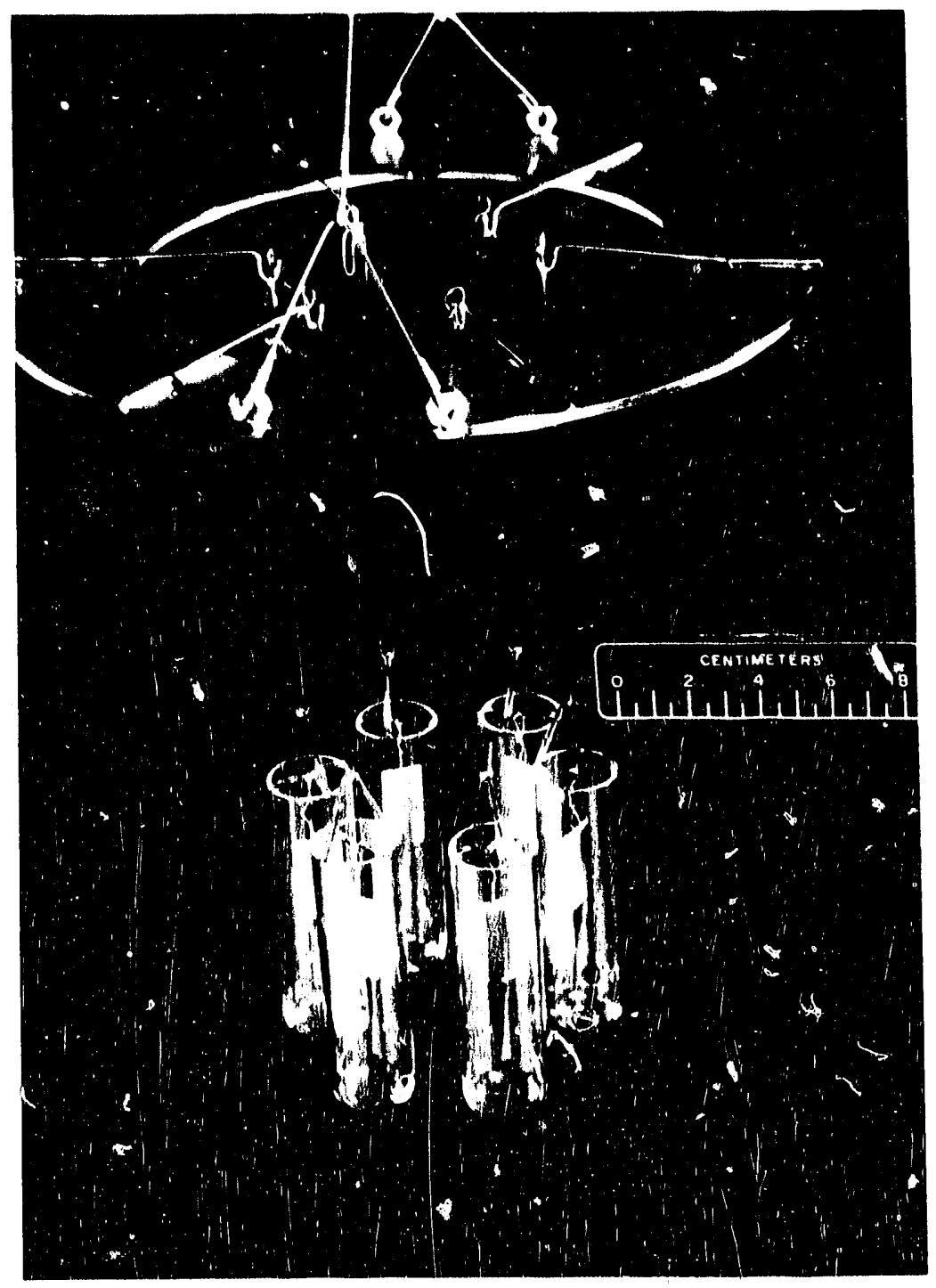

Fig. 4. Furnace fixture used in the air oxidation of flat specimens. 
YP5182

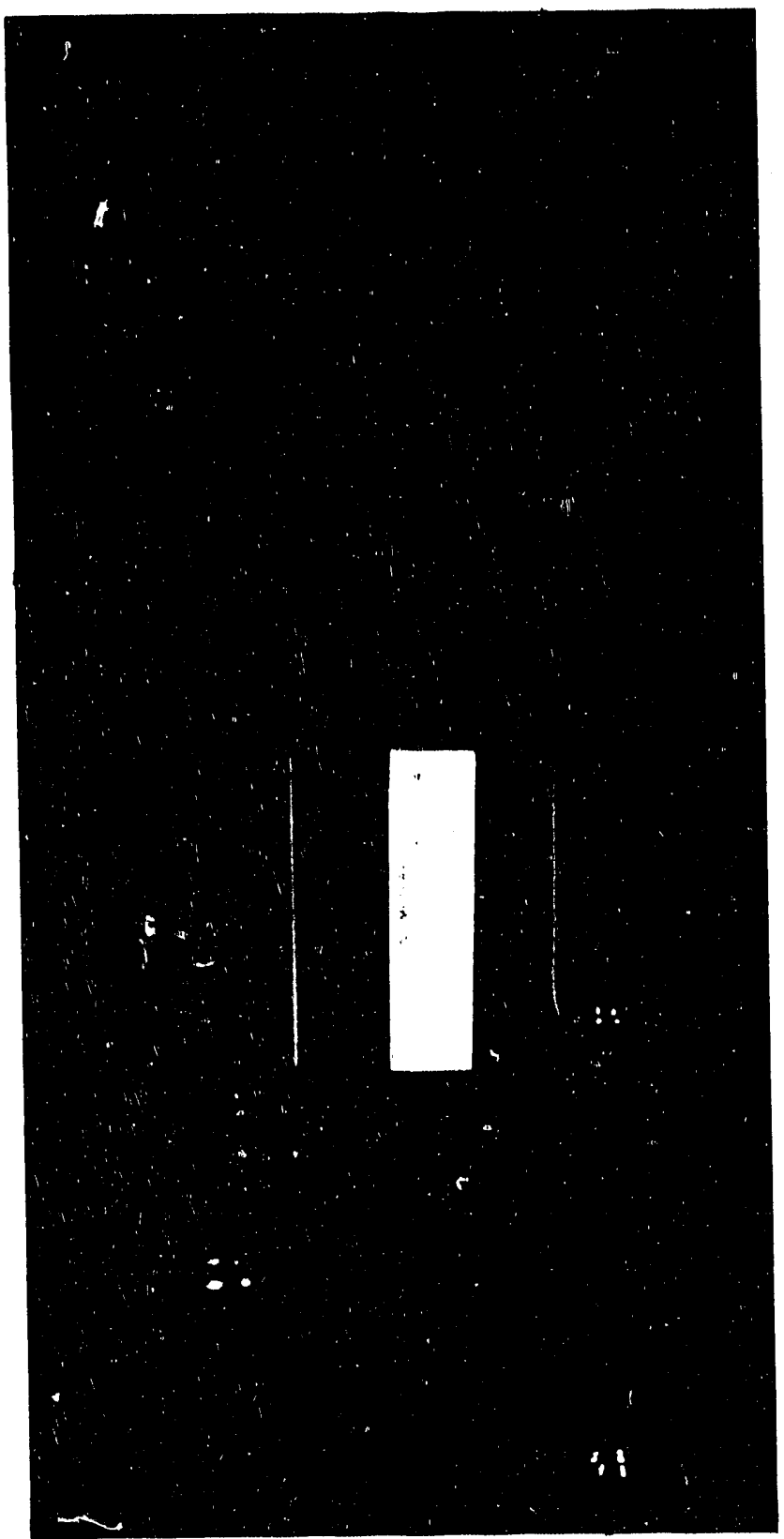

Fig. 5. Quartz capsule used in the exposure of specimens to sulfidizing gases (shown prior to the loading and re-fusing operations). 
As indicated above, two types of sulfidizing atmosphere were investigated in this research. For tests run in the "lean" sulfidizing atmosphere, which is characterized by lower sulfur pressures, a small charge (nominally 1 gram) of $\mathrm{CaSO}_{4}$ was wrapped in platinum foil and placed in the bottom of the capsule. For tests run in the "rich" sulfidizing atmosphere, the charge was comprised of approximately 8.5 parts of $\mathrm{CaSO}_{4}$ and one part of elemental sulfur. The sulfur content of this charge was limited to a maximum of $10 \mathrm{mg}$ in order to ensure that the pressure within the capsule would remain subatmospheric; i.e., nominally $0.36 \mathrm{~atm}$ at a temperature of $900^{\circ} \mathrm{C}$ for the $42 \mathrm{~cm}^{3}$ capsule volume. This type of charge was similarly wrapped in platinum foil and placed in the bottom of the capsule.

Subsequent to the selection and emplacement of the gas-generating charge, the specimen was hung in the capsule from its quartz hook by means of a platinum wire and in a manner which ensured that it would touch neither the side of the capsule nor the charge packet. While maintaining the capsule in a vertical position, it was resealed along the line of the saw cut, taking care not to heat the specimen during the fusing operation. The capsule assembly was then evacuated to a pressure of $10^{-7}$ torr. For the cases involving "lean" atmosphere charges, the capsule was baked at a temperature of $200^{\circ} \mathrm{C}$ for a period of approximately $16 \mathrm{~h}$ while being evacuated for the purpose of removing any residual, adsorbed water vapor or other gases. For charges involving "rich" atmosphere generation, the baking step was omitted in order to avoid loss of sulfur from the charge. Subsequently, the capsule was sealed under vacuum to produce the finished assembly illustrated in Fig. 6. Such assemblies were heated in vertical furnaces, thus exposing the enclosed specimens to the sulfidizing gaseous dissociation products.

\subsection{SPECIMEN EXPOSURES}

The specimens used in this research were exposed either in air or suspended in sealed quartz capsules containing calcium sulfate. The latter ones were heated to produce the sulfidizing conditions. Tests were conducted at temperatures ranging from 800 to $1000^{\circ} \mathrm{C}$ and for times between 2 and $384 \mathrm{~h}(16 \mathrm{~d})$. A summary of the exposure conditions is presented in Table 3.

Two preliminary tests were run in air at $800^{\circ} \mathrm{C}$ using specimens that had been surface finished using 600)-grit $\mathrm{SiC}$ without the benefit of electropolishing. These specimens, having $90^{\circ}$ manual bends and lacking stress-relief anneals, were exposed for 1 and $4 \mathrm{~d}$ primarily to determine qualitatively the magnitude of the stresses developed during oxidation. 
YP5351

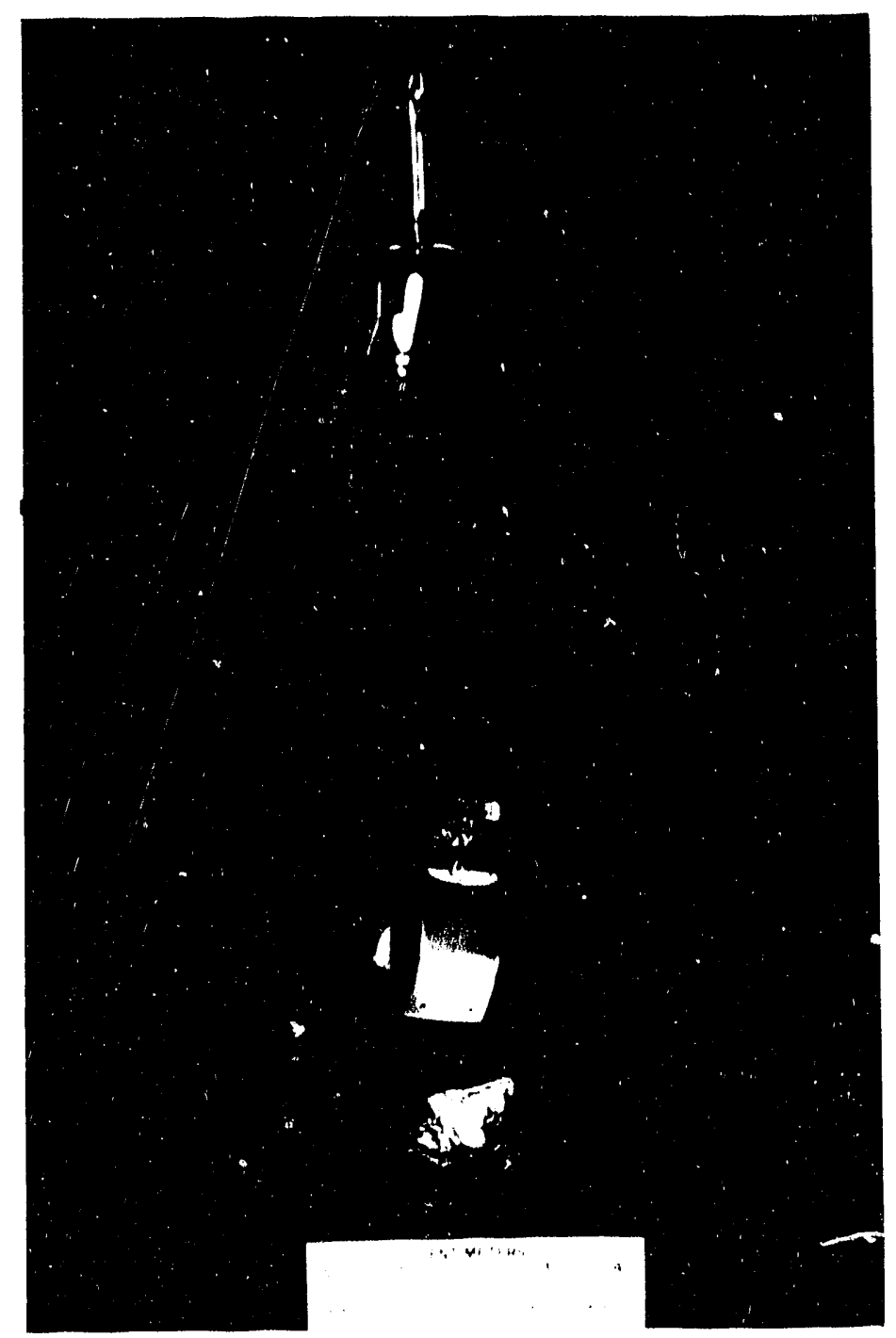

Fig. 6. Quartz capsule used in the exposure of specimens to sulfidizing gases (shown after the final sealing operation). 
Table 3. Exposure conditions for $310 \mathrm{~S}$ specimens

\begin{tabular}{|c|c|c|c|c|}
\hline $\begin{array}{l}\text { Specimen } \\
\text { number }\end{array}$ & $\begin{array}{l}\text { Specimen } \\
\text { geometry }\end{array}$ & $\begin{array}{c}\text { Temperature } \\
\left({ }^{\circ} \mathrm{C}\right)\end{array}$ & $\begin{array}{l}\text { Time } \\
(\mathrm{h})\end{array}$ & $\begin{array}{l}\text { Atmosphere } \\
\text { type/source }\end{array}$ \\
\hline \multicolumn{5}{|c|}{ Preliminary tests } \\
\hline E1R1 & E11 & 800 & 24 & Air \\
\hline E1R2 & E11 & 800 & 96 & Air \\
\hline E1R10 & E11 & 900 & 24 & Air \\
\hline E1R3 & E11 & 900 & 120 & Air \\
\hline AR7 & Flat & 900 & 5 & Air* \\
\hline \multicolumn{5}{|c|}{ Baseline air oxidation tests } \\
\hline AR1 & Flat & 900 & 24 & Air \\
\hline AR2 & Flat & 900 & 24 & Air \\
\hline AR3 & Flat & 900 & 96 & Air \\
\hline AR4 & Flat & 900 & 216 & Air \\
\hline AR5 & Flat & 900 & 384 & Air \\
\hline AR6 & Flat & 900 & 384 & Air \\
\hline \multicolumn{5}{|c|}{ Lean sulfidizing atmospheres } \\
\hline E1R4 & E11 & 800 & 24 & $\mathrm{CaSO}_{4}$ \\
\hline E1R5 & E11 & 900 & 24 & $\mathrm{CaSO}_{4}$ \\
\hline E1R6 & E11 & 900 & 216 & $\mathrm{CaSO}_{4}$ \\
\hline E1R7 & E11 & 900 & 384 & $\mathrm{CaSO}_{4}$ \\
\hline AR8 & Flat & 1000 & 24 & $\mathrm{CaSO}_{4}$ \\
\hline \multicolumn{5}{|c|}{ Rich sulfidizing atmospheres } \\
\hline AR11 & Flat & 900 & 2 & $\mathrm{CaSO}_{4}+\mathrm{S}$ \\
\hline E1R9 & E11 & 900 & 4 & $\mathrm{CaSO}_{4}+\mathrm{S}$ \\
\hline AR10 & Flat & 900 & 8 & $\mathrm{CaSO}_{4}+\mathrm{S}$ \\
\hline AR9 & Flat & 900 & 24 & $\mathrm{CaSO}_{4}+\mathrm{S}$ \\
\hline E1R8 & E11 & 900 & 24 & $\mathrm{CaSO}_{4}+\mathrm{S}$ \\
\hline
\end{tabular}

*A special test dedicated to hot X-ray diffraction studies. 
For the same primary purpese and to determine the influence of temperature upon the results, tests of ell-shaped specimens were run in air at $900^{\circ} \mathrm{C}$ for 1 and $5 \mathrm{~d}$ using specimens that had been electropolished; however, the latter did not receive the standard stress-relief anneal.

Six tests were run in air t'sing flat specimens with surfaces prepared as outlined in Sect. 2.3 in order to secure "baseline" data for the oxidation of $310 \mathrm{~S}$ in air. These tests were initiated simultaneously, using the furiace fixture shown in Fig. 4. The specimen assemblies were removed from the $900^{\circ} \mathrm{C}$ hot zone of the furnace at the following intervals: $1 \mathrm{~d}(2 \mathrm{each}), 4 \mathrm{~d}, 9 \mathrm{~d}$, and $16 \mathrm{~d}$ ( 2 each). These intervals were selected on the basis that oxidation might follow a parabolic (or slower) rate law.

Five tests were run in the "lean" sulfidizing atmosphere generated by the dissociation of calcium sulfate using quartz-encapsulated specimens and following the procedures outlined in Sects. 2.3 and 2.4. 'Two 24-h exploratory tests were conducted at temperatures of 800 and $100 \mathrm{C}^{\circ} \mathrm{C}$, and the balance of the specimens were exposed at $900^{\circ} \mathrm{C}$. The exposure intervals were selisited to coincide, as practicable, with those for the "baseline" air tests.

Finally, five tests in quartz capsules were run at $900^{\circ} \mathrm{C}$ in the "rich" sulfidizing atmosphere generated by the dissociation of calcium sulfate - sulfur mixtures following the procedures outlined in Sects. 2.3 and 2.4. These tests were also run individually in vertical furnaces. Because of the relatively rapid reaction associated with the "rich" sulfidizing atmosphere, the test times ranged from 2 to a maximum of $24 \mathrm{~h}$.

\subsection{ANALYTICAL METHODS}

The methods used to analyze exposed specimens included the following: (1) gravimetric analysis to determine the specific mass gain and from which to infer gross kinetic behavior; (2) metallographic analysis to determine especially the transverse structure of the; scale; (3) scanning electron microscopy (SEM) and associated energy dispersive X-ray spectroscopy (EDS) to determine especially the surface structure of scales and their proximal chemistries; (4) low-energy, high-resolution SEM to provide more refined data for aspects 2 and 3 above; and

(5) X-ray diffraction both at room and elevated temperatures to gain knowledge of details regarding the crystalline products within scales. Each of these methods is discussed below in the order presented here. 


\subsubsection{Mass and Dimensional Changes}

Subsequent to removal from the furnace and natural cooling, each specimen was reweighed (with its spalled scale, if any) in order to determine the mass gain due to exposure. The mass increments were divided by the respective projected areas of the specimens to obtain the specific mass gains in units of $\mathrm{mg} \mathrm{cm}^{-2}$. Similarly, the critical dimensions of each specimen were determined after exposure. The changes in specimen shape, which were noted, thus represent the sum of those changes due to heating, high-temperature reaction, and cooling. A portion of the analyses below is based upon these mass and dimensional changes.

\subsubsection{Metallography}

Selected, exposed specimens were mounted "on edge" using a metallographic epoxy resin to which Coors pelletized alumina had been added for the purpose of edge retention. Immediately after pouring, the specimen mounts were degassed using a roughing vacuum in order to ensure the removal of residual air and to promote the adhesion of the epoxy to the specimen. Subsequent to hardening at room temperature, the mounted specimens were manually ground on silicon carbide metallographic papers to a 600-grit finish. Polishing operations were conducted using vibratory polishers in the following sequence: Pellon cloth with Linde-A abrasive, then nylon cloth with $1-\mu \mathrm{m}$ diamond abrasive and, finally, nylon cloth with $1 / 2-\mu \mathrm{m}$ diamond abrasive. This procedure produced well-polished specimens with a minimum of objectionable edge rounding.

In order to reveal the grain structure of the scale upon the alloy, the polished specimens were immersion etched for a period of $45 \mathrm{~s}$. The etchant was comprised of one part saturated potassium ferricyanide solution and one part $50 \%$ sodium hydroxide stock solution and was utilized near $100^{\circ} \mathrm{C}$. Subsequent to etching, each specimen was soaked at room temperature for $2 \mathrm{~h}$ in a cleansing solution comprised of one part ammonium hydroxide solution and four parts ethyl alcohol. Specimens so prepared were examined by optical microscopy, normal SEM, and high-resolution SEM techniques.

\subsubsection{SEM and EDS}

Two distinctly different presentations of the scale layers were analyzed using SEM techniques: (1) the topography of the gas-scale interface as viewed normal to the surface of unmounted specimens and (2) the transverse section of scales using mounted and etched specimens as developed metallographically. 
In the first method, whole or partial specimens were mounted upon SEM stubs with silver-loaded paint and were carbon shadowed prior to insertion into the stage of the JEOL Model JSM-35CF scanning microscope. Both typical and special surface topographies were photographed, and, additionally, selected areas of the specimen surfaces were qualitatively analyzed for their chemical constitution using an integral Tracor-Northern Model TN 5500 X-ray Analyzer. Usual practice involved using a beam potential of $15 \mathrm{kV}$ for photography and one of $25 \mathrm{kV}$ potential for EDS. In the second method, etched specimens in epoxy metallographic mounts were striped with conductive, silver-loaded paint and we re carbon shadowed prior to insertion into the stage of the JEOL SEM. Transverse sections of the scale and the alloy adjacent to it were photographed, and, additionally, some specimens were qualitatively analyzed for their chemical constitution as before. Selected specimens of this type, which exhibited very fine detail in the scale structure, were further examined using a Hitachi Model S-800 SEM. This instrument, capable of higher resolution than the JEOL Model JSM-35CF, was typically operated using a beam potential of $5 \mathrm{kV}$ and was utilized only for photographic purposes.

It is noted that, in the analyses of EDS data, the instrumental interferences between chromium, manganese, and iron were deconvoluted arithmetically from the detector output. This was done by presuming that the integrated intensity of the $\mathrm{K}-\alpha$ signal for each of these elements was 7.5 times that of their $\mathrm{K}-\beta$ peak. Thus, a qualitative analysis could be obtained by developing intensity ratios for the $\bar{K} \sim$ excitations.

\subsubsection{X-ray Diffraction}

The crystal structures of the scales formed upon the surfaces of selected 310 specimens or of their spalled reaction products (and to some extent that of the substrate) were determined at both room and elevated temperatures by automated X-ray diffraction techniques. In all cases, $X$ rays were generated using a tube with a copper target that was operated at $45 \mathrm{kV}$ and $40 \mathrm{~mA}$. Thus, a semiquantitative comparison of intensities from different diffraction patterns is possible provided the areas of the specimens exposed to the X-ray beam were comparable (as was the usual case).

In order, first, to determine the positions of significant diffraction maxima, roomtemperature tests were conducted using a Scintag Model "PAD V" diffractometer. This instrument was operated in the $\theta / 2 \theta$ mode, and the diffracted radiation was detected with a liquid-nitrogen-cooled, solid-state, germanium crystal detector whose output was fed into a singlechannel analyzer and stored for subsequent analysis. The resolution of this system is sufficient 
to discriminate against all unwanted radiation except the desired $\mathrm{k}-\alpha$ wave length. This output was analyzed using a Data Genernl Model MV-2000 computer that could access a master file containing the JCPDS" diffraction standards. Through its capabilities of pattern searching and matching, second derivative peak searching and detection, data smoothing and profile matching, this system was capable of narrowing the field of potential crystal structures representing the observed pattern.

Because many of the scales evidenced both line broadening and specular reflections (the latter leading to intensity "spikes"), portions of many diffraction patterns were deconvoluted via an interactive computer program that permitted the input of operator judgement. A final judgement process, regarding the line assignment for each pattern, was made by one of the authors using the JCPDS diffraction standards in printed format, a process that also involved the calculation of lattice parameters for all cubic systems in order to ensure proper assignment of diffraction maxima.

Having determined the diffraction patterns of interest at room temperature, one specimen (AR7) was examined while undergoing oxidation in air at $900^{\circ} \mathrm{C}$. This was accomplished using the Scintag Model "PAD X" diffractometer, which was outfitted with an Edmund Buehler Model HDK-2 hot stage. In this instrument, the specimen remains stationary in the horizontal position while the source and detector maintain a $\theta / \theta$ relationship. This experiment was conducted by repeatedly scanning the same angular range $\left(20\right.$ to $\left.45^{\circ}, 2 \theta\right)$ in an attempt to monitor the evolution of crystallographic development and, in particular, to determine whether or not one crystalline phase exhibited evidence for strain generation. The X-ray generation, detection, and analysis details were otherwise similar to those described above for room-temperature investigations.

\section{RESULTS}

Results are presented in the order of the four types of specimen exposure that were utilized: (1) preliminary tests, (2) baseline oxidation tests in air, (3) exposures in "lean" sulfidizing atmospheres, and (4) exposures in "rich" sulfidizing atmospheres.

*Joint Committee on Powder Diffraction Standard. 


\subsection{PRELIMINARY TESTS}

Four exploratory tests were run at 800 and $900^{\circ} \mathrm{C}$ using ell-shaped specimens primarily to determine: (1) semi-quantitatively, the kinetics of the reaction and (2) qualitatively, the magnitude of the stresses generated during the oxidation process. At both temperatures, the rates of oxidation were found to be essentially parabolic. The mass gains were, therefore, fit to the parabolic rate law: $\mathrm{W}^{2}=\mathrm{kt}$ where $\left(\mathrm{W}, \mathrm{mgcm}^{-2}\right)$ is the specific mass gain; $(\mathrm{t}, \mathrm{h})$ is the exposure time; and $\left(\mathrm{k}, \mathrm{mg}^{2} \mathrm{~cm}^{-4} \mathrm{~h}^{-1}\right)$ is the parobolic rate constant. The rates of mass gain exhibited by the specimens exposed at $800^{\circ} \mathrm{C}$ were small, having an average value of $1.17 \times 10^{-3} \mathrm{mg}^{2} \mathrm{~cm}^{-4} \mathrm{~h}^{-1}$. The corresponding value of the parabolic rate constant at $900^{\circ} \mathrm{C}$ was found to be approximately $6.57 \times 10^{-3} \mathrm{mg}^{2} \mathrm{~cm}^{-4} \mathrm{~h}^{-1}$. No significant spalling was noted for specimens oxidized in air at either of these temperatures.

The deformations suffered by these four specimens as a result of their oxidation in air are summarized in Table 4.

Table 4. Deformation of ell-shaped specimens in air at 800 and $900^{\circ} \mathrm{C}$

\begin{tabular}{ccccccc}
\hline \multirow{2}{*}{$\begin{array}{c}\text { Specimen } \\
\text { number }\end{array}$} & $\begin{array}{c}\text { Exposure } \\
\text { time }\end{array}$ & $(\mathrm{h})$ & $\begin{array}{l}\text { Ells closure } \\
\text { Angle }\end{array}$ & $\begin{array}{c}\text { Rate } \\
\text { (deg) }\end{array}$ & $\begin{array}{l}\text { Linear } \\
(\mathrm{deg} / \sqrt{\mathrm{h}})\end{array}$ & $\begin{array}{c}\text { Rate } \\
(\%)\end{array}$ \\
\hline
\end{tabular}

Tests at $800^{\circ} \mathrm{C}-90^{\circ}$ ells -600 -grit finish

$\begin{array}{llllll}\text { E1R1 } & 24 & 2 & 0.41 & \text { N/A } & \text { N/A } \\ \text { E1R2 } & 96 & 4.5 & 0.46 & \text { N/A } & \text { N/A }\end{array}$

Tests at $900^{\circ} \mathrm{C}-120^{\circ}$ ells - electropolished

\begin{tabular}{lrrrrr} 
E1R10 & 24 & 26.3 & 5.37 & 1.73 & 0.353 \\
E1R3 & 120 & 63.6 & 5.81 & 3.42 & 0.312 \\
\hline
\end{tabular}

Specimens tested at $800^{\circ} \mathrm{C}$ had not been provided with either fiducial holes for determining dilatation or proper finishing treatments. Specimen E1R3 was nonstandard in that it had not received a stress-relief heat treatment. At both temperatures, a time-dependent, 
angular closure occurred in spite of the fact that the gravitational forces should have produced an opening of the original bend angle. Further, for the $900^{\circ} \mathrm{C}$ tests, a dilatation of the gage length was noted that increased with exposure time. It was, thus, concluded that oxidation-induced stresses were causal to ell angle closure.

In view of the fact that the oxidation rate had been found to be parabolic, the rates of angle closure and linear dilatation were calculated on the basis that they, too, obeyed a parabolic relationship. As indicated in Table 4, these rates are essentially constant at a fixed temperature, indicating that the mechanical deformations are directly related to the oxidation process. It is interesting to note that, while the oxidation rate at $900^{\circ} \mathrm{C}$ was approximately 6 times that at $800^{\circ} \mathrm{C}$, the rate of ell closure at $900^{\circ} \mathrm{C}$ was approximately 12 times that at $800^{\circ} \mathrm{C}$. Thus, the mechanical deformation rates are sensitive to more than simply the rate of scale thickening and probably also reflect the decrease in creep strength of the alloy with rising temperature.

The type $310 S$ starting material was initially characterized by $X$-ray diffraction. The results of the diffraction analysis, presented in Table 5, indicate that the intermetallic phase commonly known as "sigma" was present within the before test microstructure of this alloy. No other crystalline phases were detected in the metallic specimens by X-ray methods.

Knowing that the $310 \mathrm{~S}$ was essentially a two-phase alloy, the deformed specimen E1R 3 was also examined rather intensively by metallographic, SEM, and EDS techniques in order to secure additional data regarding its structural nature. The general aspects of its structure are revealed in Fig. 7, which shows a transverse section of the entire specimen. A thin-scale layer, approximately $3 \mu \mathrm{m}$ in thickness, is evident at the outer surface of the specimen. Underlying the scale is a zone of coarse austenite grains, approximately $50 \mu \mathrm{m}$ in depth, which has been denuded of the sigma phase particles shown at the interior of the specimen. In that interior zone, the austenite crystals are smaller, their growth evidently having been retarded by the presence of the sigma phase particles, which are seen to reside primarily upon the grain-boundary network of the austenite.

Details of this scale's transverse structure were revealed using the etching procedure described in Sect. 2.6.2, followed by inspection using the Hitachi S-800 SEM. The electron micrograph of Fig. 8 shows that the scale is duplex, exhibiting two layers parallel to the alloy-oxide interface. The innermost layer is composed of fine columnar grains having a typical plan dimension of approximately $0.25 \mu \mathrm{m}$ and a height of approximately $3 \mu \mathrm{m}$ (aspect ratio of 12:1). Overlying this is a layer of unresolved structure having an average thickness of somewhat less than $1 \mu \mathrm{m}$. Portions of this scale layer may have been lost in processing the specimen. Of 
Table 5. X-ray diffraction data for specimen AR7; alloy $310 \mathrm{~S}$ before exposure in air at $900^{\circ} \mathrm{C}$

\begin{tabular}{|c|c|c|c|c|c|}
\hline \multicolumn{3}{|c|}{$\begin{array}{l}\text { Diffraction data } \\
\text { (austenitic matrix) }\end{array}$} & \multicolumn{3}{|c|}{$\begin{array}{l}\text { JCPDS card 33-397 } \\
\text { (chromium iron nickel) }\end{array}$} \\
\hline \multicolumn{6}{|c|}{ Strong component } \\
\hline $2 \theta$ & $\mathrm{d}(\AA)^{a}$ & $\mathrm{I} / \mathrm{I}_{\mathrm{o}}{ }^{b}$ & (hkl) & $\mathrm{d}(\AA)^{a}$ & $1 / I_{0}{ }^{b}$ \\
\hline 43.432 & 2.0818 & 65 & (111) & 2.075 & 100 \\
\hline 50.641 & 1.8011 & 48 & $(200)$ & 1.796 & 45 \\
\hline 74.563 & 1.2717 & 100 & $(220)$ & 1.269 & 26 \\
\hline 90.594 & 1.0838 & 31 & $(311)$ & 1.082 & 30 \\
\hline 95.878 & 1.0375 & 4 & (222) & 1.037 & 12 \\
\hline $118.0 \times 5$ & 0.8982 & 3 & $(400)$ & 0.898 & 3 \\
\hline \multicolumn{3}{|c|}{$\begin{array}{c}\text { Diffraction uata } \\
\text { (sigma phase of alloy) }\end{array}$} & \multicolumn{3}{|c|}{$\begin{array}{l}\text { JCPDS card 5-708 } \\
\text { (chromium iron) }\end{array}$} \\
\hline
\end{tabular}

Medium component

\begin{tabular}{|c|c|c|c|c|c|}
\hline $2 \theta$ & $\mathrm{d}(\AA)^{a}$ & $\mathrm{I} / \mathrm{I}_{0}{ }^{c}$ & $(h k l)$ & $\mathrm{d}(\AA)^{a}$ & $\mathrm{I} / \mathrm{I}_{\mathrm{o}}{ }^{\mathrm{C}}$ \\
\hline 39.266 & 2.2926 & 51 & $(002)$ & 2.261 & 10 \\
\hline 42.204 & 2.1395 & 39 & $(112)$ & 2.128 & 100 \\
\hline \multicolumn{3}{|c|}{ Austenite interference-.............. } & (330) & 2.063 & 80 \\
\hline 44.5327 & 2.0329 & 68 & (202) & 2.015 & 60 \\
\hline 45.7669 & 1.9809 & 100 & $(212)$ & 1.964 & 80 \\
\hline 46.8344 & 1.9382 & 33 & $(411)$ & 1.928 & 100 \\
\hline 48.0626 & 1.8915 & 10 & (331) & 1.877 & 80 \\
\hline 49.3219 & 1.8461 & 8 & (222) & 1.830 & 10 \\
\hline 51.62 .46 & 1.7691 & 17 & $(312)$ & 1.755 & 10 \\
\hline \multicolumn{3}{|c|}{ Not detected-................ } & $(322)$ & 1.664 & 1 \\
\hline \multicolumn{3}{|c|}{ Not detected-a } & (431) & 1.638 & 1 \\
\hline \multicolumn{3}{|c|}{ Not detected } & $(511)$ & 1.611 & 1 \\
\hline 67.225 & 1.3915 & 9 & $(432)$ & 1.390 & 1 \\
\hline \multicolumn{3}{|c|}{ Not detected-a. } & $(522)$ & 1.327 & 1 \\
\hline \multicolumn{3}{|c|}{ Austenite interference } & $(532)$ & 1.258 & 10 \\
\hline 75.563 & 1.2573 & 9 & $(550)$ & 1.244 & 10 \\
\hline 76.7672 & 1.2406 & 10 & (413) & 1.236 & 40 \\
\hline 77.1983 & 1.2347 & 5 & (333) & 1.224 & 20 \\
\hline 77.6805 & 1.2282 & 18 & $(720)^{d}$ & 1.209 & 40 \\
\hline 77.7701 & 1.2271 & 12 & $(720)^{d}$ & 1.209 & 40 \\
\hline \multicolumn{3}{|c|}{ 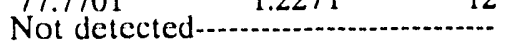 } & $\left(423^{\prime}\right)(551)$ & 1.199 & 10 \\
\hline \multicolumn{3}{|c|}{ 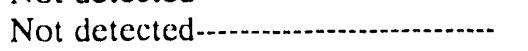 } & $(622)$ & 1.186 & 10 \\
\hline \multicolumn{3}{|c|}{ Not detected................................. } & $(542)(641)$ & 1.177 & 10 \\
\hline \multicolumn{3}{|c|}{ 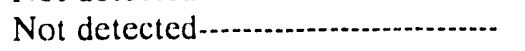 } & $(721)$ & 1.169 & 10 \\
\hline \multicolumn{3}{|c|}{ 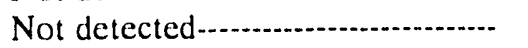 } & $(513)$ & 1.138 & 40 \\
\hline 99.872 & 1.0065 & 19 & $(414)$ & 1.004 & 20 \\
\hline
\end{tabular}

$a_{\mathrm{a}_{\mathrm{o}}}=3.5944 \AA ;$ strong (110) texture.

$b_{I_{0}}=42383 \mathrm{cpm}$.

$c_{\mathrm{I}_{\mathrm{o}}}=5044 \mathrm{cpm}$.

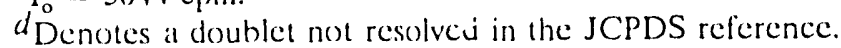




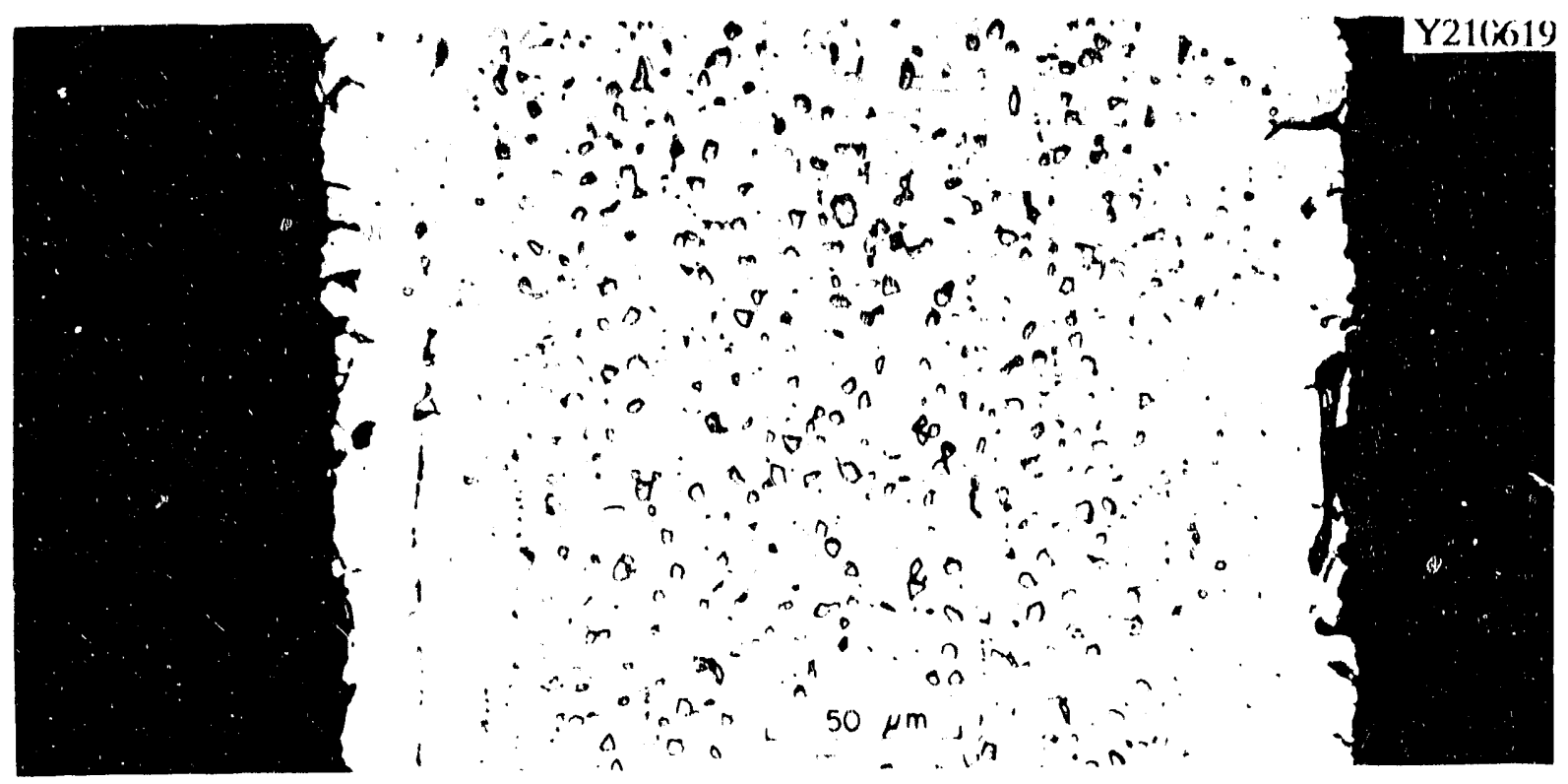

Fig. 7. Photomicrograph of a transverse section of specimen E1R3 after 120-h exposure in air at $900^{\circ} \mathrm{C}$ (glyceregia etch).

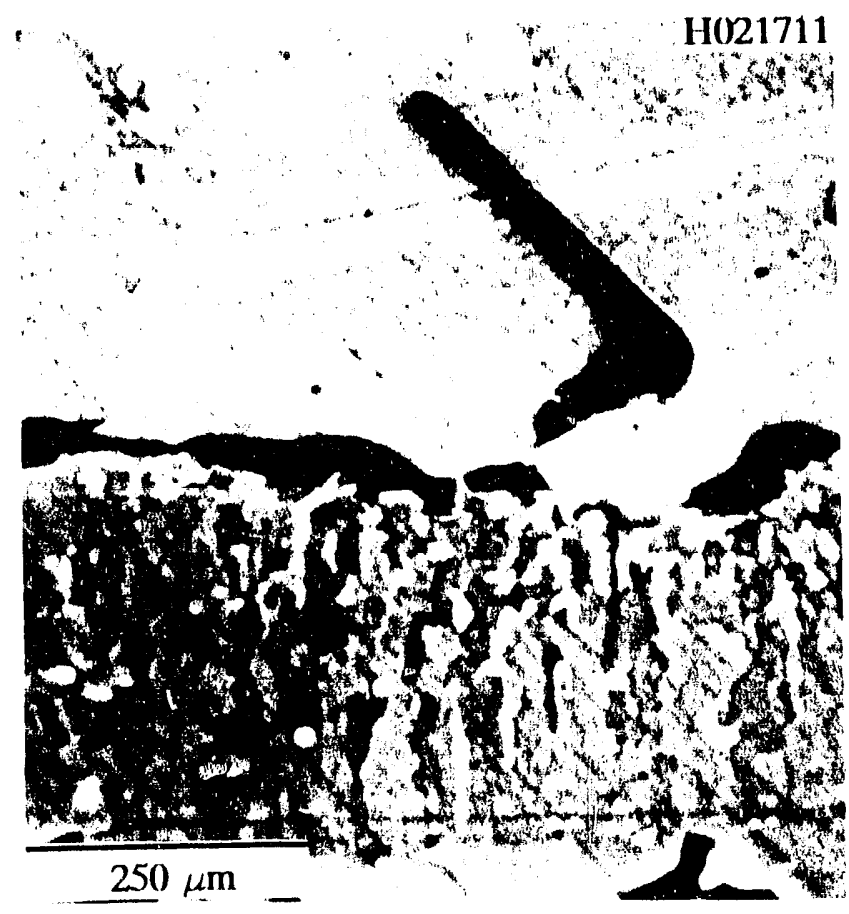

Fig. 8. Electron micrograph showing the transverse scale structure of specimen E1R3 after 120-h exposure in air at $900^{\circ} \mathrm{C}$. 
additional interest in this figure are: (1) a crack near the interface between the scale layers, but just within the underlying columnar crystals, and (2) the existence of smooth voids both at the metal-oxide interface and, apparently, at the junction of the grain-boundary network of the alloy with that interface.

Obviously, such prolific void formation must both be related to and affect the mechanism by which the scale forms. It may, for example, be indicative of reaction rates, which decrease with time, and may also reflect very limited oxide plasticity.

The transverse section of specimen E1R3, shown in Figs. 7 and 8, was also examined by EDS techniques. In these analyses, various portions of the cross section were qualitatively analyzed for their elemental content. The results are summarized in Table 6.

Table 6. Qualitative EDS analyses for specimen E1R3 after 120 -h exposure in air at $900^{\circ} \mathrm{C}$ (summary of relative elemental abundance) ${ }^{a}$

\begin{tabular}{lrcrr}
\hline & \multicolumn{4}{c}{ Position in transverse section $b$} \\
\cline { 2 - 5 } Chemical & (A) & (B) & (C) & (D) \\
\hline Iron & 100 & 100 & 100 & 100 \\
Chromium & 76 & 60 & 47 & 48 \\
Nickel & 22 & 23 & 23 & 22 \\
Manganese & 3 & 0.2 & 0 & 0 \\
Silicon & 2 & 3 & 2 & 4 \\
\hline
\end{tabular}

$a_{\text {Relative elemental abundance is in terms of }}$ each element's $\mathrm{K}-\alpha$ excitation divided by that for the strongest element (presented as percentages).

$b_{\text {Key to positions: }}$

(A): Sigma phase particle near center of section.

(B): Denuded zone distal from the alloy-oxide interface.

(C): Denuded zone proximal to the alloy-oxide interface.

(D): Voided alloy grain boundary in denuded zone. 
Additionally, it was shown that chromium and manganese both exist at appreciable concentration levels in the scale; however, as this specimen was not properly cleaned prior to EDS analysis, the numerical values (biased by contamination) are not presented here. Taken as a whole, the EDS data show that chromium and manganese are depleted from the subsurface zone of the alloy to participate in scale building, while the nickel and silicon concentrations appear to be little affected by oxidation. (It will later be shown that silicon does, in fact, participate in the oxidation reaction.)

The last of the preliminary tests was directed toward the generation of information regarding the crystalline nature of the reaction products and their evolution. During this test, specimen AR7 was simultaneously subjected to oxidation in air at $900^{\circ} \mathrm{C}$ and to analyses by $\mathrm{X}$-ray diffraction, described in Sect. 2.6.4. The diffraction data representing mean oxidation times of $0.25,0.5,1,3,3.75$, and $5 \mathrm{~h}$ were stored temporarily while the specimen was cooled to room temperature, after which it was again $x$-rayed to determine which reaction products formed. The results of this analysis, detailed in Table 7 , indicated that the primary reaction products were: (1) a spinel oxide similar in composition to $\mathrm{MnFe}_{2} \mathrm{O}_{4}$, later shown to be an external scale layer, and (2) a sesquioxide similar in composition to $\mathrm{Cr}_{2} \mathrm{O}_{3}$, later shown to be an inner scale layer. The intensities of the diffraction maxima associated with these products reinforce the relative positions of the ssale layers just described.

Knowing the positions of the most intense reflections for the reaction products formed, the stored high-temperature diffraction data were then analyzed. For both compounds, it was found that the diffraction angle changed smoothly with time, as shown in Fig. 9. The lattice of the $\mathrm{Cr}_{2} \mathrm{O}_{3}$-like compound decreased in dimension as time progressed and, further, consistently exhibited a very broad $\left(0.4^{\circ}\right)$ diffraction maxima for its (104) line. Such behavior, when coupled with the texture exhibited by the diffraction pattern as a whole, is indicative of a tractive force between the alloy and the inner scale layer, as occurs in epitaxial relations. Conversely, the lattice of the $\mathrm{MnFe}_{2} \mathrm{O}_{4}$-like compound increased in dimension as time progressed and exhibited an early maximum in the breadth of the diffraction peak for its (311) line at about $1 \mathrm{~h}$ of exposure time. Such behavior, when coupled with the essentially textureless diffraction pattern as a whole, is indicative of a relatively slow change in lattice parameter, possibly due to selective elemental transport between the alloy and the outer scale layer. It is noted that some peak broadening does persist even in this outer scale layer, and such may be due to either compositional gradients or crystallographic strains within that layer or possibly both. 
Table 7. Room-temperature X-ray diffraction data for specimen AR7 after 5-h exposure in air at $900^{\circ} \mathrm{C}$

\begin{tabular}{|c|c|c|c|c|c|}
\hline \multicolumn{3}{|c|}{$\begin{array}{l}\text { Diffraction data } \\
\text { (austenitic matrix) }\end{array}$} & \multicolumn{3}{|c|}{$\begin{array}{l}\text { JCPDS card } 33-397 \\
\text { (chromium iron nickel) }\end{array}$} \\
\hline \multicolumn{6}{|c|}{ Strong components } \\
\hline $2 \theta$ & $\mathrm{d}(\AA)^{a}$ & $\mathrm{I} / \mathrm{I}_{\mathrm{o}}{ }^{b}$ & (hkl) & $\mathrm{d}(\boldsymbol{A})^{a}$ & $\mathrm{I} / \mathrm{I}_{\mathrm{o}}^{b}$ \\
\hline 43.492 & 2.0791 & 58 & (111) & 2.075 & 100 \\
\hline 50.714 & 1.7987 & 35 & $(200)$ & 1.796 & 45 \\
\hline 74.640 & 1.2706 & 100 & $(220)$ & 1.269 & 26 \\
\hline 90.674 & 1.0830 & 27 & (311) & 1.082 & 30 \\
\hline 95.953 & 1.0369 & 3 & $(222)$ & 1.037 & 12 \\
\hline 118.303 & 0.8972 & 2 & $(400)$ & 0.898 & 3 \\
\hline
\end{tabular}

\begin{tabular}{|c|c|c|c|c|c|}
\hline \multicolumn{3}{|c|}{$\begin{array}{c}\text { Diffraction data } \\
\text { (Pt-Rh vapor deposit) }\end{array}$} & \multicolumn{3}{|c|}{$\begin{array}{l}\text { JCPDS card } 4-802 \\
\text { (unalloyed platinum) }\end{array}$} \\
\hline $2 \theta$ & $\mathrm{d}(\AA)^{C}$ & $\mathrm{I} / \mathrm{I}_{\mathrm{o}}{ }^{d}$ & $(h k l)$ & $\mathrm{d}(\boldsymbol{A})^{c}$ & $\mathrm{I} / \mathrm{I}_{\mathrm{o}}{ }^{d}$ \\
\hline 39.6161 & 2.2731 & 100 & (111) & 2.265 & 100 \\
\hline 46.1056 & 1.9671 & 32 & $(200)$ & 1.961 & 53 \\
\hline 67.385 & 1.3886 & 15 & $(220)$ & 1.387 & 31 \\
\hline 81.207 & 1.1836 & 10 & $(311)$ & 1.182 & 33 \\
\hline 85.642 & 1.1333 & 3 & $(222)$ & 1.132 & 12 \\
\hline \multicolumn{3}{|c|}{ Not detected-...- } & $(400)$ & 0.980 & 6 \\
\hline \multirow[t]{2}{*}{117.717} & 0.9000 & 3 & (331) & 0.900 & 22 \\
\hline & $\begin{array}{l}\text { ion dat } \\
\text { ip heat }\end{array}$ & & \multicolumn{3}{|c|}{$\begin{array}{l}\text { JCPDS card } 4-802 \\
\text { (unalloyed platinum) }\end{array}$} \\
\hline
\end{tabular}

Medium components

$\begin{array}{llrrrr}2 \theta & \mathrm{d}(\AA)^{c} & \mathrm{I}^{\prime} \mathrm{I}_{\mathrm{o}}{ }^{e} & (\mathrm{hkl}) & \mathrm{d}(\AA)^{c} & \mathrm{I} / \mathrm{I}_{\mathrm{o}}{ }^{e} \\ 39.4755 & 2.2809 & 100 & (111) & 2.265 & 100 \\ 45.8148 & 1.9788 & 45 & (200) & 1.961 & 53 \\ 67.119 & 1.3934 & 16 & (220) & 1.387 & 31 \\ 80.735 & 1.1893 & 11 & (311) & 1.182 & 33 \\ 85.642 f & 1.1333 & 8 & (222) & 1.132 & 12\end{array}$


Table 7. (Continued)

\begin{tabular}{|c|c|c|c|c|c|}
\hline \multicolumn{3}{|c|}{$\begin{array}{l}\text { Diffraction data } \\
\text { (spinel oxide scale) }\end{array}$} & \multicolumn{3}{|c|}{$\begin{array}{c}\text { JCPDS card } 10-319 \\
\left(\mathrm{MnFe}_{2} \mathrm{O}_{4}\right)\end{array}$} \\
\hline $2 \theta$ & $\mathrm{d}(\AA) g$ & $\mathrm{I} / \mathrm{I}_{\mathrm{o}}{ }^{h}$ & $(\mathrm{hkl})$ & $\mathrm{d}(\AA) g$ & $\mathrm{I} / \mathrm{I}_{\mathrm{o}}{ }^{h}$ \\
\hline 29.3496 & 3.0407 & 35 & $(220)$ & 3.005 & 35 \\
\hline 34.6008 & 2.5 .03 & 100 & $(311)$ & 2.563 & 100 \\
\hline 36.212 & 2.4786 & 16 & $(222)$ & 2.450 & 12 \\
\hline $42.229^{i}$ & 2.1383 & $<22$ & $(400)$ & 2.124 & 25 \\
\hline \multicolumn{3}{|c|}{ Not detected- } & $(422)$ & 1.734 & 20 \\
\hline 55.609 & 1.6514 & 20 & $(511)$ & 1.635 & 35 \\
\hline 61.124 & 1.5149 & 23 & $(440)$ & 1.503 & 40 \\
\hline $64.362^{j}$ & 1.4463 & $<14$ & $(531)$ & 1.437 & 4 \\
\hline \multicolumn{3}{|c|}{ Not detected } & $(620)$ & 1.344 & 4 \\
\hline 72.212 & 1.3072 & 7 & $(533)$ & 1.296 & 20 \\
\hline \multicolumn{3}{|c|}{ Not detected-......................... } & $(622)$ & 1.281 & 15 \\
\hline $77.689^{k}$ & 1.2281 & 8 & $(444)$ & 1.227 & 10 \\
\hline \multicolumn{3}{|c|}{ Platinum interference } & $(711)$ & 1.190 & 12 \\
\hline \multicolumn{3}{|c|}{ Not detected- } & $(642)$ & 1.135 & 7 \\
\hline \multicolumn{3}{|c|}{ 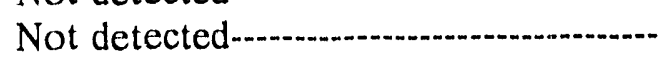 } & $(553)$ & 1.106 & 30 \\
\hline \multicolumn{3}{|c|}{$\begin{array}{c}\text { Diffraction data } \\
\text { (sesquioxide scale) }\end{array}$} & \multicolumn{3}{|c|}{$\begin{array}{l}\text { JCPDS card 35-112 } \\
\qquad\left(\mathrm{Cr}_{1.3} \mathrm{Fe}_{0.7} \mathrm{O}_{3}\right)\end{array}$} \\
\hline \multicolumn{6}{|c|}{ Weak components } \\
\hline $2 \theta$ & $\mathrm{d}(\AA) g$ & $\mathrm{I} / \mathrm{I}_{\mathrm{o}}^{l}$ & $(\mathrm{hkl})$ & $\mathrm{d}(\AA) g$ & $\mathrm{I} / \mathrm{I}_{\mathrm{o}}^{l}$ \\
\hline 24.1472 & 3.6827 & 94 & $(012)$ & 3.654 & 45 \\
\hline 33.170 & 2.6986 & 100 & $(104)$ & 2.676 & 100 \\
\hline 35.706 & 2.5126 & 92 & $(110)$ & 2.499 & 75 \\
\hline \multicolumn{3}{|c|}{ Platinum interference } & $(006)$ & 2.270 & 4 \\
\hline 40.929 & 2.2032 & 14 & $(113)$ & 2.189 & 25 \\
\hline \multicolumn{2}{|c|}{ Austenite interference } & 16 & $(024)$ & 1.827 & 35 \\
\hline 49.421 & 1.8427 & 16 & $(024)$ & 1.827 & 35 \\
\hline 54.330 & 1.6872 & 54 & $(116)$ & 1.680 & 65 \\
\hline \multicolumn{3}{|c|}{ Not detected- } & $(122)$ & 1.590 & 5 \\
\hline \multicolumn{3}{|c|}{ 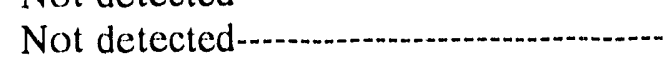 } & $(010)$ & 1.585 & 6 \\
\hline \multicolumn{3}{|c|}{ Not detected-...... } & $(214)$ & 1.474 & 25 \\
\hline \multirow{2}{*}{\multicolumn{3}{|c|}{$\begin{array}{l}64.362 \\
\text { Not detected-... }\end{array}$}} & $(300)$ & 1.442 & 25 \\
\hline & & & (208) & 1.338 & 1 \\
\hline \multirow{2}{*}{\multicolumn{3}{|c|}{$\begin{array}{l}72.212 \\
\text { Not detected }-. . . . .\end{array}$}} & $(1010)$ & 1.299 & 12 \\
\hline & \multicolumn{2}{|c|}{ Not detected-a } & $(220)$ & 1.249 & 6 \\
\hline $77.689^{k}$ & 1.2281 & $<18$ & $(306)$ & 1.218 & 3 \\
\hline \multicolumn{3}{|c|}{ Platinum interference } & $(128)$ & 1.179 & 2 \\
\hline \multicolumn{3}{|c|}{ Nut detected-... } & $\left(\begin{array}{lll}0 & 2 & 10\end{array}\right)$ & $\begin{array}{l}1.152 \\
1.132\end{array}$ & $\begin{array}{l}4 \\
7\end{array}$ \\
\hline
\end{tabular}


Table 7. (Continued)

\begin{tabular}{|c|c|c|c|c|c|}
\hline \multicolumn{3}{|c|}{$\begin{array}{c}\text { Diffraction data } \\
\text { (sigma phase of alloy) }\end{array}$} & \multicolumn{3}{|c|}{$\begin{array}{l}\text { JCPDS card 5-708 } \\
\text { (chromium iron) }\end{array}$} \\
\hline $2 \theta$ & $\mathrm{d}(\AA) g$ & $\mathrm{I} / \mathrm{I}_{\mathrm{o}}^{m}$ & (hkl) & $\mathrm{d}(\boldsymbol{A}) g$ & $\mathrm{I} / \mathrm{I}_{\mathrm{o}}{ }^{m}$ \\
\hline \multicolumn{3}{|c|}{ Platinum interference } & $(002)$ & 2.261 & 10 \\
\hline $42.229^{j}$ & 2.1383 & 100 & $(112)$ & 2.128 & 100 \\
\hline \multicolumn{3}{|c|}{ Austenite interference } & $(330)$ & 2.063 & 80 \\
\hline 44.552 & 2.0321 & 92 & $(202)$ & 2.015 & 60 \\
\hline \multicolumn{3}{|c|}{ Platinum interference } & $(212)$ & 1.964 & 80 \\
\hline \multicolumn{3}{|c|}{ Not detected...................... } & (411) & 1.928 & 100 \\
\hline 48.233 & 1.8852 & 27 & $(331)$ & 1.877 & 80 \\
\hline 49.867 & 1.8272 & 63 & $(222)$ & 1.830 & 10 \\
\hline \multicolumn{3}{|c|}{ Not detected..................... } & $(312)$ & 1.755 & 10 \\
\hline 55.058 & .6666 & 94 & $(322)$ & 1.664 & 1 \\
\hline \multicolumn{3}{|c|}{ 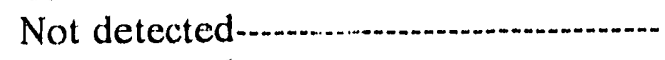 } & $(431)$ & 1.638 & 1 \\
\hline \multicolumn{3}{|c|}{ 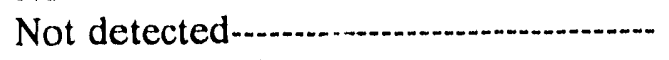 } & $(511)$ & 1.611 & 1 \\
\hline \multicolumn{3}{|c|}{ Platinum interference } & $(432)$ & 1.390 & 1 \\
\hline \multicolumn{3}{|c|}{ 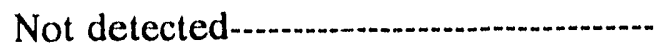 } & $(522)$ & 1.327 & 1 \\
\hline \multicolumn{3}{|c|}{ 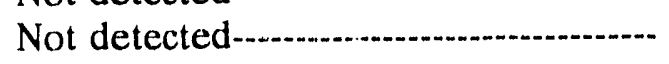 } & $(532)$ & 1.258 & 10 \\
\hline \multicolumn{3}{|c|}{ Not detected } & $(550)$ & 1.244 & 10 \\
\hline 76.808 & 1.2400 & 56 & (413) & 1.236 & 40 \\
\hline \multicolumn{3}{|c|}{ Not detected-.... } & (333) & 1.224 & 20 \\
\hline $77.689^{k}$ & $1.22: 81$ & $<38$ & $(720)$ & 1.209 & 40 \\
\hline
\end{tabular}

$a_{\mathrm{a}_{\mathrm{o}}}=3.5942 \AA ;$ V.strong (110) texture.

$b_{\mathrm{I}_{\mathrm{o}}}=31618 \mathrm{cpm}$.

$c_{\mathrm{a}_{\mathrm{o}}}=3.926 \AA$; some (111) texture.

$d_{\mathrm{I}_{\mathrm{o}}}=11084 \mathrm{cpm}$.

$e_{I_{0}}=3903 \mathrm{cpm}$.

$f_{\text {Line shared by }} \mathrm{Pt}-\mathrm{RH}$ heater and sesquioxide.

$g_{\mathrm{a}_{\mathrm{o}}}=8.55 \AA$.

$h_{\mathrm{I}_{\mathrm{o}}}=2215 \mathrm{cpm}$. Spinel is highly strained, coarse grained.

$i_{\text {Line shared by spinel and sigma phase. }}$

$j_{\text {Line shared by spinel and sesquioxide. }}$

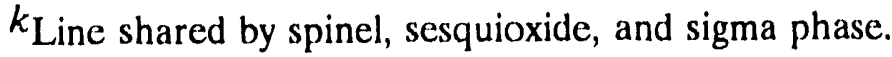

$l_{\mathrm{I}_{\mathrm{o}}}=918 \mathrm{cpm}$; some (110 texture).

$m_{\mathrm{I}_{\mathrm{o}}}=477 \mathrm{cpm}$.

Note: Heater is not located on the focusing circle of the diffractometer; therefore, $d$-values are listed for information purposes only. 


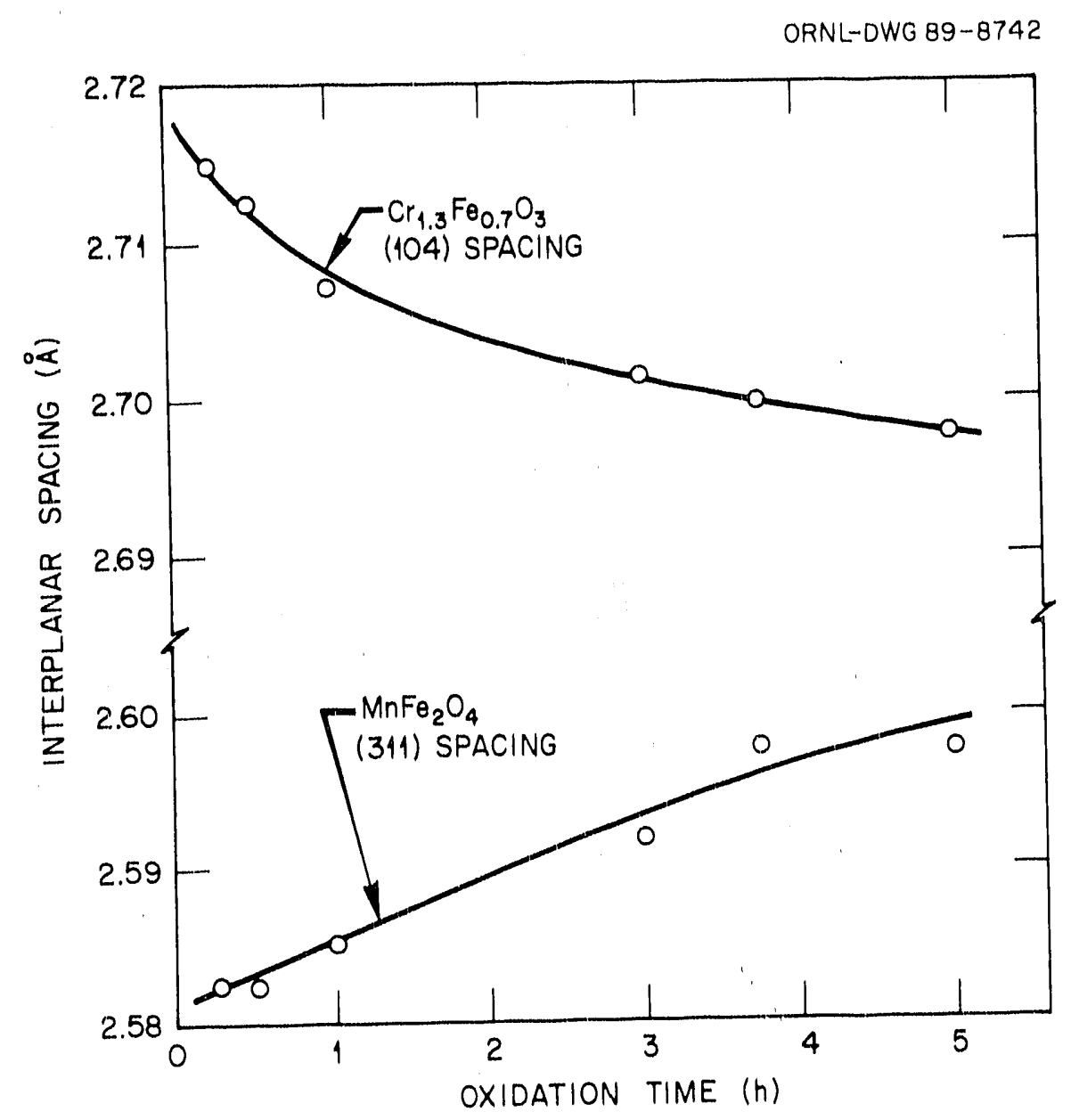

Fig. 9. Changes in the interplanar spacing of scale compounds on specimen AR7 during its early exposure in air at $900^{\circ} \mathrm{C}$.

\subsection{BASELINE OXIDATION IN AIR}

The main purpose of this group of tests was to determine: (1) the kinetics of reaction of $310 \mathrm{~S}$ in air and (2) structural information regarding the reaction products which formed. These dalit thus serve as a baseline against which to compare results obtained in sulfidizing atmospheres (discussed later). As flat specimens only were used in these $900^{\circ} \mathrm{C}$ exposures, no quantitative information regarding mechanical deformation was obtained.

The observed weight gains for the six specimens exposed in air for times up to $384 \mathrm{~h}$ (16 (1) are shown in Fig. 10. The data indicate that, aside from an initial transient, the kinetics are essentially parabolic in character. The value of the parabolic rate constant associated with the linear portion of this graph has a value of $3.88 \times 10^{-3} \mathrm{mg}^{2} \mathrm{~cm}^{-4} \mathrm{~h}^{-1}$. This value is smaller than thal found in the preliminary tests, wherein the existence of the transient was not recognized. 


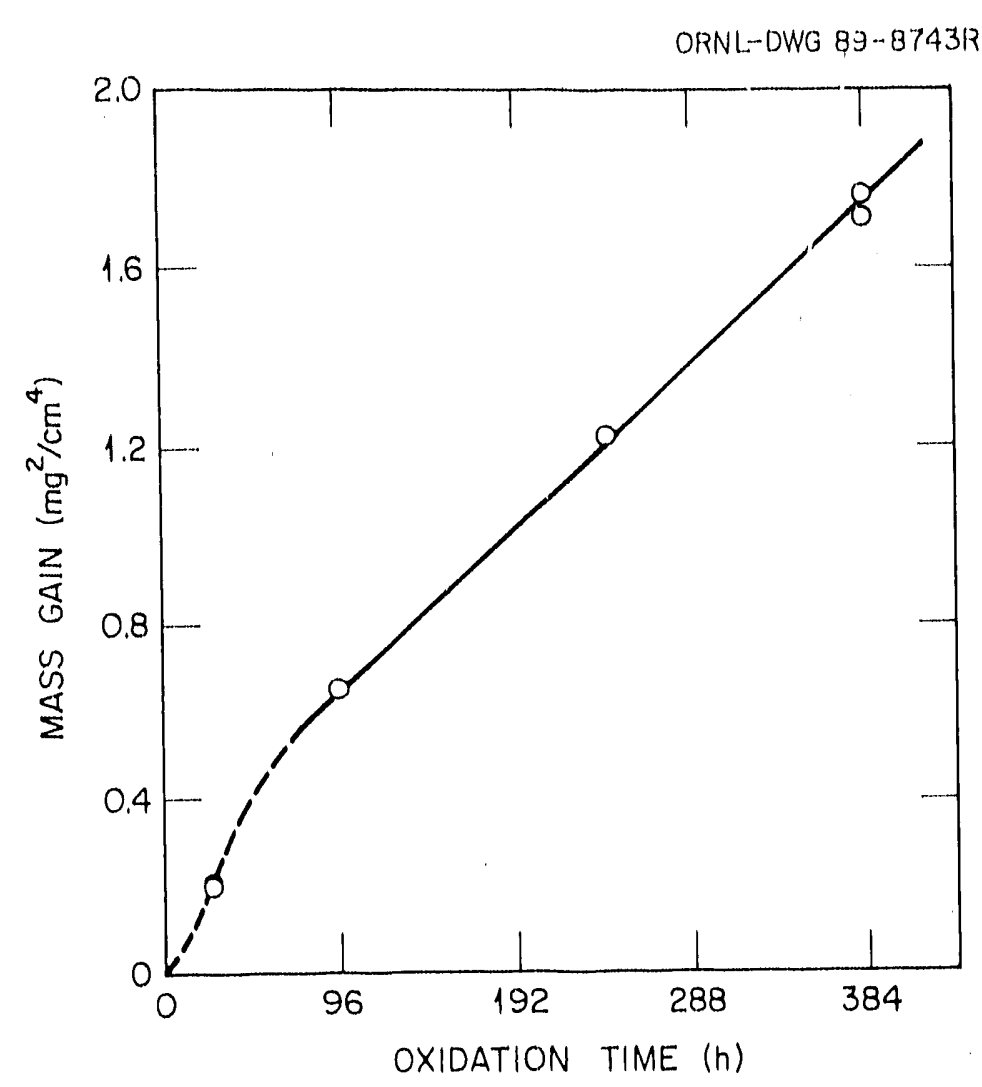

Fig. 10. Square of specific mass gain as a function of time for specimens exposed in air at $900^{\circ} \mathrm{C}$.

Fortuitously, the transient portion of the weight gain curve can be approximated by a higher initial value of the parabolic rate constant. Thus, the argument presented in Sect. 3.1 regarding the relation between oxidation and deformation is retained.

The results of an EDS analysis for this same specimen after the 24-h exposure are summarized in Table 8. It appears from this analysis that the granular scale is rich in chromium and surprisingly rich in manganese, the other major alloy elements being essentially absent.

The structure of the air-formed scales developed on $310 \mathrm{~S}$ after $24 \mathrm{~h}$ of exposure is shown in the electron micrographs of Fig. 11. The outermost portion of the scale is seen to be composed of faceted grains. Any special regularity in their shape is difficult to discern. The lower photograph, Fig. 11(b), illustrates an area of the specimen where spalling has occurred. A light filamentary network is seen to reside below the granular outer scale but above the alloy substrate. It appears that the network, at some prior time, may have been associated with the 
Table 8. Qualitative EDS analyses for specimen

AR1 alter 24 h cxposure air at $9(x)^{\circ} \mathrm{C}$ summary of relative elemental abundance ${ }^{a}$

\begin{tabular}{lrrr}
\hline & \multicolumn{3}{c}{ Featured in normal section $b$} \\
\cline { 2 - 4 } $\begin{array}{l}\text { Chemical } \\
\text { element }\end{array}$ & (A) & (B) & (C) \\
\hline Iron & 0 & 22 & 100 \\
Chromium & 100 & 11 & 40 \\
Nickel & 0 & 5 & 22 \\
Manganese & 39 & 1 & 0 \\
Silicon & 0 & 100 & 5.5 \\
\hline
\end{tabular}

$a_{\text {Relative elemental abundance is in terms of }}$ each element's K- $\alpha$ excitation divided by that for the strongest element (presented as percentages).

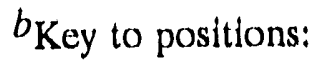

(A): External surface of the granular scale.

(B): Filamentary network near the alloy-oxide interface.

(C): Substrate grains near the alloy-oxide interface.
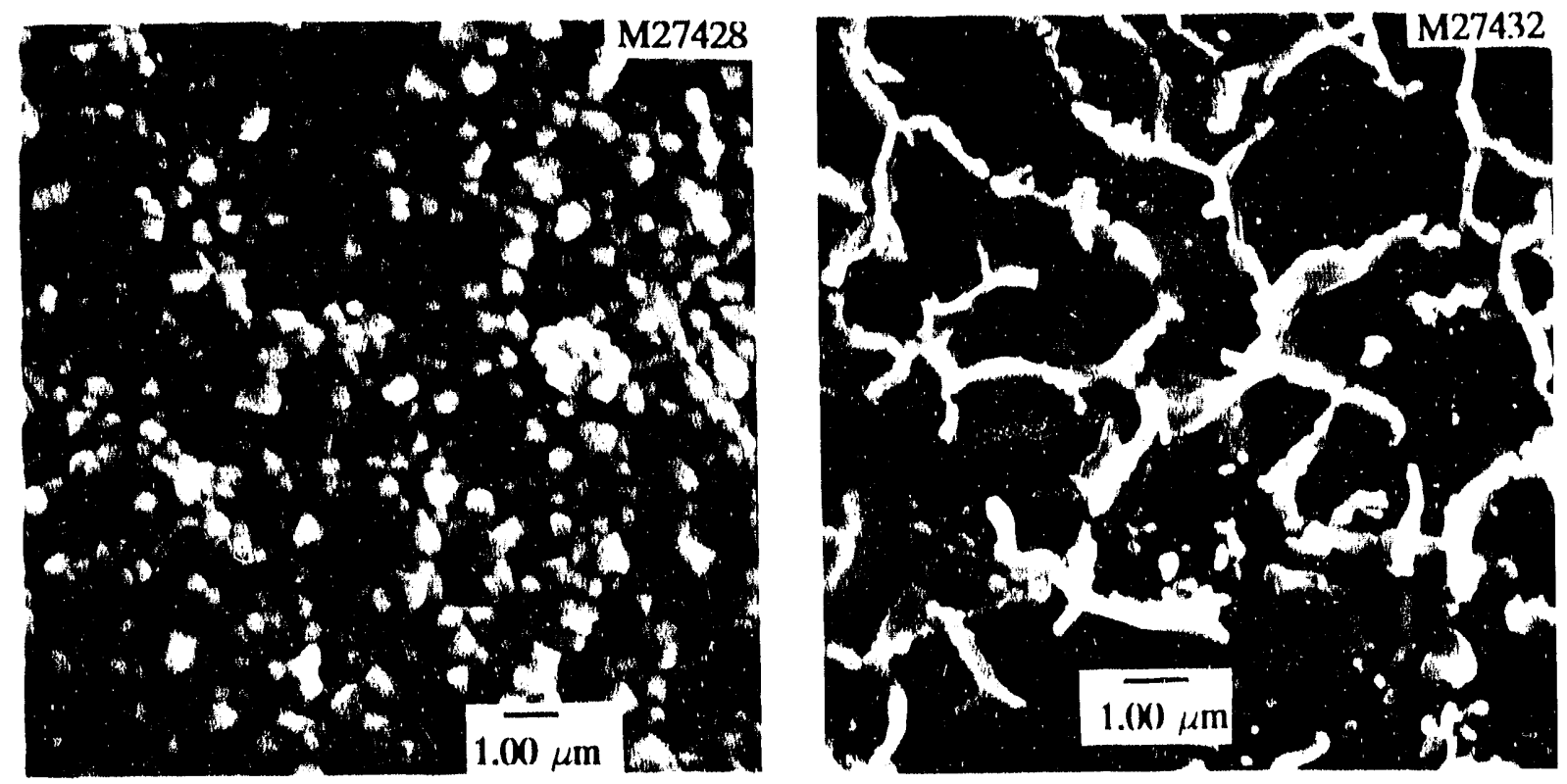

Fig. 11. Electron micrographs showing the scale structure of specimen AR1 after 24-h exposure in air at $900^{\circ} \mathrm{C}$. 
grain-boundary network of the alloy. The primary metallic element of the light-colored network of' Fig. 11(b) is silicon; the compound may be essentially pure silica, as some "spillover" of signal from surrounding features is probable. Finally, at points of that same specimen (but between the (ilaments) is found what appears to be the austenite matrix depleted of manganese and perhaps somewhat enriched in sillicon.

Inspection of specimen AR1 by X-ray diffraction indicated the presence of both a spinel and a sesquiloxide as surface compounds, as shown in Table 9. However, no sillicon-bearing compound could be identified in that diffraction pattern, Indicating that the silicon, which had been found by EDS, may be in an amorphous form. While the spinel pattern was matched to the JCPDS card for $\mathrm{MnFe}_{2} \mathrm{O}_{4}$, the EDS analysis indicates that it is more likely to be a compound of the general formulation $(\mathrm{Mn}, \mathrm{Cr})_{3} \mathrm{O}_{4}$, the $\mathrm{X}$-ray method being sensitive to crystal structure rather than chemical constitution. Similarly, the sesquioxide pattern was matched to the JCPDS card for $\mathrm{Cr}_{1.3} \mathrm{Fe}_{0.7} \mathrm{O}_{3}$, while an EDS analysis to be presented shortly will indicate that it is more likely to be a distorted compound of the general formulation $\mathrm{Cr}_{2} \mathrm{O}_{3}$.

The air-formed scales developed after $216-\mathrm{h}(9-\mathrm{d})$ exposure at $900^{\circ} \mathrm{C}$ are more mature versions of those just discussed. Figure 12 illustrates an optical photomicrograph of a transverse section through specimen AR4, clearly showing a two-layered scale. The outer layer exhibits a relatively large and blocky grain size, while the inner layer is apparently of much finer structure. Details of this structure are more clearly evident in the electron micrograph of Fig. 13(a) where the inner layer appears to be relatively compact and composed of fine columns approximately $0.25 \mu \mathrm{m}$ in width. Beneath the scale, voids are clearly evident upon the grain-boundary network of the alloy.

While the structure shown in Fig. 13(a) (216-h exposure) is similar in kind to that developed at lesser times, as shown in Fig. 8 (120-h exposure), the detail of the external scale layer is clearer here, and the amount of interfacial voiding appears to be reduced. These differences are probably attributable to difficulties encountered in specimen preparation, and it is, thus, advisable to consider these two transverse sections as a single set when attempting to formulate the true structure of the scale layers.

The results of an EDS analysis of the transwerse section shown in Fig. 13(a) are summarized in l'ahle 10. Here, it is seen that the outer scale layer contains essentially only chromium and manganese als metallic elements and, in parallel with the earlier data for specimen ARI $(24-h$ exposure), most probably represents a $(\mathrm{Mn}, \mathrm{Cr})_{3} \mathrm{O}_{4}$-type spinel product. Also, in parallel with thail carlicer sel of observations, the inner scale layer is likely a distorted $\mathrm{Cr}_{2} \mathrm{O}_{3}$ compound. It is also 
Table 9. X-ray diffraction data for specimen AR1 after 24-h exposure in air at $9000^{\circ} \mathrm{C}$

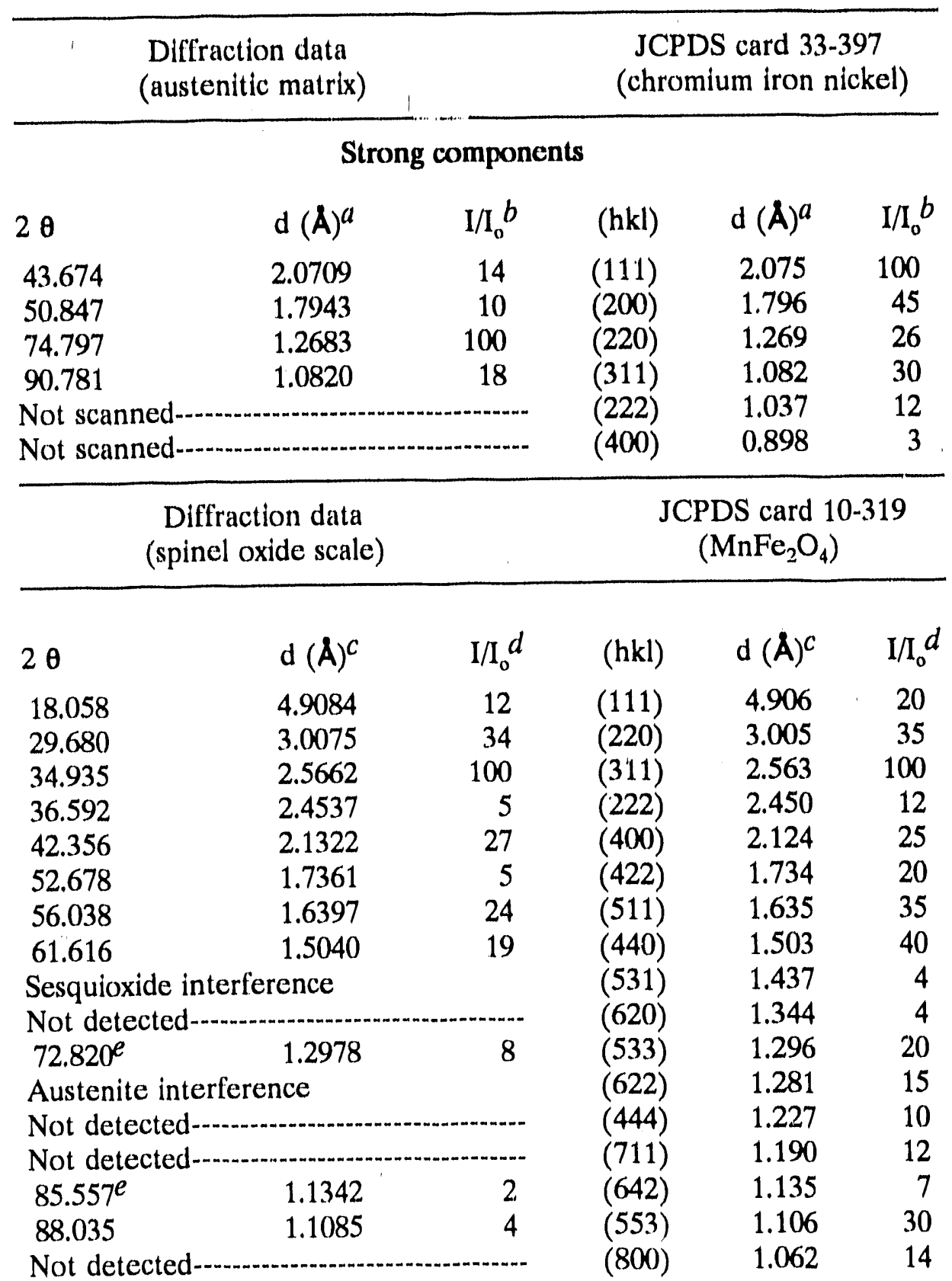


Table 9. (Continued)

\begin{tabular}{|c|c|c|c|c|c|}
\hline \multicolumn{2}{|c|}{$\begin{array}{l}\text { Diffraction data } \\
\text { (sesquioxide scale) }\end{array}$} & & \multicolumn{3}{|c|}{$\begin{array}{l}\text { JCPDS card 35-1112 } \\
\quad\left(\mathrm{Cr}_{1,3} \mathrm{Fe}_{0,7} \mathrm{O}_{3}\right)\end{array}$} \\
\hline \multicolumn{6}{|c|}{ Medium components } \\
\hline $2 \theta$ & $\mathrm{d}(\AA)^{c}$ & $\mathrm{I} / \mathrm{I}_{\mathbb{d}}^{f}$ & (hkl) & $\mathrm{d}(\AA)^{c}$ & $\mathrm{I} / \mathrm{I}_{\mathrm{o}}^{f}$ \\
\hline 24.337 & 3.6543 & 42 & (012) & 3.654 & 45 \\
\hline 33.387 & 2.6816 & 31 & (104) & 2.676 & 100 \\
\hline 35.891 & 2.5001 & 100 & (110) & 2.499 & 75 \\
\hline Not detec & & & (006) & 2.270 & 4 \\
\hline 41.238 & 2.1874 & 21 & (113) & 2.189 & 25 \\
\hline \multicolumn{2}{|c|}{ Austenite interference } & & (202) & 2.063 & 4 \\
\hline 49.881 & 1.8267 & 21 & (024) & 1.827 & 35 \\
\hline 54.520 & 1.6818 & 23 & (116) & 1.680 & 65 \\
\hline $57.963 \mathrm{~g}$ & 1.5898 & 4 & (122) & 1.590 & 5 \\
\hline $57.963 \mathrm{~g}$ & 1.5898 & 4 & (010) & 1.585 & 6 \\
\hline 62.952 & 1.4753 & 13 & (214) & 1.474 & 25 \\
\hline 64.475 & 1.4429 & 27 & $(300)$ & 1.442 & 25 \\
\hline Not dete & & & (208) & 1.338 & 1 \\
\hline $72.820^{e}$ & 1.2978 & 15 & $(10: 10)$ & 1.299 & 12 \\
\hline 76.227 & 1.2480 & 9 & $(220)$ & 1.249 & 6 \\
\hline \multirow{2}{*}{\multicolumn{3}{|c|}{$\begin{array}{l}\text { Not detected-at } \\
\text { Not detected-a }\end{array}$}} & $(306)$ & 1.218 & 3 \\
\hline & & & (128) & 1.179 & 2 \\
\hline \multicolumn{3}{|c|}{ 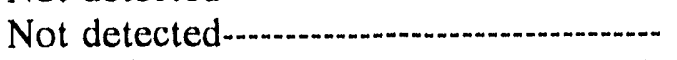 } & $(02: 10)$ & 1.152 & 4 \\
\hline $85.552^{e}$ & 1.1342 & 5 & $(134)$ & 1.132 & 7 \\
\hline \multicolumn{3}{|c|}{ Not detected-1. } & (226) & 1.095 & 7 \\
\hline
\end{tabular}

\footnotetext{
$a_{\mathrm{a}_{\mathrm{o}}}=3.558 \AA ;$ V.Strong (110) texture.

$b_{\mathrm{I}_{\mathrm{o}}}=17271 \mathrm{cpm}$.

$c_{\mathrm{a}_{\mathrm{o}}}=8.51 \AA$.

$d_{\mathrm{I}_{\mathrm{o}}}=13311 \mathrm{cpm}$. Spinel is highly strained and has a large grain size.

${ }^{e}$ Line shared by spinel and sesquioxide.

$f_{\mathrm{I}_{\mathrm{o}}}=6804 \mathrm{cpm}$; exhibits some (110 texture). Sesquioxide is strained and had a large grain size.
}

8 Single, very broad line assigned both reflections.

Note: No silica or silicate was detected. 


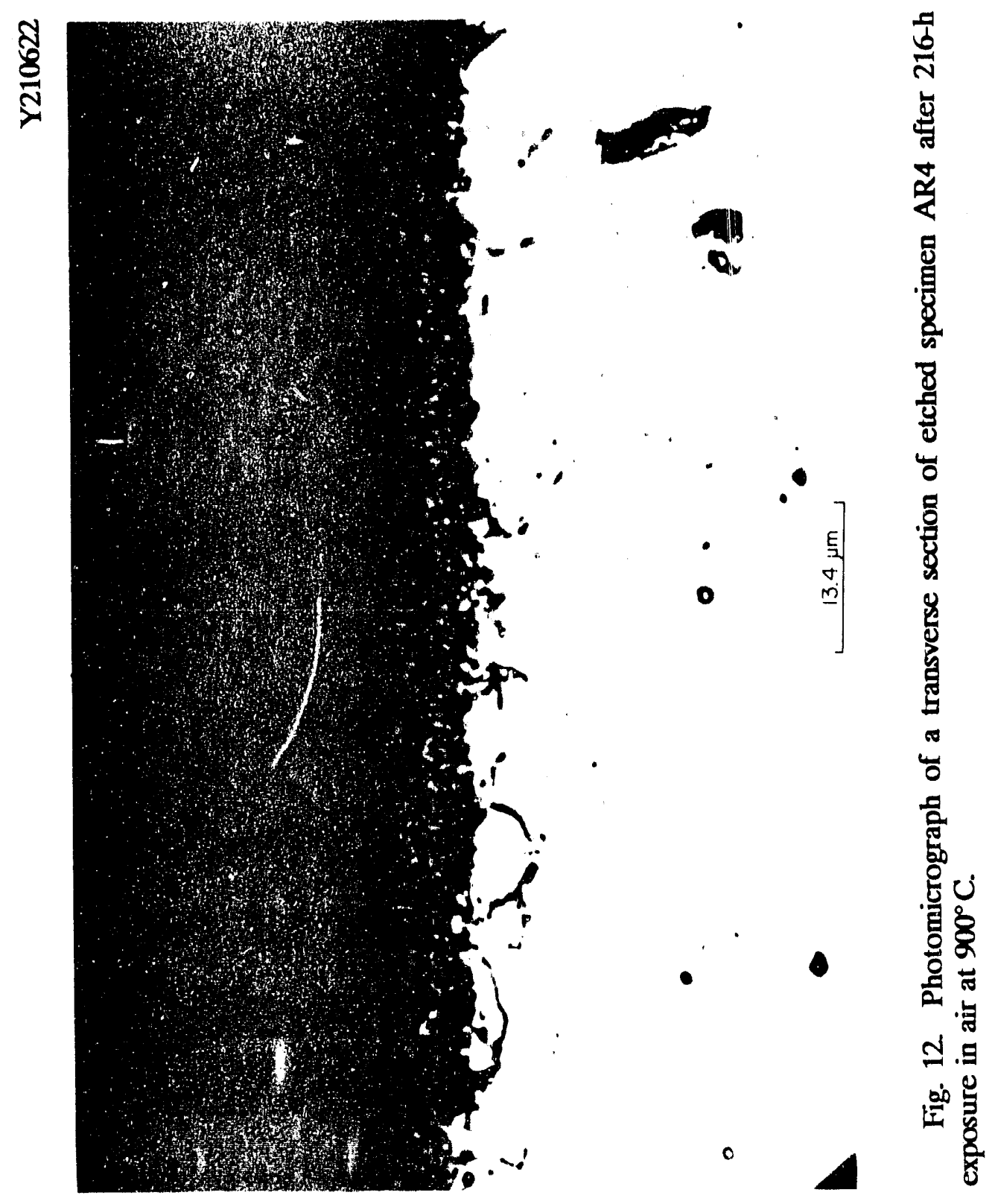




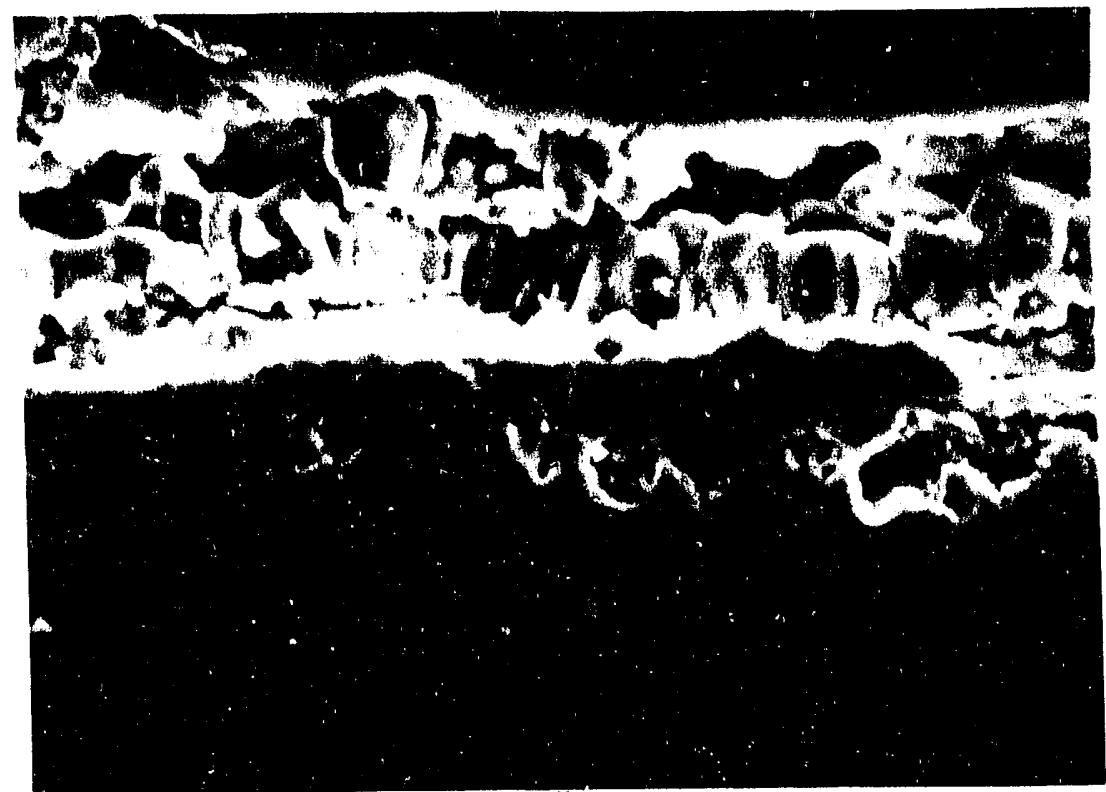

(a)

$1 . \overline{00 \mu \mathrm{m}}$

M27558

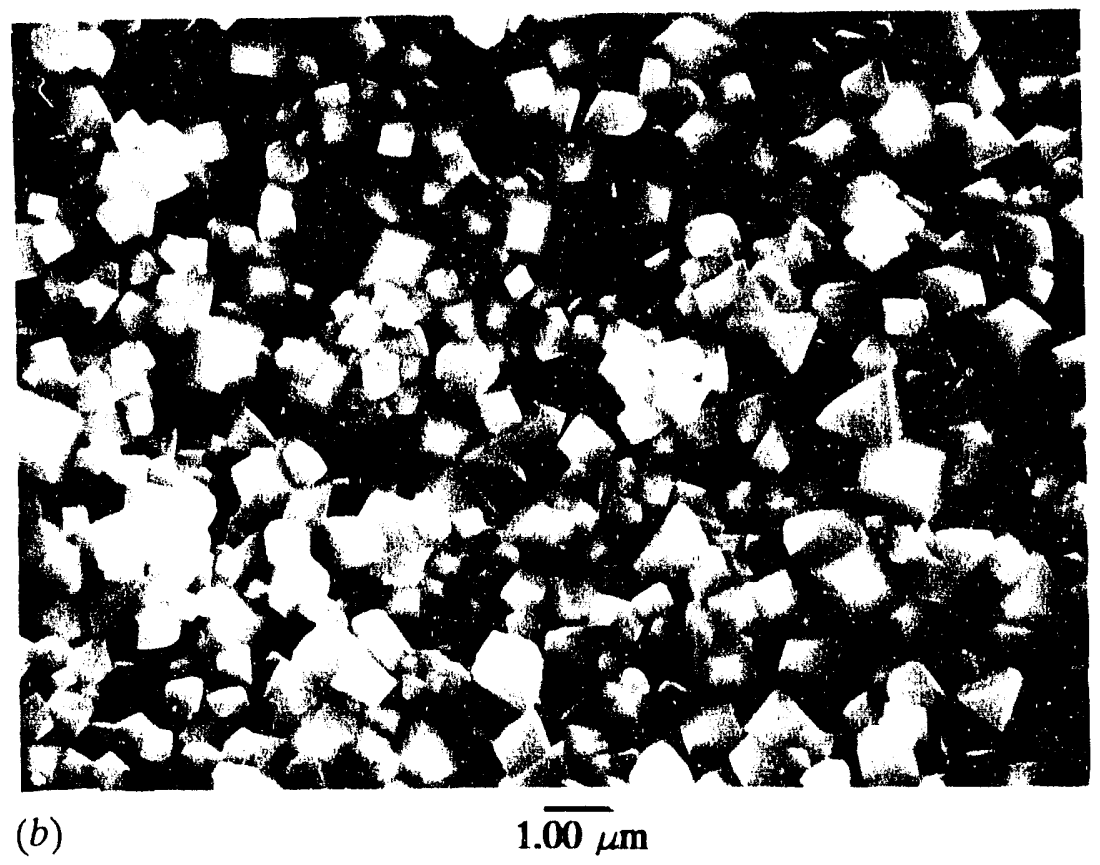

Fig. 13. Electron micrographs showing the scale structure of specimens AR4 and AR5, respectively, after exposure in air at $900^{\circ} \mathrm{C}$ : (a) transverse section after $216 \mathrm{~h}$ and $(b)$ external surface after $384 \mathrm{~h}$. 
Table 10. Qualitative EDS analysis for specimen AR4

after 216-h exposure in air at $900^{\circ} \mathrm{C}$

(summary of relative elemental abundance) ${ }^{a}$

\begin{tabular}{lrrcr}
\hline & \multicolumn{4}{c}{ Position in transverse section $b$} \\
\cline { 2 - 5 } Chemical element & (A) & $(\mathrm{B})$ & $(\mathrm{C})$ & (D) \\
\hline Iron & 100 & 100 & 1 & 0 \\
Chromium & 67 & 54 & 100 & 100 \\
Nickel & 27 & 25 & 0.2 & 0 \\
Manganese & 0.4 & 0.6 & 0.2 & 52 \\
Silicon & 0.9 & 0.8 & 0.4 & 0.6 \\
\hline
\end{tabular}

$a_{\text {Relative elemental abundance is in terms of each }}$ elements $\mathrm{K}-\alpha$ excitation divided by that for the strongest element (presented as percentages).

$b_{\text {Key to positions: }}$

(A): Denuded zone distal from the alloy-oxide interface.

(B): Denuded zone proximal to the alloy-oxide interface.

(C): Inner scale layer; nearest alloy-oxide interface.

(D): Outer scale layer; nearest gas-oxide interface.

noted that the denuded zone, immediately below the scale, is somewhat poorer in chromium than the bulk alloy, as may be expected if chromium is utilized in the scale-building process.

The qualitative chemistries for the inner and outer scale layers closely parallel those obtained from the transverse section, Table 10. A feature of this analysis, also observed for several other specimens, was a mound-like rosette of idiomorphic crystals, which were extremely rich in titanium. It is believed that such growths originated from "tramp" titanium in the alloy. Because these mounds are many times seen in linear arrays, it is believed that the titanium initially formed as carbides that were subsequently drawn into the form of particle strings by the metalworking practice. Due to the very high affinity of titanium for oxygen, the carbides were subsequently oxidized to produce a very low areal density of such mounds.

This description of the scale is reinforced by data gathered from an EDS analysis done on the external surface of the scale and summarized in Table 11. 
Table 11. Qualitative EDS analysis for specimen AR4 after 216-h exposure in air at $900^{\circ} \mathrm{C}$ (summary of relative elemental abundance) ${ }^{a}$

\begin{tabular}{lrcc}
\hline & \multicolumn{3}{c}{ Feature in normal section $b$} \\
\cline { 2 - 4 } Chemical element & $(\mathrm{A})$ & $(\mathrm{B})$ & $(\mathrm{C})$ \\
\hline Iron & 0 & 2 & 0 \\
Chromium & 100 & 100 & 47 \\
Nickel & 0 & 0.5 & 0 \\
Manganese & 42 & 3 & 20 \\
Silicon & 0 & 0.7 & 0 \\
Titanium & 0 & 0 & 100 \\
\hline
\end{tabular}

$a_{\text {Relative elemental abundance is in terms of each }}$ element's $k-\alpha$ excitation divided by that for the strongest element (presented as percentages).

$b_{\text {Key to positions: }}$

(A): Outermost surface of the scale layers.

(B): Inner scale layer as exposed by local spalling.

(C): Localized rosette mound of idiomorphic crystals.

At the longest test period investigated, $384 \mathrm{~h}(16 \mathrm{~d})$, the outermost surface of the scale matures into relatively large, faceted, nodular crystals. As shown in Fig. 13(b), some of these crystals exhibit an octahedral morphology as would be expected in the formation of a spinel-type structure. Such was confirmed by X-ray diffraction as shown in Table 12 below. Here, it is seen that the strongest portion of the pattern does, indeed, arise from spinel structures, with a weaker $\mathrm{Cr}_{1.3} \mathrm{Fe}_{0.7} \mathrm{O}_{3}$ pattern evidently being evolved from the inner scale layer. Of special interest in this analysis is that two, rather than one, spinels have formed in this late stage of scale growth. This is suggestive of an incongruent solid-state reaction occurring within the spinel phase as time progresses. It is possible that such reaction is encouraged by chemical gradients that occur within the scale and arise, fundamentally, from the fact that the chemical fluxes during the initial portion of oxidation may be grossly different from those that occur later. 
Table 12. X-ray diffraction data for specimen AR6 after 384 $\mathrm{h}$ exposure in air at $900^{\circ} \mathrm{C}$ (File CT357C)

\begin{tabular}{|c|c|c|c|c|c|}
\hline \multicolumn{3}{|c|}{$\begin{array}{l}\text { Diffraction data } \\
\text { (spinel oxide scale) }\end{array}$} & \multicolumn{3}{|c|}{$\begin{array}{l}\text { JCPDS card 10-319 } \\
\left(\mathrm{MnFe}_{2} \mathrm{O}_{4}\right)\end{array}$} \\
\hline \multicolumn{6}{|c|}{ Strong components } \\
\hline $2 \theta$ & $\mathrm{d}(\AA)^{a}$ & $\mathrm{~L} / \mathrm{I}_{0}{ }^{b}$ & $(\mathrm{hkl})$ & $\mathrm{d}(\AA)^{a}$ & $1 / \pi_{0}^{b}$ \\
\hline \multicolumn{3}{|c|}{ Not scanned-.... } & (111) & 4.906 & 20 \\
\hline 29.722 & 3.0034 & 33 & $(220)$ & 3.005 & 35 \\
\hline 34.981 & 2.5630 & 100 & (311) & 2.563 & 100 \\
\hline 36.681 & 2.4480 & 6 & (222) & 2.450 & 12 \\
\hline 42.513 & 2.1247 & 31 & $(400)$ & 2.124 & 25 \\
\hline 52.765 & 1.7335 & 6 & (422) & 1.734 & 20 \\
\hline 56.190 & 1.6357 & 27 & (511) & 1.635 & 35 \\
\hline 61.774 & 1.5005 & 24 & (440) & 1.503 & 40 \\
\hline \multicolumn{3}{|c|}{ Sesquioxide interference } & $(531)$ & 1.437 & 4 \\
\hline 70.104 & 1.3412 & 2 & (620) & 1.344 & 4 \\
\hline $73.117^{c}$ & 1.2932 & 4 & (533) & 1.296 & 20 \\
\hline 73.981 & 1.2802 & 2 & (622) & 1.281 & 15 \\
\hline 77.855 & 1.2259 & 1 & (444) & 1.227 & 10 \\
\hline \multicolumn{3}{|c|}{ Not detected..... } & (711) & 1.190 & 12 \\
\hline $85.655^{c}$ & 1.1331 & 3 & $(642)$ & 1.135 & 7 \\
\hline 88.354 & 1.1053 & 4 & $(553,731)$ & 1.106 & 30 \\
\hline 92.768 & 1.0640 & 2 & $(800)$ & 1.062 & 14 \\
\hline 100.690 & 1.0005 & 1 & $(660)$ & Not listed & $\mathbf{X}$ \\
\hline 103.6834 & 0.9796 & 2 & $(555,751)$ & 0.982 & 20 \\
\hline 104.3477 & 0.9752 & 1 & $(662)$ & Not listed & $\mathrm{X}$ \\
\hline \multirow[t]{2}{*}{108.0566} & 0.9518 & 2 & $(840)$ & Not listed & $\mathrm{x}$ \\
\hline & \multicolumn{2}{|c|}{$\begin{array}{c}\text { Diffraction data } \\
\text { [spinel oxide scale (ghost)] }\end{array}$} & \multicolumn{3}{|c|}{$\begin{array}{c}\text { JCPDS card } 10-319 \\
\left(\mathrm{MnFe}_{2} \mathrm{O}^{4}\right)\end{array}$} \\
\hline $2 \theta$ & $\mathrm{d}(A)^{d}$ & $\mathrm{I} / \mathrm{I}_{0}^{b}$ & (hkl) & $\mathrm{d}(\AA)^{d}$ & $\mathrm{I} / \mathrm{I}_{\mathrm{o}} b$ \\
\hline \multicolumn{6}{|c|}{ Reads on primary spinel at all higher "d-values." } \\
\hline $70.387^{c}$ & 1.3365 & 1 & $(620)$ & 1.344 & 4 \\
\hline 73.394 & 1.2890 & 2 & (533) & 1.296 & 20 \\
\hline 74.233 & 1.2765 & 2 & (622) & 1.281 & 15 \\
\hline 78.214 & 1.2212 & 1 & (444) & 1.227 & 10 \\
\hline \multicolumn{3}{|c|}{ Not detected-..-... } & (711) & 1.190 & 12 \\
\hline 85.793 & 1.1317 & 3 & $(642)$ & 1.135 & 7 \\
\hline 88.543 & 1.1035 & 4 & $(553,731)$ & 1.106 & 30 \\
\hline 93.330 & 1.0590 & 2 & $(800)$ & 1.062 & 14 \\
\hline \multicolumn{3}{|c|}{ 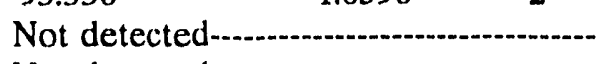 } & $(660)$ & Not listed & $\mathrm{X}$ \\
\hline \multicolumn{3}{|c|}{ Not detected-a...................................... } & $(555,751)$ & 0.982 & 20 \\
\hline \multirow{2}{*}{\multicolumn{3}{|c|}{$\begin{array}{l}\text { Not detected } \\
1093002\end{array}$}} & $(662)$ & Not listed & $\mathrm{X}$ \\
\hline & 0.9444 & 2 & (840) & Not listed & $\mathrm{X}$ \\
\hline
\end{tabular}


Table 12. (Continued)

\begin{tabular}{|c|c|c|c|c|c|}
\hline \multicolumn{3}{|c|}{$\begin{array}{l}\text { Diffraction data } \\
\text { (sesquioxide scale) }\end{array}$} & \multicolumn{3}{|c|}{$\begin{array}{l}\text { JCPDS card 35-1112 } \\
\left(\mathrm{Cr}_{1,3} \mathrm{Fe}_{0,7} \mathrm{O}_{3}\right)\end{array}$} \\
\hline \multicolumn{6}{|c|}{ Medium components } \\
\hline $2 \theta$ & $\mathrm{d}(A)^{d}$ & $\mathrm{I} / \mathrm{I}_{0}{ }^{e}$ & (hkl) & $\mathrm{d}(A)^{d}$ & $\mathrm{I} / \mathrm{I}_{0}^{e}$ \\
\hline 24.315 & 3.6576 & 19 & $(012)$ & 3.654 & 45 \\
\hline 33.359 & 2.6838 & 13 & (104) & 2.676 & 100 \\
\hline 35.870 & 2.5015 & 100 & $(110)$ & 2.499 & 75 \\
\hline Not dete & (n)............. & & $(006)$ & 2.270 & 4 \\
\hline 41.195 & 2.1896 & 17 & (113) & 2.189 & 25 \\
\hline 43.759 & 2.0670 & 5 & (202) & 2.063 & 4 \\
\hline 49.881 & 1.8268 & 21 & (024) & 1.827 & 35 \\
\hline 54.493 & 1.6825 & 19 & (116) & 1.680 & 65 \\
\hline 57.913 & 1.5911 & 6 & (122) & 1.590 & 5 \\
\hline Not dete & & & (010) & 1.585 & 6 \\
\hline 62.976 & 1.4748 & 19 & (214) & 1.474 & 25 \\
\hline $64.525^{c}$ & 1.4430 & 54 & $(300)$ & 1.442 & 25 \\
\hline 70.387 & 1.3365 & 4 & (208) & 1.338 & 1 \\
\hline $73.117^{c}$ & 1.2932 & 14 & $(10: 10)$ & 1.299 & 12 \\
\hline 76.188 & 1.2485 & 11 & $(220)$ & 1.249 & 6 \\
\hline 78.312 & 1.2199 & 5 & (306) & 1.218 & 3 \\
\hline 81.488 & 1.1807 & 6 & $(128)$ & 1.179 & 2 \\
\hline Not dete & & ........ & $(02: 10)$ & 1.152 & 4 \\
\hline 85.655 & 1.1331 & 11 & $(134)$ & 1.132 & 7 \\
\hline 89.473 & 1.0944 & 6 & (226) & 1.095 & 7 \\
\hline \multicolumn{3}{|c|}{$\begin{array}{c}\text { Diffraction data } \\
\text { (austenitic matrix) }\end{array}$} & \multicolumn{3}{|c|}{$\begin{array}{l}\text { JCPDS card } 33-397 \\
\text { (chromium iron nickel) }\end{array}$} \\
\hline $2 \theta$ & $\mathrm{d}(A) f$ & $1 / I_{0} g$ & (hkl) & $\mathrm{d}(A)^{f}$ & $I / I_{0}^{g}$ \\
\hline 43.591 & 2.0746 & $498 s$ & (111) & 2.075 & 1003.593 \\
\hline 50.752 & 1.7974 & $471 \mathrm{~s}$ & $(200)$ & 1.796 & 453.595 \\
\hline 74.698 & 1.2697 & $7091 \mathrm{~s}$ & (220) & 1.269 & 263.591 \\
\hline 90.730 & 1.0825 & 1810 s & (311) & 1.082 & 303.590 \\
\hline Not dete & 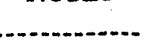 & 0 & (222) & 1.037 & 12 \\
\hline Not dete & . & 0 & $(400)$ & 0.898 & 3 \\
\hline
\end{tabular}

$a_{\mathrm{a}_{\mathrm{o}}}=8.50 \AA$; spinel has line broadening.

$b_{\mathrm{I}_{\mathrm{o}}}=30824 \mathrm{cpm}$.

$c^{c}$ Line shared by spinel and sesquioxide.

$d_{\mathrm{a}_{\mathrm{o}}}=8.46 \AA_{\text {; spinel has line broadening. }}$

$e_{\mathrm{I}_{\mathrm{o}}}=8290 \mathrm{cpm}$; exhibits some (110) texture.

$f_{\mathrm{a}_{\mathrm{o}}}=3.592 \AA ;$ V.Strong (110) texture.

$g_{\mathrm{I}_{\mathrm{o}}}=7091 \mathrm{cpm}$. 
The exact chemical nature of these spinels has not been determined here; however, one of them is probably of the $(\mathrm{Mn}, \mathrm{Cr})_{3} \mathrm{O}_{4}$ as has been suggested above.

\section{3 "LEAN" SULFIDIZING ATMOSPHERES}

Five tests were run in the "lean" sulfidizing atmosphere at temperatures of 800,900 , and $1000^{\circ} \mathrm{C}$ using both flat and ell-shaped specimens. Their purpose was to determine: (1) the kinetics of the reaction; (2) qualitatively, the magnitude of the stresses generated during the oxidation process; and (3) structural information regarding the reaction products that were formed.

At $900^{\circ} \mathrm{C}$, the rate of oxidation was found to be essentially parabolic subsequent to an initial transient period during which the rate was more rapid. This behavior is shown in Fig. 14, from which the effective parabolic rate constant was determined to be $1.11 \times 10^{-3} \mathrm{mg}^{2} \mathrm{~cm}^{-4} \mathrm{~h}^{-1}$. This rate was approximately equal to that experienced in air at $800^{\circ} \mathrm{C}$ and more than 3 times smaller than that found for the baseline tests run in air at $900^{\circ} \mathrm{C}$. As sulfur was not overtly involved in compound formation upon these specimens (described below), the reduction in rate is most probably associated with the $10^{6}$ times lower oxygen partial pressures involved in these tests (Appendix I). As in the case of oxidation in air, no sensible spalling or evidence of scale breakdown was noted for these specimens.

The deformations suffered by ell-shaped specimens as a result of exposure to the "lean" sulfidizing atmosphere at 800 and $900^{\circ} \mathrm{C}$ differed grossly from those exposed in air. At $800^{\circ} \mathrm{C}$, neither angle closure nor dilatation was observed; while at $900^{\circ} \mathrm{C}$, the angles of the ells increased and the dilatations were very small. These dimensional changes for the $900^{\circ} \mathrm{C}$ exposures are summarized in Table 13 below. Because weak dilatations of the gage lengths were found and because its rate appears to be related to the parabolic reaction, it is presumed that the opening of the ells is primarily a creep-related phenomenon induced by gravitational effects. Had these mechanical deformations been directly related to the amount of scale formation, then, by calculation, one would have expected an angle closure of approximately $15^{\circ}$ and a dilatation of approximately $1 \%$ after $24 \mathrm{~h}$ of exposure in the sulfidizing atmosphere. As the observed values were very much smaller, it is concluded that the cooperative, tractive forces between the scale and its alloy substrate are greatly diminished, if not completely absent, in the "lean" sulfidizing atmosphere. For the latter case, the small dilatations that were observed may arise from phenomena as oxygen solution in the alloy, oxide formation within the alloy or scale, etc. 
ORNL-DWG 89-8744R

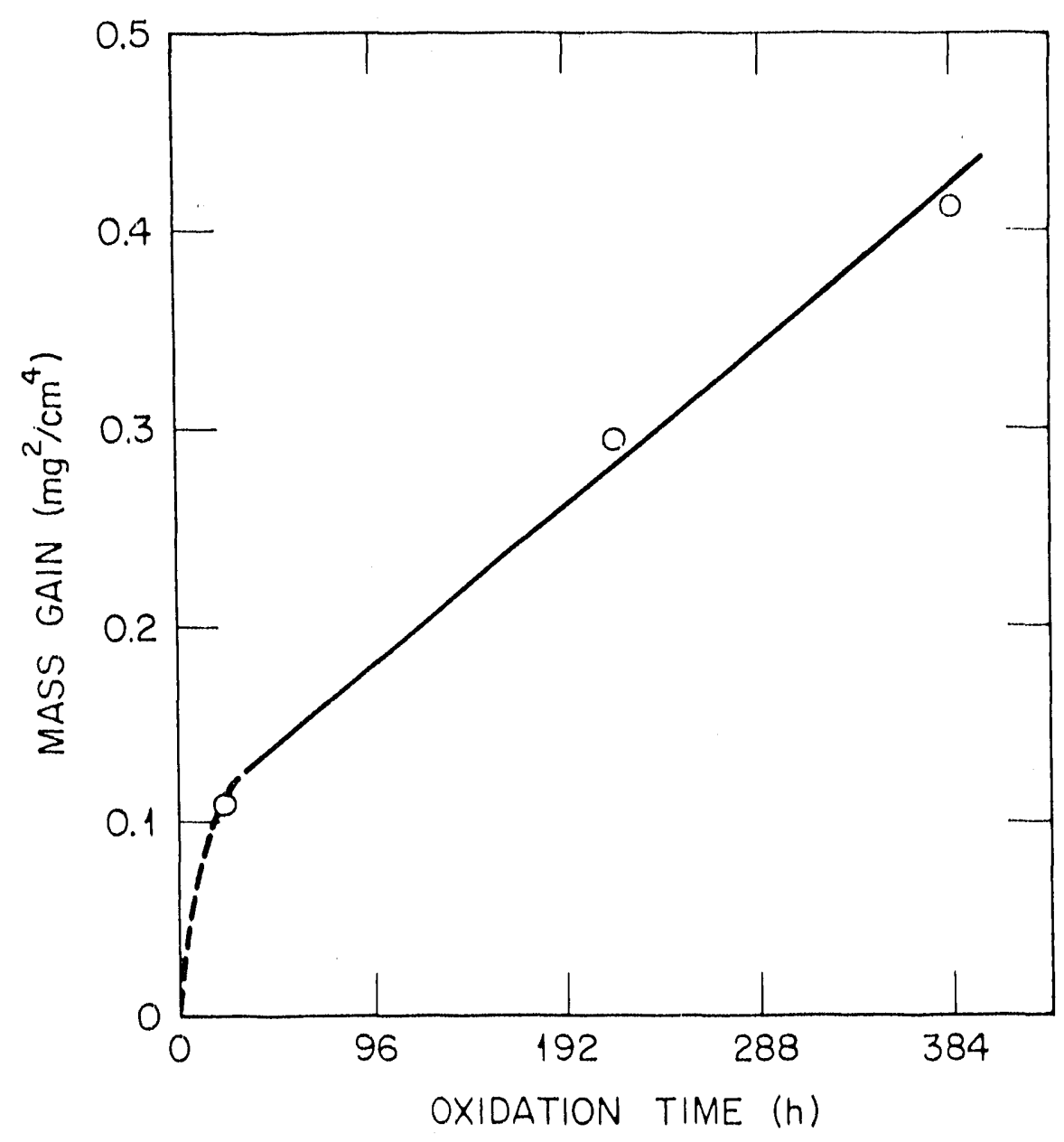

Fig. 14. Square of specific mass gain as a function of time for specimens exposed in the "lean" sulfidizing atmosphere at $900^{\circ} \mathrm{C}$.

Table 13. Deformation of ell-shaped specimens in the "lean" sulfidizing atmosphere at $900^{\circ} \mathrm{C}$

\begin{tabular}{lccccc}
\hline Specimen & $\begin{array}{c}\text { Exposure } \\
\text { time } \\
\text { number }\end{array}$ & $\begin{array}{c}\text { Angle } \\
\text { closure } \\
(\mathrm{deg})\end{array}$ & $\begin{array}{c}\text { Closure } \\
\text { rate } \\
\left(\mathrm{deg} / \mathrm{h}^{1 / 2}\right)\end{array}$ & $\begin{array}{c}\text { Linear } \\
(\%)\end{array}$ & $\begin{array}{c}\text { Rate } \\
\left(\mathrm{h}^{1 / 2}\right)\end{array}$ \\
\hline E1R5 & 24 & -4.0 & -0.82 & 0.23 & 0.047 \\
E1R6 & 216 & -6.0 & -0.41 & 0.38 & 0.026 \\
E1R7 & 384 & -9.5 & -0.48 & 0.80 & 0.041 \\
\hline
\end{tabular}


The structural aspects of the scales formed in the "lean" sulfidizing atmosphere also differed markedly from those formed in air. The most striking aspect was the formation of blade-like products as seen from the gas-oxide interface of the scales. Two photographs, which represent what are essentially the limiting cases of this structural aspect, are shown in Fig. 15 for 24-h exposures at 800 and $1000^{\circ} \mathrm{C}$. At the lower temperature, Fig. 15(a), the visible portion of the product is almost totally bladelike, whereas at the higher temperature, small blades are admixed with nodules and, in a few selected areas, mounds of product involving ribbon-like growths are seen as shown in Fig. $15(b)$. That the structures of Fig. 15 represent extremes in reaction product evolution is reinforced by a similar set of micrographs of scales obtained from specimens exposed for 24 and $384 \mathrm{~h}$ at $900^{\circ} \mathrm{C}$, as shown in Fig. 16. For the earlier time [Fig. 16(a)], the structure is predominantly bladelike; however, upon close inspection, one may discern small nodules having formed between the blades. For the longer time, the nodules dominate the structure, either the size or the areal density of the blades having been decreased as seen in Fig. 16(b). In addition, that photograph shows one of the ribbon-like growths noted earlier for the $1000^{\circ} \mathrm{C}$ exposure.

The average (integrated) surface and product blade chemistries of these scales, developed after $24 \mathrm{~h}$ of reaction, are summarized in Table 14. It is seen that the surface is chromium-rich for all exposures with manganese again participating in the formation of reaction products, especially at the higher temperatures. The presence of sulfur is also noted; however, it is not known with certainty whether it appears as part of the scale or as a sulfate contamination due to the manipulation of specimens during or after their exposure. The presence of manganese may be associated with the development of the nodular product. The blade and average surface chemistries are similar, but the temperature dependence of the manganese concentration for the blades is inverse to that for the average surfaces. This suggests that manganese is to be associated with blade formation at the lower temperature, or early in the scale evolution, and that later on, or at higher temperatures, some of the manganese leaves the blade sites to develop the nodular product. The concept of manganese-rich nodules was reinforced by EDS examination of the specimens exposed long term at $900^{\circ} \mathrm{C}$. The relative abundance of manganese in the overall scale was found to increase from 22 to 47 to 64 as the exposure times increased from 24 to 216 to $384 \mathrm{~h}$. Further, the relative abundances of manganese and chromium in the nodules per se were found to be 100 and 53 after the 216-h exposure. It is therefore concluded that manganese is to be associated with the nodular morphology observed here. 
M27309

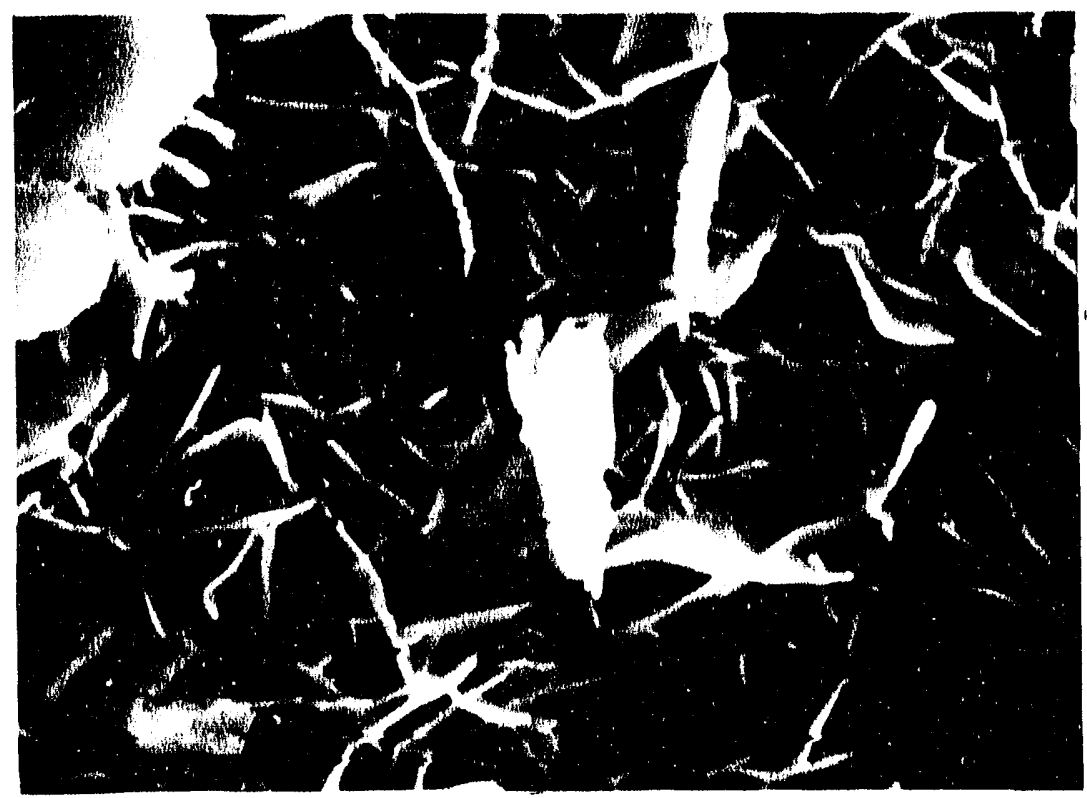

(a)

$1 . \overline{00 \mu \mathrm{m}}$

M27594

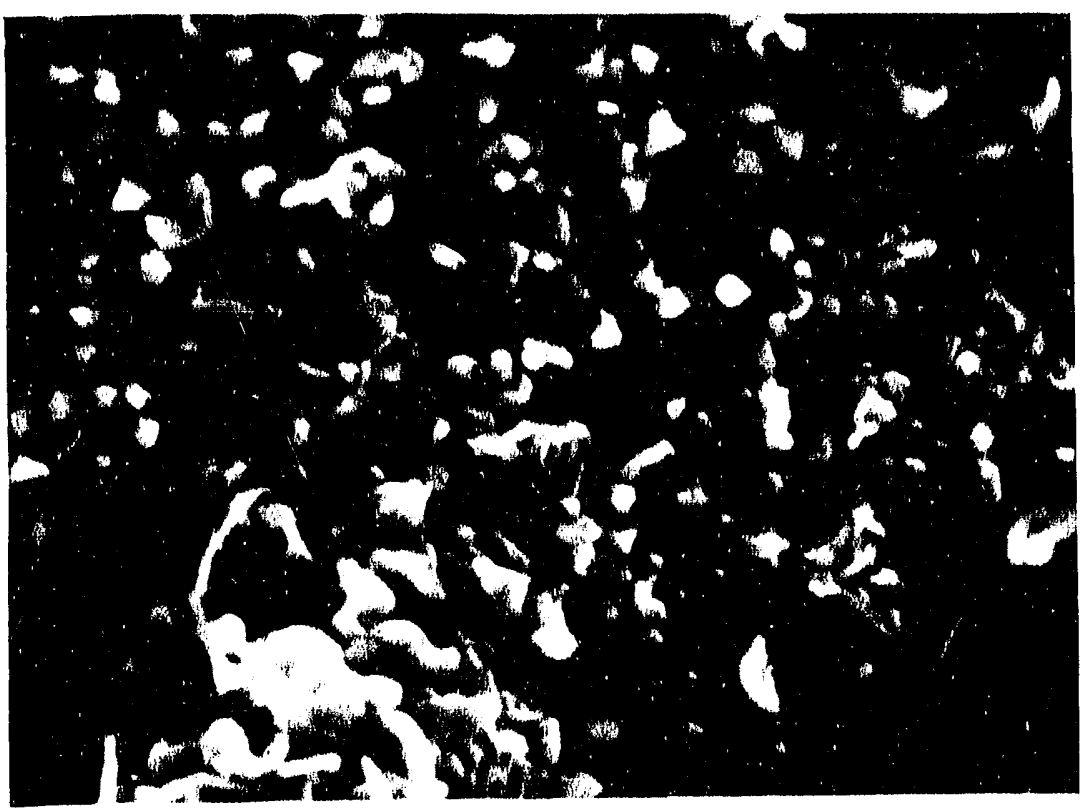

(b)

$$
1 . \overline{00 \mu \mathrm{m}}
$$

Fig. 15. Electron micrographs showing the scale structure of specimens E1R4 and AR8 after exposure in the "lean" sulfidizing atmosphere: (a) Surface after $24 \mathrm{~h}$ at $800^{\circ} \mathrm{C}$ and (b) surface after $24 \mathrm{~h}$ at $10(0){ }^{\circ} \mathrm{C}$. 
M27673

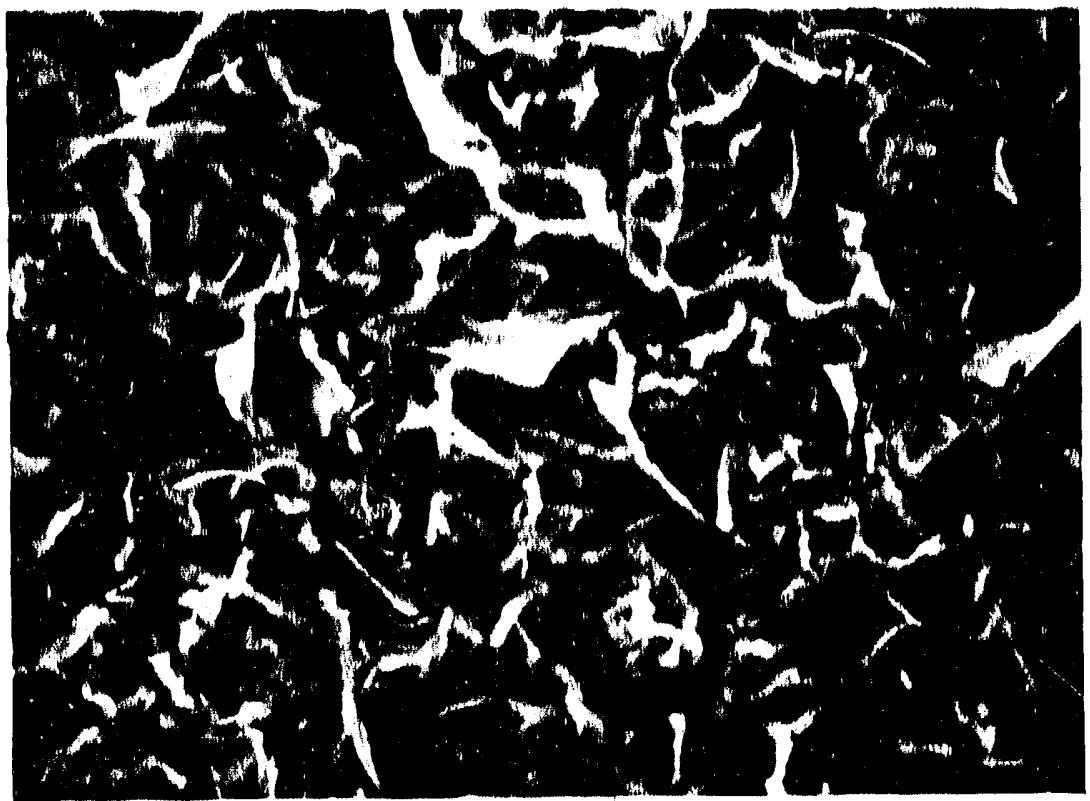

(a)

$1 . \bar{x} \mu \mathrm{m}$

M27392

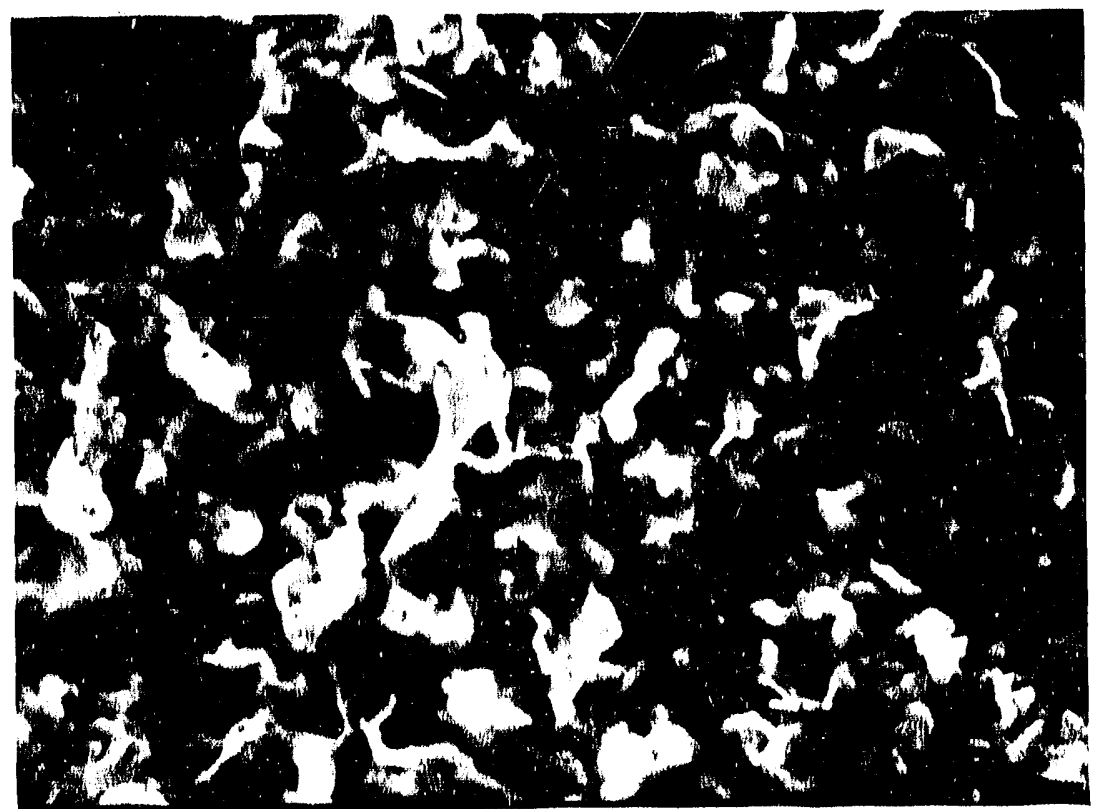

(b)

$$
1 . \overline{0} \mu \mathrm{m}
$$

Fig. 16. Electron micrographs showing the scale structure of specimens E1R5 and E1R7 after exposure in the "lean" sulfidizing atmosphere at $9(x)^{\circ} \mathrm{C}$ : (a) Surface after $24 \mathrm{~h}$ and $(b)$ surface after $384 \mathrm{~h}$. 
Table 14. Qualitative EDS analyses for specimens

E1R4, E1R5, and AR8 after 24-h cxposure in the "lean" sulfidizing atmosphere

(summary of relative elemental abundance) $)^{d}$

\begin{tabular}{lccc}
\hline Chemical element & $800^{\circ} \mathrm{C}$ & $900^{\circ} \mathrm{C}$ & $1000^{\circ} \mathrm{C}$ \\
\hline & Average surface density \\
Iron & 3 & 4 & \\
Chromium & 100 & 100 & 1.9 \\
Nickel & 0.8 & 2 & 100 \\
Manganese & 3 & 22 & 0.4 \\
Sillicon & 2.5 & 0.7 & 29 \\
Titanium & 0 & 0 & 0 \\
Sulfur & 0 & 0 & 2.7 \\
& & & 0.7
\end{tabular}

Product blade chemistry

$\begin{array}{lrcc}\text { Iron } & 3 & 7 & 1.2 \\ \text { Chromium } & 100 & 100 & 100 \\ \text { Nickel } & 0 & 2 & 0.3 \\ \text { Manganese } & 24 & 15 & 9 \\ \text { Silicon } & 3 & 0.7 & 0.4 \\ \text { Titanium } & 0 & 0 & 1.1 \\ \text { Sulfur } & 1.6 & 0 & 0\end{array}$

\footnotetext{
$a_{\text {Relative elemental abundance is in terms of each }}$ element's $\mathrm{K}-\alpha$ excitation divided by that for the strongest elcment (presented as percentages).
}

Because the scale structure had evolved furthest on the specimen exposed at $1000^{\circ} \mathrm{C}$, its surface was examined more intensively by the EDS technique. The chemistries of selected special surface features are summarized in Table 15.

Beneath a microscopic area of spalled scale was found an inner scale layer with featureless topography, which was apparently a chromia layer. Below it was the alloy substrate partially covered by various crystal types, some of which were very rich in titanium (which is involved in the production of the localized rosette structures cited earlier). This suggests that the spalled area may represent the base of a rosette mound that had fallen away. Such mounds were observed on this specimen, similar to those observed in air (Table 11). At the external surface of the scale were found the manganese- and chromium-rich ribbon and nodular idiomorphs in association with 
Table 15. Qualitativo EDS analysis for specimon AR8 after 24-h exposure in the "lean" sulfidizing atmosphere at $1(0)^{\circ} \mathrm{C}$ (summary of relative elemental abundance)"

\begin{tabular}{lcccc}
\hline & \multicolumn{4}{c}{ Feature in normal section $b$} \\
\cline { 2 - 5 } Chemical element & $(\mathrm{A})$ & $(\mathrm{B})$ & $(\mathrm{C})$ & $(\mathrm{D})$ \\
\hline Iron & 14 & 100 & 1.1 & 1.7 \\
Chromium & 100 & 95 & 32 & 92 \\
Nickel & 3.7 & 24 & 0.4 & 0 \\
Manganese & 1.7 & 0.4 & 100 & 100 \\
Silicon & 1.8 & 2.8 & 2.2 & 1.0 \\
Titanium & 0 & 39 & 0 & 0 \\
Sulfur & 0 & 0 & 3.8 & 1.7 \\
\hline
\end{tabular}

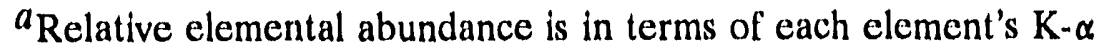
excitation divided by that for the strongest element (presented as percentages).

$b_{\text {Key to positions: }}$

(A): Inner scale layer as revealed by local spalling.

(B): Material beneath inner scale layer; same spall area.

(C): Ribbon-like crystals on the outer scale layer.

(D): Nodular crystals on the outer layer scale.

relatively small amounts of sulfur. The sulfur signal is much too weak to be representative of sulfides; yct, these idiomorphs contain sulfur concentrations up to five times that of the scale, in general, and thus represent sulfur "hot spots." The role that sulfur plays in this instance is unclear.

An X-ray diffraction analysis of the specimen exposed to the "lean" atmosphere for $24 \mathrm{~h}$ at $90\left(0^{\circ} \mathrm{C}\right.$ indicated the very strong presence of $\mathrm{Cr}_{2} \mathrm{O}_{3}$ (undistorted) and less intense patterns representing the spinels $\mathrm{Mn}_{1.5} \mathrm{Cr}_{1.5} \mathrm{O}_{4}$ and $\mathrm{MnFe}_{2} \mathrm{O}_{4}$ (Table 16). In view of the chemical data for this specimen (see Table 16), it is more probable that the latter spinel is again actually of the $(\mathrm{Mn}, \mathrm{Cr})_{3} \mathrm{O}_{4}$ type. Another analysis conducted on the specimen similarly exposed at $800^{\circ} \mathrm{C}$ also indicated that chromia and only the $\mathrm{Mn}_{1.5} \mathrm{Cr}_{1.5} \mathrm{O}_{4}$ spinel were present; that diffraction pattern is not documented here.

To further understand the details of the scale structure developed in the "lean" sulfidizing atmosphere, a transverse section of the specimen exposed for $216 \mathrm{~h}$ was prepared and examined. The micrographs of that section, illustrating the two-layer scale, are shown in Fig. 17. Of special 
Table 16. X-ray difrraction data for specimen E1R5 after $24 \mathrm{~h}$ exposure in "lean" sulfidizing atmosphere at $900^{\circ} \mathrm{C}$

\begin{tabular}{|c|c|c|c|c|c|}
\hline \multicolumn{2}{|c|}{$\begin{array}{l}\text { Diffraction data } \\
\text { (austenitic matrix) }\end{array}$} & & \multicolumn{3}{|c|}{$\begin{array}{l}\text { JCPDS card } 33-397 \\
\text { (chromium iron nickel) }\end{array}$} \\
\hline \multicolumn{6}{|c|}{ Strong components } \\
\hline $2 \theta$ & $\mathrm{d}(\AA)^{a}$ & $\mathrm{I} / \mathrm{I}_{0}^{b}$ & (hkl) & $\mathrm{d}(\mathrm{A})^{a}$ & $I_{1}{ }^{b}$ \\
\hline $\begin{array}{r}43.719 \\
50.908 \\
74.811 \\
90.814 \\
96.115 \\
118.258\end{array}$ & $\begin{array}{l}2.0689 \\
1.7923 \\
1.2681 \\
1.0817 \\
1.0356 \\
0.8974\end{array}$ & $\begin{array}{r}30 \\
19 \\
100 \\
15 \\
2 \\
1\end{array}$ & $\begin{array}{l}(111) \\
(200) \\
(220) \\
(311) \\
(222) \\
(400)\end{array}$ & $\begin{array}{l}2.075 \\
1.796 \\
1.269 \\
1.082 \\
1.037 \\
0.898\end{array}$ & $\begin{array}{r}100 \\
45 \\
26 \\
30 \\
12 \\
3\end{array}$ \\
\hline \multicolumn{2}{|c|}{$\begin{array}{l}\text { Diffraction data } \\
\text { (sesquioxide scale) }\end{array}$} & & \multicolumn{3}{|c|}{$\begin{array}{l}\text { JCPDS card 6-504 } \\
\left(\mathrm{Cr}_{2} \mathrm{O}_{3}\right)\end{array}$} \\
\hline $2 \theta$ & $d(\AA)^{c}$ & $1 / \mathbb{I}_{0}{ }^{d}$ & (hkl) & $d(A)^{c}$ & $\mathrm{I}_{\mathrm{o}}{ }^{d}$ \\
\hline $\begin{array}{l}24.448 \\
33.472 \\
35.985 \\
39.526 \\
41.282 \\
\text { Austenite } \\
\text { interference } \\
50.361 \\
54.575 \\
\text { Not detected } \\
63.071 \\
64.575 \\
72.411 \\
76.186 \\
\text { Not detected } \\
\text { Not detected } \\
83.670 \\
85.860 \\
89.415 \\
94.704\end{array}$ & $\begin{array}{l}1.8225 \\
1.6802 \\
0 \\
1.4728 \\
1.4420 \\
1.3041 \\
1.2486 \\
0 \\
0 \\
1.1549 \\
1.1309 \\
1.0950 \\
1.0473\end{array}$ & $\begin{array}{r}30 \\
100 \\
49 \\
7 \\
16\end{array}$ & $\begin{array}{c}(012) \\
(104) \\
(110) \\
(006) \\
(113) \\
(202) \\
(024) \\
(116) \\
(122) \\
(214) \\
(300) \\
(10: 10) \\
(220) \\
(306) \\
(312) \\
(02: 10) \\
(134) \\
(226) \\
(21: 10)\end{array}$ & $\begin{array}{l}3.633 \\
2.666 \\
2.480 \\
2.264 \\
2.176 \\
2.048 \\
1.816 \\
1.672 \\
1.579 \\
1.465 \\
1.431 \\
1.296 \\
1.240 \\
1.210 \\
1.173 \\
1.148 \\
1.124 \\
1.087 \\
1.042\end{array}$ & $\begin{array}{r}75 \\
100 \\
95 \\
12 \\
40 \\
10 \\
40 \\
90 \\
14 \\
25 \\
40 \\
20 \\
18 \\
8 \\
14 \\
10 \\
10 \\
18 \\
16\end{array}$ \\
\hline \multicolumn{2}{|c|}{$\begin{array}{l}\text { Diffraction data } \\
\text { (spinel oxide scale) }\end{array}$} & & \multicolumn{3}{|c|}{$\begin{array}{l}\text { JCPDS card } 35-1112 \\
\left(\mathrm{Mn}_{1.5} \mathrm{Cr}_{1.5} \mathrm{O}_{4}\right)\end{array}$} \\
\hline $2 \theta$ & $\mathrm{d}(A)^{e}$ & $\mathrm{I} / \mathrm{I}_{\delta}$ & (hkl) & $d(A)^{e}$ & $\mathrm{I} / \mathrm{d}_{\mathrm{f}}$ \\
\hline $\begin{array}{l}\text { Not scanned- } \\
29.8729\end{array}$ & 2.9886 & 72 & $\begin{array}{r}(111) \\
5196 \mathrm{~d}(220)\end{array}$ & $\begin{array}{c}4.88 \\
2.985\end{array}$ & $\begin{array}{l}25 \\
508.45\end{array}$ \\
\hline
\end{tabular}


Table 16. (Continued)

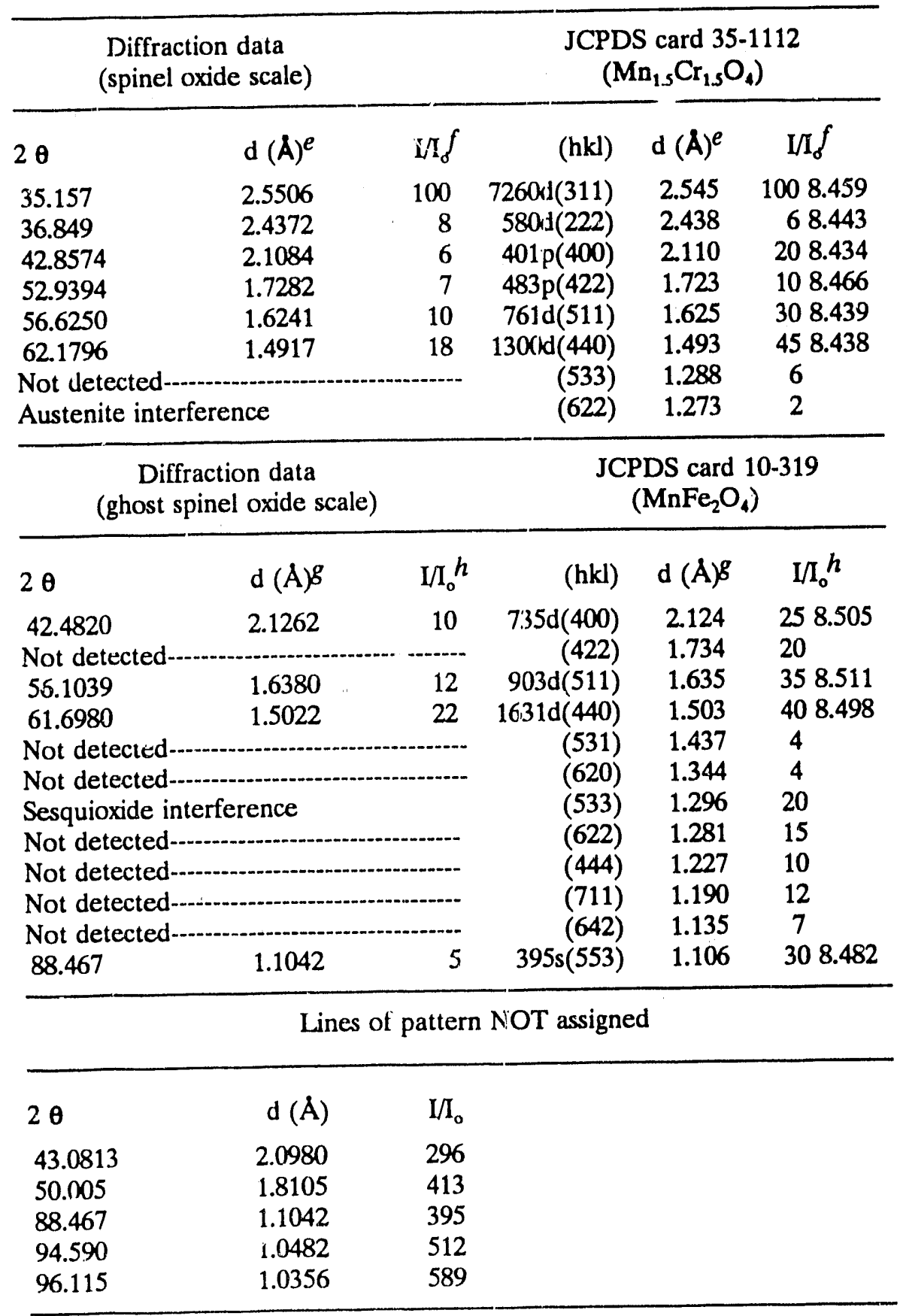

$a_{\mathrm{a}_{\mathrm{o}}}=3.588 \mathrm{~A}$; V.Strong (110) texture.

$b_{\mathrm{I}_{\mathrm{o}}}=30024 \mathrm{cpm}$.

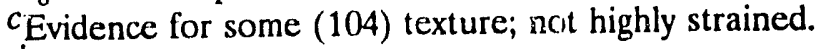

$d_{\mathrm{I}_{\mathrm{o}}}=11601 \mathrm{cpm}$.

$e_{\mathrm{a}_{\mathrm{o}}}=8.45 \AA$; strained and large grain size.

$f_{\mathrm{I}_{\mathrm{o}}}=7260 \mathrm{cpm}$; apparently textured.

$g_{\mathrm{a}_{\mathrm{o}}}=8.50 \AA$; strained and large grain size.

$h^{h_{0}}=720 \hat{0} \mathrm{cpm}$.

Note: Lines with larger "d-values" are not separable from above. 
M27868

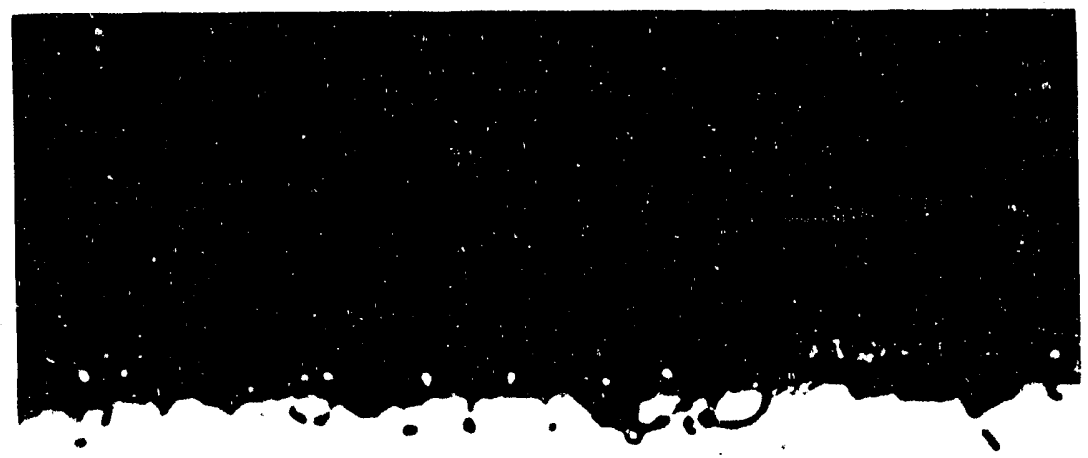

(a)

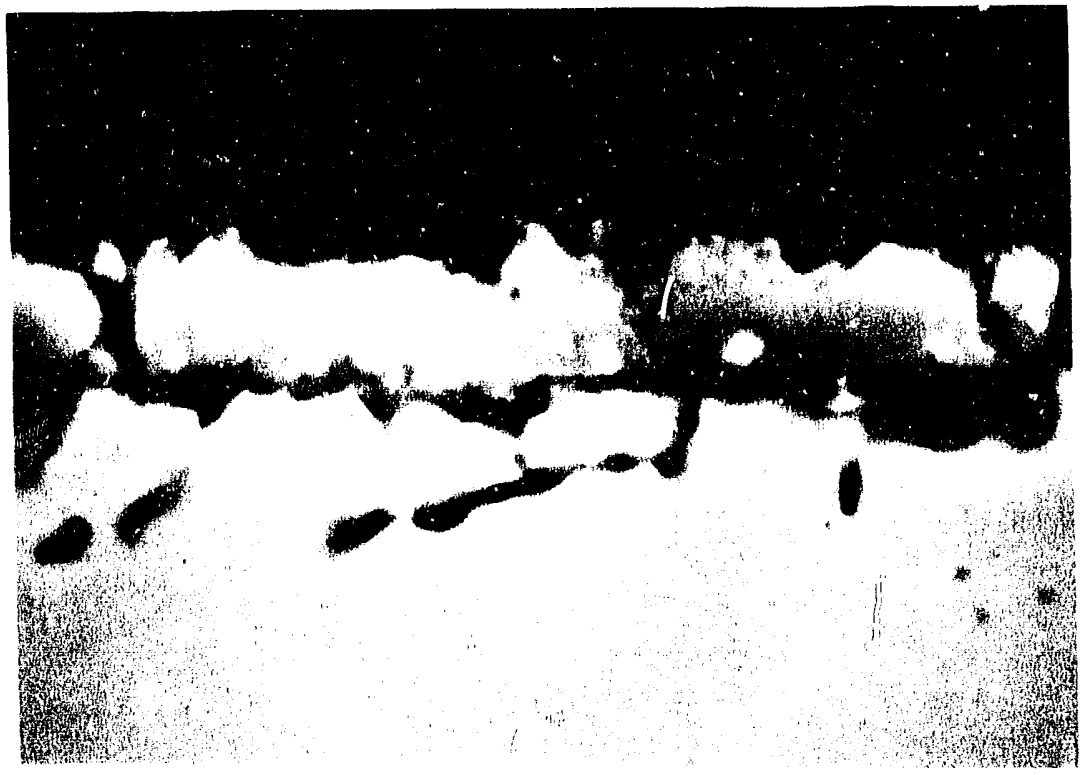

(b)

$1 . \overline{00} \mu \mathrm{m}$

Fig. 17. Micrographs of the transverse scale structure of specimen E1R6 after 216-h exposure in the "lean" sulfidizing atmosphere at $900^{\circ} \mathrm{C}:(a)$ Optical photomicrograph and (b) slectron micrograph 
interest here are the bright and somewhat spherical particles embedded in the inner layer of scale near the metal-oxide interface. The fact that they appear bright in the electron micrograph of Fig. $17(b)$ indicates that they probably have a metallic character. The results of an EDS analysis of that transverse section are summarized in Table 17. The particles appear to be rich in chromium; however, this is believed to be an artifact due to signal "spillover" from the surrounding inner scale layer. Tentatively, these features are identified as mechanically enfolded austenite particles possibly originating from the encirclement of austenite grains by the sulfidation process as seems to be suggested in the photograph of Fig. 17(a). It is noted that no such structural feature was observed for the case of oxidation in air.

Table 17. Qualitative EDS analyses for specimen

E1R6 after 216-h exposure in the "lean" sulfidizing atmosphere at $900^{\circ} \mathrm{C}$ (summary of relative elemental abundance) ${ }^{a}$

\begin{tabular}{lccc}
\hline & \multicolumn{3}{c}{ Feature in transverse section $b$} \\
\cline { 2 - 4 } Chemical element & $(\mathrm{A})$ & $(\mathrm{B})$ & $(\mathrm{C})$ \\
\hline Iron & 30 & 2.1 & 0 \\
Chromium & 100 & 100 & 100 \\
Nickel & 9.0 & 0.8 & 0 \\
Manganese & 5.9 & 6.1 & 54 \\
Silicon & 2.0 & 1.1 & 1.9 \\
Titanium & 0 & 0 & 0 \\
Sulfur & 0 & 0 & 0 \\
\hline
\end{tabular}

$a_{\text {Relative elemental abundance is in terms of each }}$ element's $\mathrm{K}-\alpha$ excitation divided by that for the strongest element (presented as percentages).

$b_{\text {Key to positions: }}$
(A): Spheroidalmetallic particle embedded in scale.
(B): Inner scale layer near particle.
(C): Outer scale layer.

In support of the prior discussions of scale structure, the data of Table 17 indicate that the inner scale layer is essentially $\mathrm{Cr}_{2} \mathrm{O}_{3}$, while the outer layer is probably a mixture of that chromia 
and a spinel of mixed chemistry as: $(\mathrm{Mn}, \mathrm{Cr})_{3} \mathrm{O}_{4}$. Combining this information with the scale topographies discussed earlier, it "appears that the chromia forms first as vertical blades and later grows laterally to become a continuous inner layer. Subsequently, nodular crystals of spinel form between the blades, which are overgrown by it at still later times.

\section{4 "RICH" SULFIDIZING ATMOSPHERES}

Five tests were run in the "rich" sulfidizing atmosphere at the single temperature of $900^{\circ} \mathrm{C}$ using both flat and ell-shaped specimens. Their purpose was to determine: (1) the kinetics of the reaction; (2) qualitatively, the magnitude of the stresses generated during the oxidation process; and (3) structural information regarding the reaction products that were formed.

The results are relatively complex as the "rich" atmosphere reacts rapidly and extensively with the 310 S substrate. After cooling and examination of the capsule contents, it was found that at least a portion of the reaction products had spalled. Mass gains were calculated based on both the reacted sample and spalled material. The kinetic behavior is illustrated in Fig. 18 for specimens exposed at times ranging from 2 to $24 \mathrm{~h}$, again with data plotted in a parabolic format. The initial linear portion of that curve (shown dotted) represents a parabolic rate constant whose value is $2.20 \mathrm{mg}^{2} \mathrm{~cm}^{-4} \mathrm{~h}^{-1}$, a value some three orders of magnitude greater than that found for the "lean" sulfidizing atmosphere. The true reaction is believed to follow the sigmoidal curve represented by the solid line in Fig. 18. The decrease in the rate of reaction at the longest times is known to be associated with the near total consumption of the calcium sulfate - sulfur mixtures; thus, the fact that these data lie upon an extension of the dotted curve is purely fortuitous. In fact, the initial parabolic kinetics give way to some type of breakaway oxidation process at an exposure time near $5 \mathrm{~h}$.

Only two of the specimens used in this series of tests were ell shaped and both of these exhibited an opening of the bend angle as was the case for the "lean" sulfidizing atmosphere. The values of dilatation for these specimens were also small, ranging from -0.3 to $+0.1 \%$; however, due to severe warpage of the specimens during reaction, the uncertainties in their measurement are equally large. As a result, it is concluded that, in this "rich" sulfidizing atmosphere, the cooperative tractive forces between the scale and its substrate are extremely weak (or nonexistent) and that one dominant mode of ell deformation involves creep induced by gravity. Because of the severe buckling of these specimens, it is clear that stress sources not simply related 


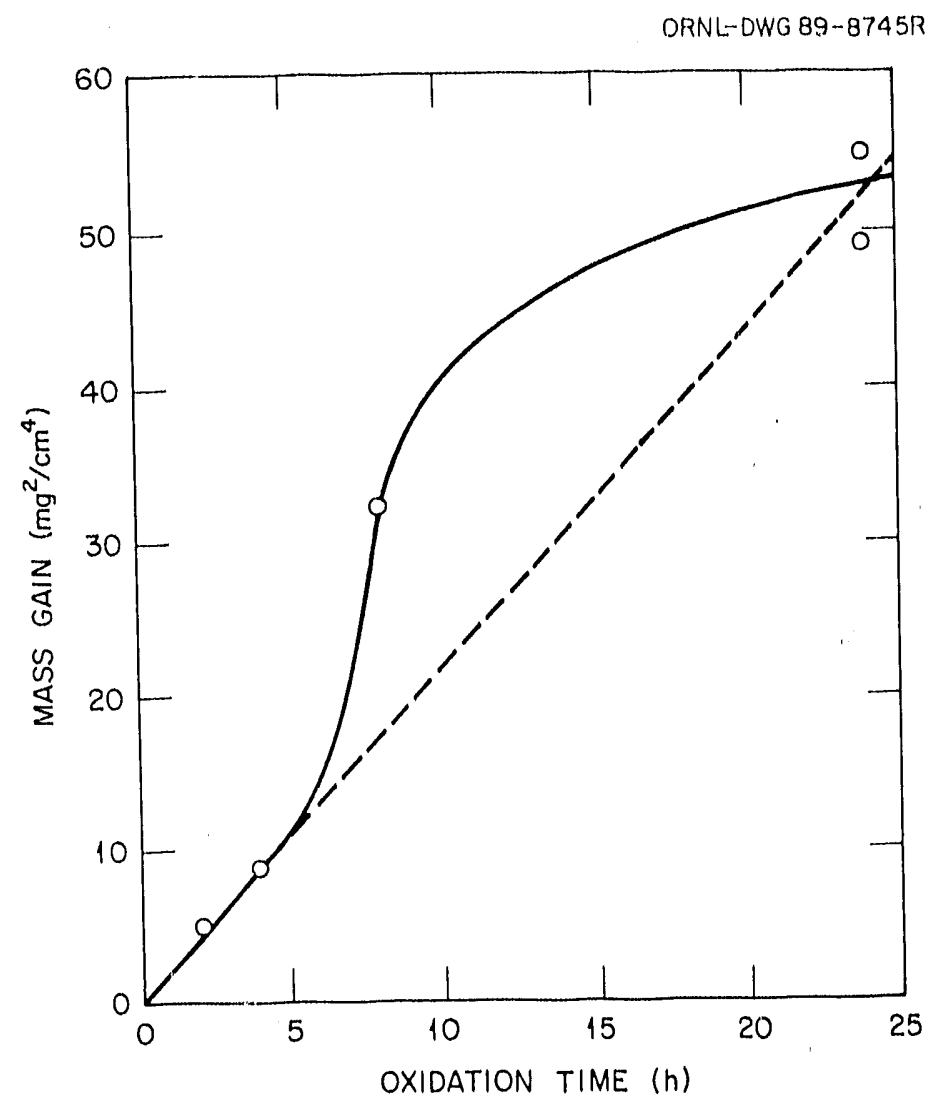

Fig. 18. Square of specific mass gain as a function of time for specimens exposed in the "rich" sulfidizing atmosphere at $900^{\circ} \mathrm{C}$.

to the macroscopic geometry of the specimen are large and do come into play. The sources of these stresses are, as yet, undefined but may be related to internal compound formation or piecewise, discontinuous adhesion of scale.

The complexity of the reaction, even at short times where the scale is relatively "protective," is underscored by the photomicrographs of Figs. 19 and 20, representing a specimen exposed for only $2 \mathrm{~h}$. The transverse view of the specimen edge shown in Fig. 19 indicates that the scale forms thicker lobes at the specimen corners, which may arise from growth stresses. The scale shown there consists of at least two external layers with the innermost layer containing rounded and entrapped metallic particles. Immediately beneath the external scale is a second metallic layer that has entrapped particles of one of the reaction products, some of which, in turn, 


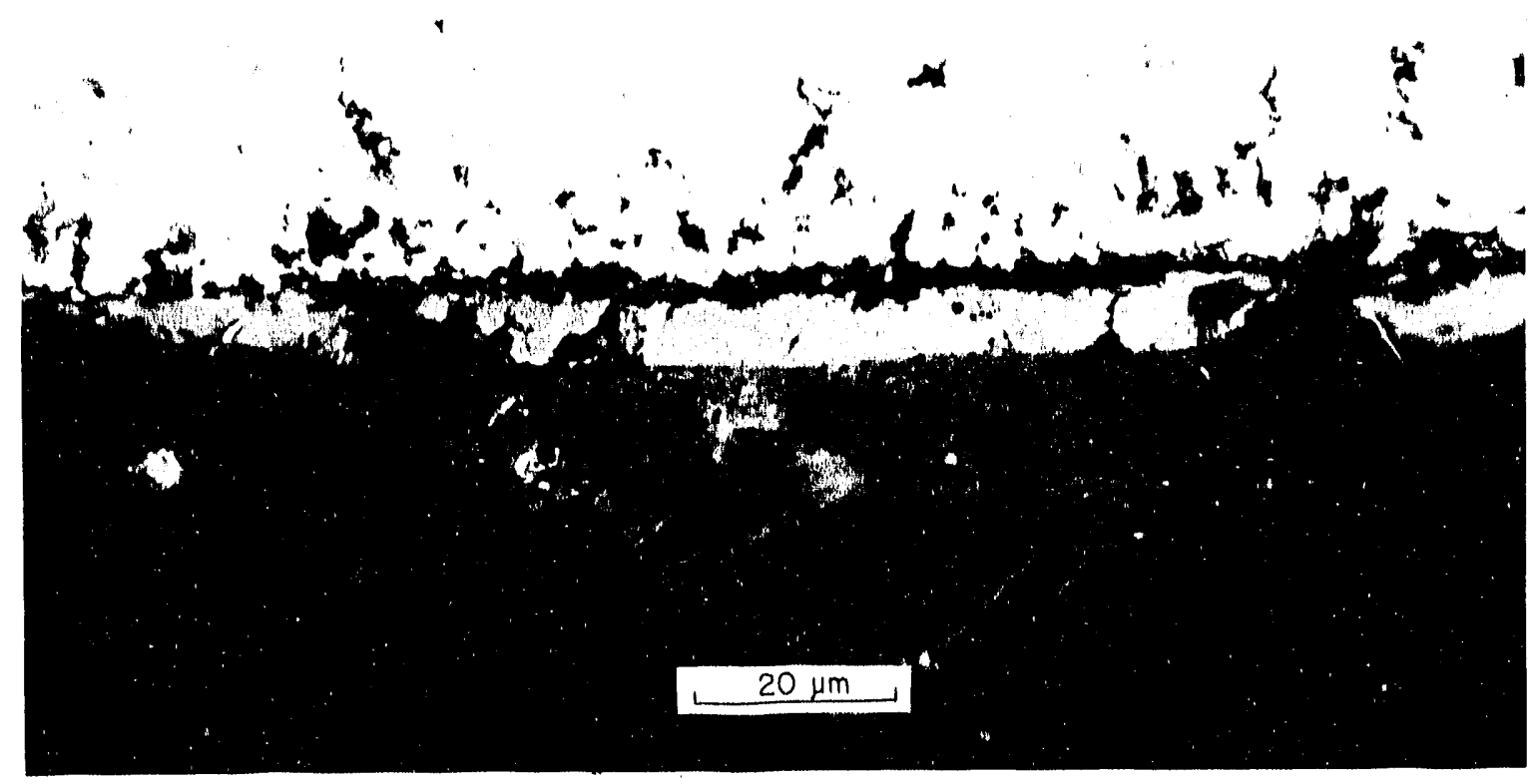

Fig. 19. Photomicrograph of a transverse section of specimen AR11 after 2-h exposure at $900^{\circ} \mathrm{C}$ in the "rich" sulfidizing atmosphere (Glyceregia etch).

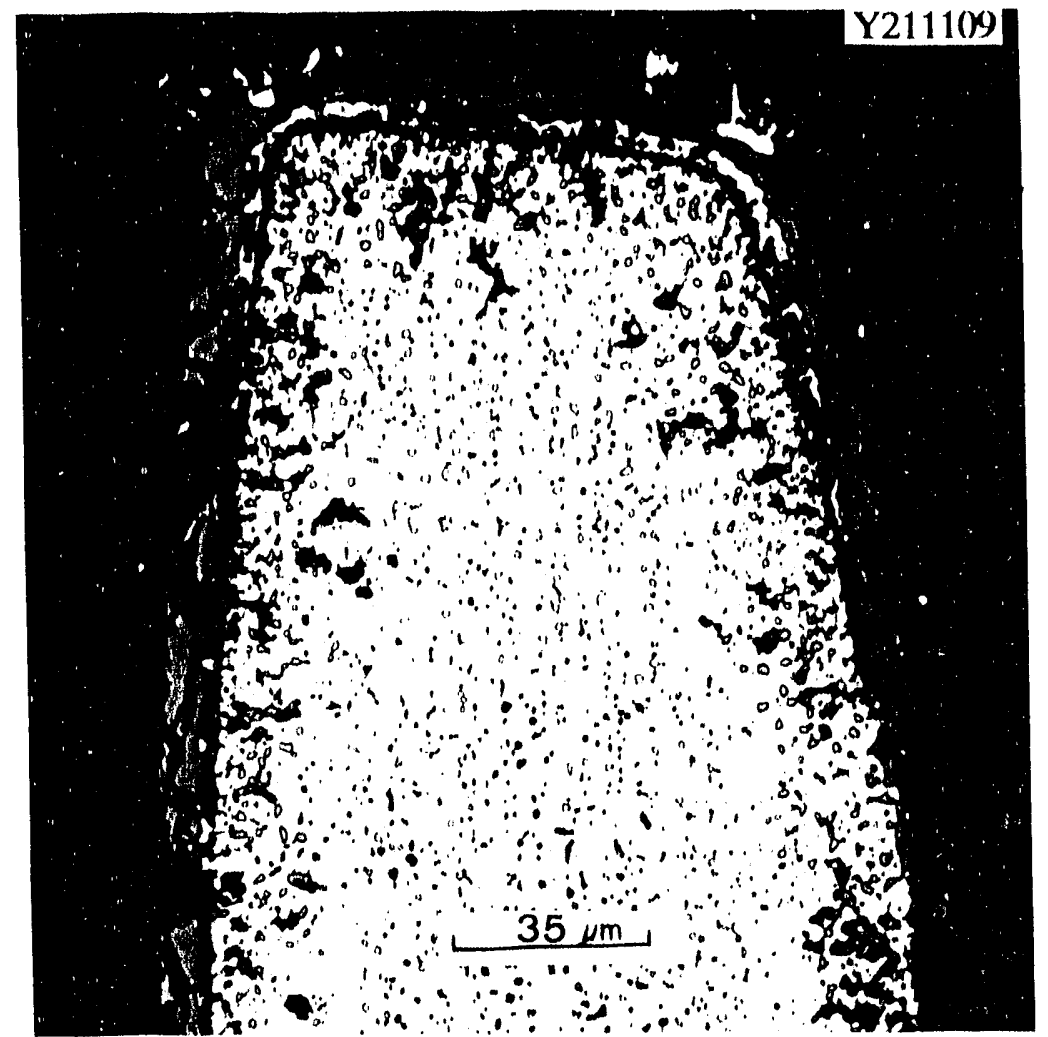

Fig. 20. Photomicrograph of as-polished transverse section of specimen $A R 11$ after 2 -h exposure at $9(x)^{\circ} \mathrm{C}$ in the "rich" sulfidizing atmosphere. 
contain voids. Further inward is a continuous layer of reaction product, which appears to be composed of particles sintered end to end. Beneath that layer are discrete, rounded particles of reaction product, some of which appear to be aligned along the substrate alloy grain-boundary network and many of which exhibit internal voids. Finally, the alloy's sigma phase decorates the interior of the specimen. It is strongly suspected that a low-melting sulfide was present as a liquid at temperature, and at least some of the void space observed is associated with the solidification shrinkage of that sulfide.

At occasional sites along the edge of that specimen exist protrusions such as that shown in Fig. 20. Here, one sees at least three scale layers: the outermost being nearly structureless and blocky; the central one contai ....-me porosity, some metallic particles, and some trapped second phase; and an inner layer that is essentially featureless, except that it is veined, normal to the alloy-scale interface, by a thin, light-colored phase. The veins of this innermost layer are believed to be a re-solidified sulfide, as are the subscale particles (the sigma phase is not revealed here since no etchant was used).

At longer sulfidation times, the features of the structure coarsen and are, therefore, somewhat more amenable to analysis. Thus, Fig. 21 shows neatly separated layers representing what is believed to be three of the inner suite of the scale layers developed after $24 \mathrm{~h}$ of exposure. The innermost of these layers again exhibits a vein-like pattern, which, in this case, traverses all of the scale layers shown. An outer series of layers, initially present, has spalled away and its position is now replaced by that of the mounting material. The results of an EDS analysis of the same area as that shown in Fig. 21 are presented in Table 18.

The protrusions appear to be chromium-depleted austenite particles that lie upon an oxide layer rich in chromium, iron and manganese. The central scale layer appears to be composed of an essentially pure chromia. The innermost scale layer and the subscale particles appear to be chromium and mixed-metal sulfides, respectively. Thus, sulfides reside primarily in the region of the metal-scale interface insofar as this inner suite of scale layers is concerned.

At occasional sites on the surface of this specimen, it was possible to observe both the inner and outer suites of scale layers. These observations are brought together in Fig. 22 where electron micrographs taken using a $55^{\circ}$ tilt angle are presented. It is seen that the overall scale is composed of at least six identifiable layers. The fine granular layer shown at the bottom of Fig. 22(b) has the same sulfur-rich chemistry as was displayed by the innermost scale layer of Fig. 21 (column D, Table 18). The results of EDS analyses on the outer suite of scale layers, shown in Fig. 22(a), are presented in Table 19. 


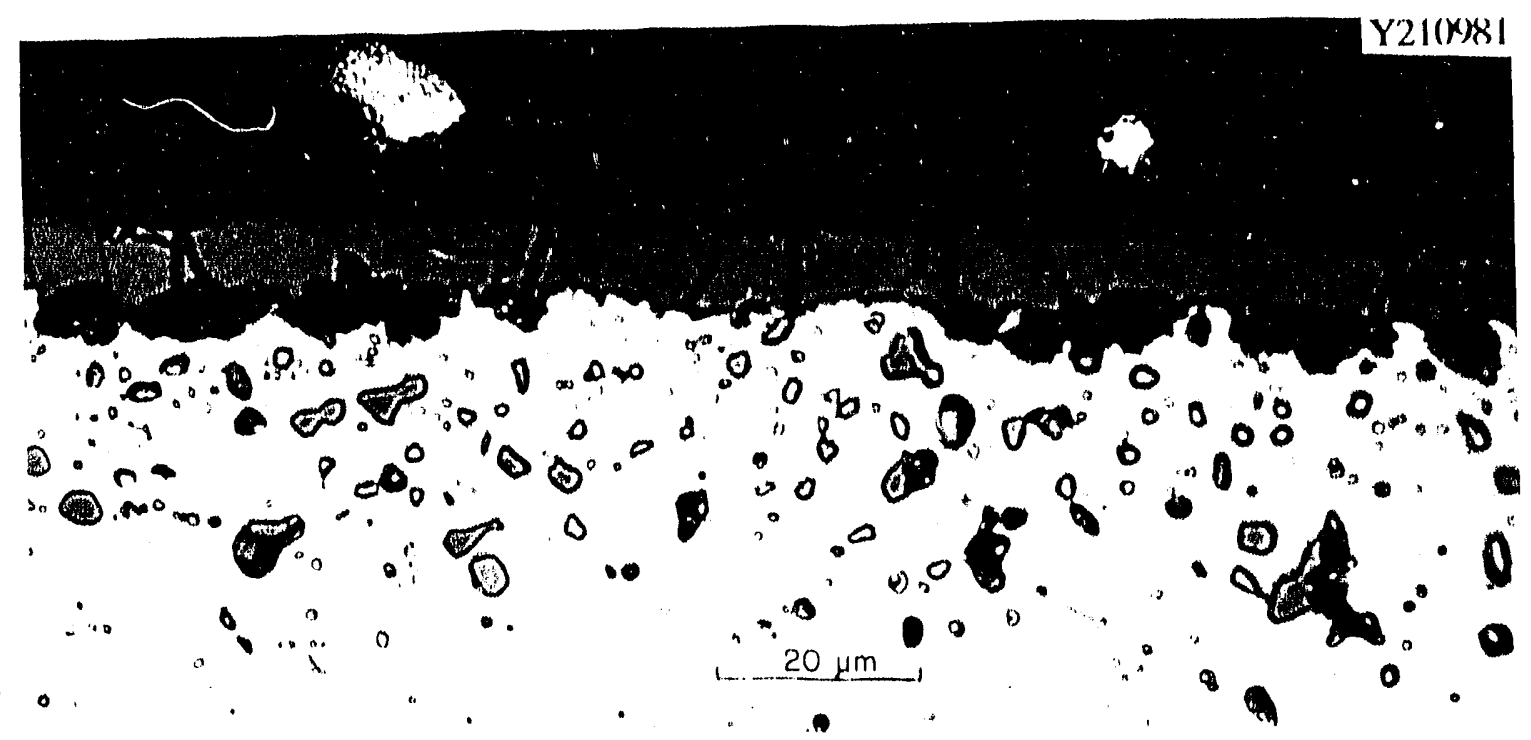

Fig. 21. Photomicrograph of etched transverse section of specimen E1R8 after 24-h exposure at $900^{\circ} \mathrm{C}$ in the "rich" sulfidizing atmosphere.

Table 18. Qualitative EDS analyses for specimen E1R8 after 216-h exposure in the rich" sulfidizing atmosphere at $900^{\circ} \mathrm{C}$ (summary of relative elemental abundance) ${ }^{a}$

\begin{tabular}{lccccr}
\hline & \multicolumn{5}{c}{ Feature in transverse section $b$} \\
\cline { 2 - 6 } Chemical element & $(\mathrm{A})$ & $(\mathrm{B})$ & $(\mathrm{C})$ & (D) & (E) \\
\hline Iron & 100 & 50 & 7.3 & 1.1 & 82 \\
Chromium & 3.0 & 100 & 100 & 100 & 100 \\
Nickel & 32 & 0 & 0 & 0 & 14 \\
Manganese & 0.1 & 21 & 6.2 & 2.4 & 31 \\
Sulfur & 0 & 0 & 0 & 79 & 77 \\
\hline
\end{tabular}

${ }^{a}$ Relative elemental abundance is in terms of each element's $\mathrm{K}-\boldsymbol{\alpha}$ excitation divided by that for the strongest element (presented as percentages).

$b_{\text {Key }}$ to positions:
(A): Rounded surface protrusion at outer portion of scale.
(B): Outermost of the scale layers shown.
(C): Central of the scale layers shown.
(D): Innermost of the scale layers shown.
(E): Subscale particles. 


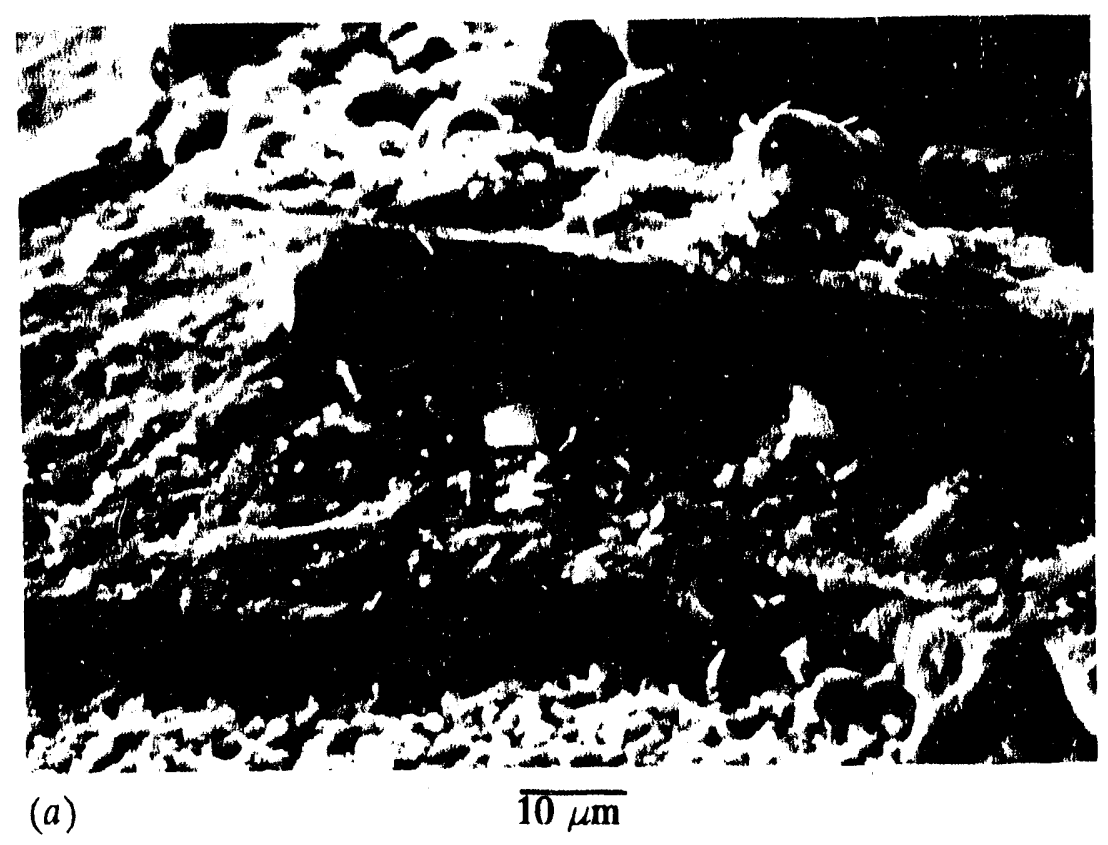

M27759

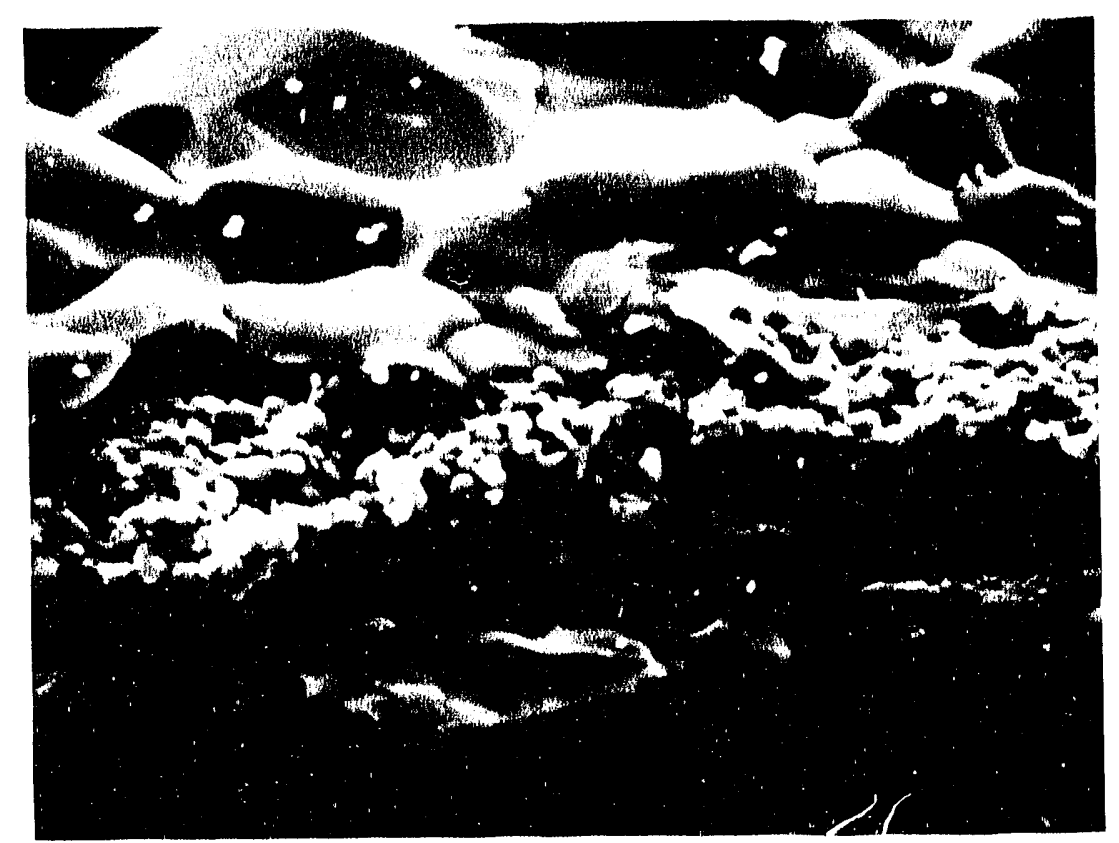

(b)

\section{$\overline{10 \mu \mathrm{m}}$}

Fig. 22. Electron micrographs of the scale structure of specimen E1R8 after 24-h exposure in the "rich" sulfidizing atmosphere at $900^{\circ} \mathrm{C}$ : (a) Outer suite of scale layers, $55^{\circ}$ tilt, and $(b)$ inner suite of scale layers, $55^{\circ}$ tilt. 
Table 19. Qualitative EDS analyses for specimen

E1R8 after 216-h exposure in the "rich" sulfidizing atmosphere at $900^{\circ} \mathrm{C}$ (summary of relative elemental abundance) ${ }^{a}$

\begin{tabular}{lccc}
\hline & \multicolumn{3}{l}{ Feature in transverse section } \\
\cline { 2 - 4 } Chemical element & (A) & (B) & (C) \\
\hline Iron & 100 & 94 & 8 \\
Chromium & 7 & 100 & 100 \\
Nickel & 0 & 0.5 & 1 \\
Manganese & 16 & 16 & 3.7 \\
Sulfur & 0 & 2.7 & 39 \\
\hline
\end{tabular}

${ }^{a}$ Relative elemental abundance is in terms of each element's $\mathrm{K}-\alpha$ excitation divided by that for the strongest element (presented as percentages).

$b_{\text {Key to positions: }}$

(A): Large grains of the outermost scale layer.

(B): Nodular grains in the central scale layer.

(C): Featureless, lower layer in the outer scale layers.

It is seen that the outer two layers probably involve the formation of iron-rich compounds containing manganese and chromium; some of these compounds will later be shown to be spinels. The featureless inner layer is rich in chromium and is also relatively rich in sulfur. It is postulated that sulfur may have reached this position in the scale layer by means of the vein-like network, described earlier, which passes through the inner suite of scale layers; i.e., liquid sulfide transport through channels is proposed.

The SEM inspections and EDS analyses for the specimen exposed the shortest time, and in the "protective" region, indicated that the scales formed early in the process were also moderately complex. Low- and high-magnification electron micrographs for the specimen exposed for $2 \mathrm{~h}$ are presented in Fig. 23. Here, as shown in Fig. 23(a), the outer layer of the scale has partially spalled away, leaving behind a finer grain size inner scale layer adherent to the alloy substrate. The hemispherical protrusion seen standing upon the outer scale layer is believed to be similar to the cross section of the one shown in Fig. 20. 


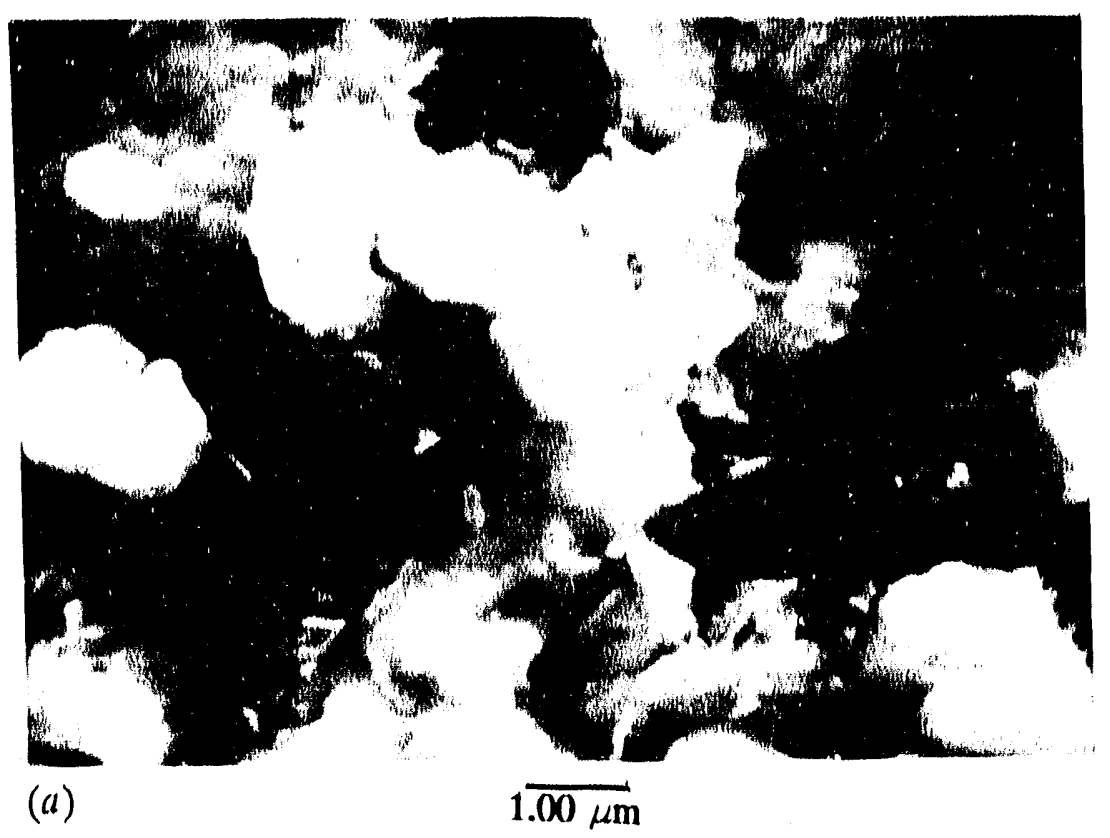

M27850

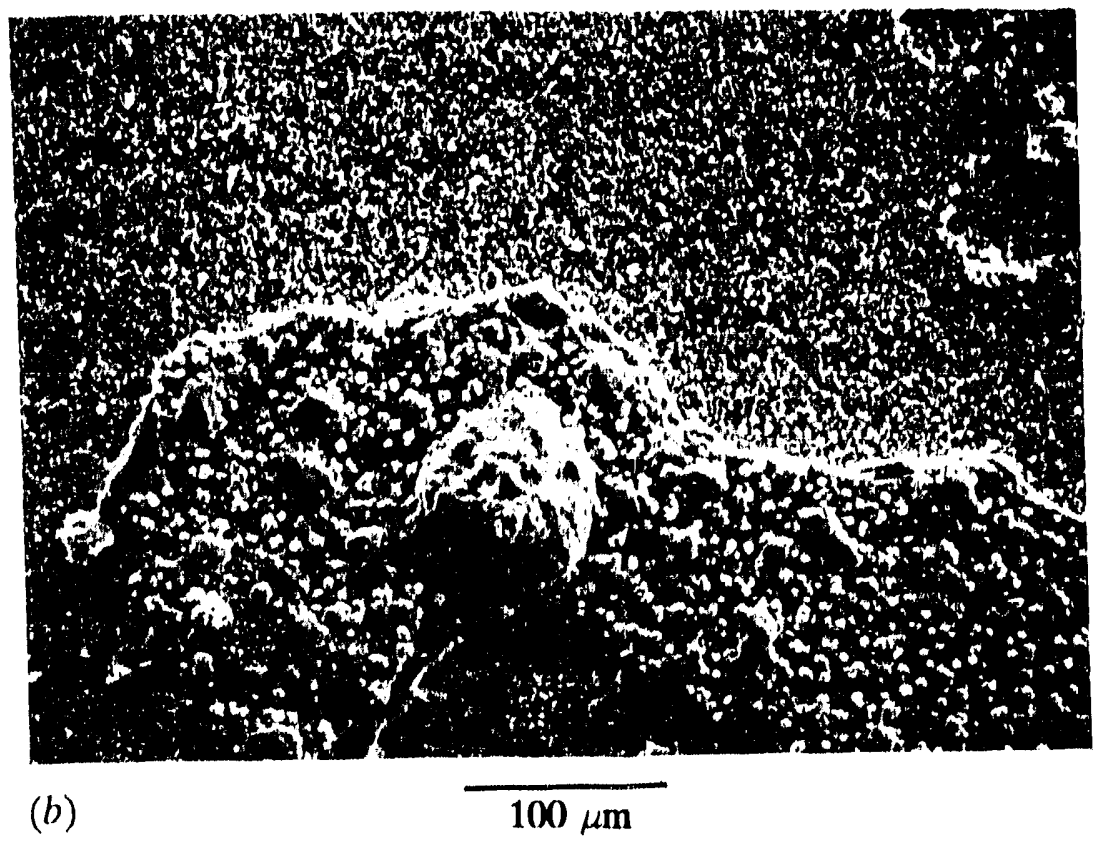

Fig. 23. Electron micrographs of the scale structure of specimen AR11 after 2-h exposure in the "rich" sulfidizing atmosphere at 900$)^{\circ} \mathrm{C}:(a)$ Overview of specimen; partially spalled specimen, and $(b)$ bright $\mathrm{Cr}-\mathrm{S}$ crystals; part of inner scale. 
Selected results of the EDS analysis for this specimen are presented in Table 20, It is seen that both the inner and outer seale layers contain regions of considerable sulfur content. For the inner scalc layer, sulfur was found to be concentrated in association with chromium at a relatively small number of bright hexagenal crystals, shown in Fig. 23(b). At the outer surface, sulfur is found in profusien associaled with nickel in glassy nodules-obviously molten at the test cemperature.

'Table 20. Qualitative EDS analysis for specimen AR11 after 2-h exposure in the "rich" sulfidizing atmosphere at $9(x)^{\circ}$

(summary of relative elemental abundance) ${ }^{l}$

\begin{tabular}{lrrcr}
\hline & \multicolumn{4}{c}{ Feature in plan section $b$} \\
\cline { 2 - 5 } Chemical clement & (A) & (B) & (C) & (D) \\
\hline Iron & 100 & 50 & 7.3 & 1.1 \\
Chromium & 52 & 100 & 12 & 76 \\
Nickel & 24 & 6 & 97 & 4 \\
Manganese & 4 & 4 & 6 & 1 \\
Silicon & 3 & 3 & 0 & 2 \\
Sulfur & 11 & 76 & 100 & 100 \\
\hline
\end{tabular}

"Relative elemental abundance is in terms of each element's K- $\alpha$ excitation clivided by that for the strongest element (presented as perecentiges).

brey (o) positions:

(A): Inner scale layer; integral chemistry.

(B): Bright, hexagonal crystal on inner scale layer.

(C): Glissy nodule on outer scale layer.

(D): Sulfur-rich spalled particle (outer layer).

In an allempt to further analye this extremely complex strusture, the same specimen, with a portion of its oulermost scale spalled away, was examined by X-ray diffraction; the findings are presented in Tible 21. As is secen there, two austenite phases of slightly different lattice parameter were present. The dominant pattern is most probably associated either with alloy particles within the scale or with a separated layer of metal, as shown in Fig. 19. The strongest oxide patterns present are those associated with $\mathrm{Mn}_{1.5} \mathrm{Cr}_{1.5} \mathrm{O}_{4}$ and $\mathrm{Cr}_{2} \mathrm{O}_{3}$. Finally, weak patterns 
Table 21. X-ray diffraction data for specimen AR11 after 24-h cxpossure in "lean" sulfidizing atmosphere at $900^{\circ} \mathrm{C}$

\begin{tabular}{|c|c|c|c|c|c|}
\hline \multicolumn{2}{|c|}{$\begin{array}{c}\text { Diffraction data } \\
\text { [austenitic matrix }\left(G^{\prime}\right) \text { ] }\end{array}$} & & \multicolumn{3}{|c|}{$\begin{array}{l}\text { JCPDS card 33.397 } \\
\text { (chromium iron nickel) }\end{array}$} \\
\hline \multicolumn{6}{|c|}{ Strong components } \\
\hline $2 \theta$ & $\mathrm{d}(\AA)^{a}$ & $1 / I_{0}^{b}$ & (hkl) & $\mathrm{d}(\AA)^{a}$ & $1 / t_{0}^{b}$ \\
\hline 43.4677 & 2.0802 & 100 & (111) & 2.075 & 100 \\
\hline 50.5566 & 1.8039 & 6 & (200) & 1.796 & 45 \\
\hline 74.7546 & 1.2689 & 18 & (220) & 1.269 & 26 \\
\hline Not dete & & $\ldots$ & $(311)$ & 1.082 & 30 \\
\hline $96.189^{C}$ & 1.0350 & $<2$ & (222) & 1.037 & 12 \\
\hline Not dete & 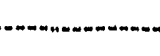 & ..... & $(400)$ & 0.898 & 3 \\
\hline \multicolumn{2}{|c|}{$\begin{array}{l}\text { Diffraction data } \\
\text { [spinel oxide scale (S1)] }\end{array}$} & & \multicolumn{3}{|c|}{$\begin{array}{l}\text { JCPDS card 33-892 } \\
\left(\mathrm{Mn}_{1,5} \mathrm{Cr}_{1,5} \mathrm{O}_{4}\right)\end{array}$} \\
\hline $2 \theta$ & $\mathrm{d}(A)^{d}$ & $\mathrm{I} / \mathrm{I}_{0}^{e}$ & $(\mathrm{hkl})$ & $\mathrm{d}(A)^{d}$ & $\mathrm{I}_{\mathrm{a}}{ }^{e}$ \\
\hline 18.1558 & 4.8822 & 13 & (111) & 4.88 & 25 \\
\hline 29.7440 & 3.0012 & 52 & (220) & 2.985 & 50 \\
\hline 35.0235 & 2.5600 & 100 & (311) & 2.545 & 100 \\
\hline 36.6564 & 2.4496 & 7 & (222) & 2.438 & 6 \\
\hline 42.5509 & 2.1229 & 11 & (400) & 2.110 & 20 \\
\hline 52.7429 & 1.7342 & 11 & (422) & 1.723 & 10 \\
\hline 56.2877 & 1.6331 & 11 & (511) & 1.625 & 30 \\
\hline 62.6294 & 1.5037 & 35 & (440) & 1.493 & 45 \\
\hline Not dete & 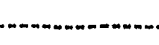 & ...... & (533) & 1.288 & 6 \\
\hline Not dete & 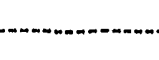 & & (622) & 1.273 & 2 \\
\hline \multicolumn{2}{|c|}{$\begin{array}{c}\text { Diffraction data } \\
\text { [spinel oxide scale (S1)] }\end{array}$} & & \multicolumn{3}{|c|}{$\begin{array}{l}\text { JCPDS card 33-892 } \\
\left(\mathrm{Mn}_{1.5} \mathrm{Cr}_{1.5} \mathrm{O}_{4}\right)\end{array}$} \\
\hline $2 \theta$ & $\mathrm{d}(\AA) f$ & $\mathrm{I} / \mathrm{I}_{0} g$ & (hkl) & $\mathrm{d}(A) f$ & $\mathrm{I} / \mathrm{o}_{\mathrm{o}} \mathrm{g}$ \\
\hline 43.6692 & 2.0711 & 100 & (111) & 2.075 & 100 \\
\hline 50.8965 & 1.7927 & 40 & (200) & 1.796 & 45 \\
\hline 74.9038 & 1.2667 & 88 & (220) & 1.269 & 26 \\
\hline 90.958 & 1.0804 & 30 & (311) & 1.082 & 30 \\
\hline 96.283 & 1.0342 & 6 & (222) & 1.037 & 12 \\
\hline 118.598 & 0.8959 & 6 & (400) & 0.898 & 3 \\
\hline \multicolumn{2}{|c|}{$\begin{array}{l}\text { Diffraction data } \\
\text { (sesquioxide scale) }\end{array}$} & & \multicolumn{3}{|c|}{$\begin{array}{l}\text { JCPDS card 6-504 } \\
\left(\mathrm{Cr}_{2} \mathrm{O}_{3}\right)\end{array}$} \\
\hline $2 \theta$ & $\mathrm{d}(\AA)^{f}$ & $\mathrm{I} / \mathrm{I}_{\mathrm{o}}{ }^{h}$ & (hkl) & $\mathrm{d}(A) f$ & $\mathrm{I} / \mathrm{I}_{\mathrm{o}}{ }^{h}$ \\
\hline 24.5223 & 3.6272 & 69 & (012) & 3.633 & 75 \\
\hline 33.5809 & 2.66666 & 100 & (104) & 2.666 & 100 \\
\hline 36.1207 & 2.4847 & 44 & (110) & 2.480 & 95 \\
\hline
\end{tabular}


Table 21. (Continued)

\begin{tabular}{|c|c|c|c|c|c|}
\hline \multicolumn{2}{|c|}{$\begin{array}{l}\text { Diffraction data } \\
\text { (sesquloxide scale) }\end{array}$} & & \multicolumn{3}{|c|}{$\begin{array}{l}\text { JCPDS card 6-504 } \\
\left(\mathrm{Cr}_{2} \mathrm{O}_{3}\right)\end{array}$} \\
\hline 39.829 & 2.2614 & 10 & $(006)$ & 2.264 & 12 \\
\hline 41.456 & 2.1764 & 25 & $(113)$ & 2.176 & 40 \\
\hline Not detect & & -..... & (202) & 2.048 & 10 \\
\hline 50.164 & 1.8171 & 28 & (024) & 1.816 & 40 \\
\hline 54.730 & 1.6758 & 59 & (116) & 1.672 & 90 \\
\hline Not detect & 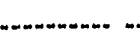 & 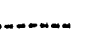 & (122) & 1.579 & 14 \\
\hline 63.257 & 1.4689 & 10 & $(214)$ & 1.465 & 25 \\
\hline $64.8530^{2}$ & 1.4365 & $<20$ & $(300)$ & 1.431 & 40 \\
\hline $72.7196^{i}$ & 1.2993 & $<26$ & $(10: 10)$ & 1.296 & 20 \\
\hline \multicolumn{3}{|c|}{ Not detected.... } & $(220)^{\prime}$ & 1.240 & 18 \\
\hline \multicolumn{3}{|c|}{ Not detected.............. } & $(306)$ & 1.210 & 8 \\
\hline \multicolumn{3}{|c|}{ Not detected. } & $(312)$ & 1.173 & 14 \\
\hline \multicolumn{3}{|c|}{ Not detected... } & $(02: 10)$ & 1.148 & 10 \\
\hline \multicolumn{3}{|c|}{ Not detected.-... } & $(134)$ & 1.124 & 10 \\
\hline \multicolumn{3}{|c|}{ Not detected........... } & $(226)$ & 1.087 & 18 \\
\hline \multicolumn{3}{|c|}{ 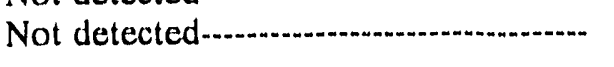 } & $(21: 10)$ & 1.042 & 16 \\
\hline \multicolumn{3}{|c|}{$\begin{array}{l}\text { Diffraction data } \\
\text { (sulfide scale) }\end{array}$} & \multicolumn{3}{|c|}{$\begin{array}{l}\text { JCPDS card 2-1273 } \\
\left(\mathrm{NiS}_{1,03}\right)\end{array}$} \\
\hline \multicolumn{6}{|c|}{ Weak Components } \\
\hline $2 \theta$ & $\mathrm{d}\left(A_{*}\right) f$ & $\mathrm{I} / \mathrm{I}_{0} \mathrm{~g}$ & $(\mathrm{hkl})$ & $\mathrm{d}(\AA) f$ & $\mathrm{I} / \mathrm{I}_{0} \mathrm{~g}$ \\
\hline 30.0320 & 2.9731 & 89 & $(100)$ & 2.98 & 60 \\
\hline \multicolumn{3}{|c|}{ Not detected....................... } & $(002)$ & 2.69 & 10 \\
\hline \multicolumn{3}{|c|}{ Sesquioxide interference } & (101) & 2.62 & 50 \\
\hline 45.5030 & 1.9918 & 100 & (102) & 1.99 & 100 \\
\hline $53.2846^{k}$ & 1.7178 & $<33$ & (110) & 1.72 & 80 \\
\hline \multicolumn{3}{|c|}{ Not detected-... } & (103) & 1.53 & 40 \\
\hline $62.204^{k}$ & 1.4912 & $<55$ & (200) & 1.49 & 40 \\
\hline $64.8530^{i}$ & 1.4365 & $<51$ & (201) & 1.44 & 40 \\
\hline \multicolumn{3}{|c|}{ Not detected................................... } & $(004)$ & 1.34 & 40 \\
\hline $72.7196^{j}$ & 1.2993 & $<67$ & (202) & 1.30 & 70 \\
\hline \multicolumn{3}{|c|}{ 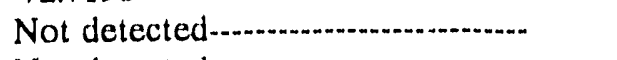 } & $(104)$ & 1.22 & 40 \\
\hline \multicolumn{3}{|c|}{$\begin{array}{l}\text { Not detected. } \\
\text { Not detected. }\end{array}$} & (203) & 1.14 & 20 \\
\hline \multicolumn{3}{|c|}{ Not detected-.................................... } & $(210)$ & 1.13 & 20 \\
\hline 87.9812 & 1.1091 & 95 & (211) & 1.10 & 60 \\
\hline \multicolumn{3}{|c|}{ Not detected....... } & (114) & 1.06 & 70 \\
\hline \multirow{2}{*}{\multicolumn{3}{|c|}{$\begin{array}{lll}96.1891^{c} & 1.0350 & <17 \\
\text { Not detected-a } & \end{array}$}} & $(212)$ & 1.04 & 70 \\
\hline & & & (105) & 1.01 & 20 \\
\hline 103.336 & 0.9820 & 21 & $(300)$ & 0.99 & 50 \\
\hline \multicolumn{3}{|c|}{ Not detected-............................ } & (213) & 0.95 & 40 \\
\hline
\end{tabular}


Table 21. (Continued)

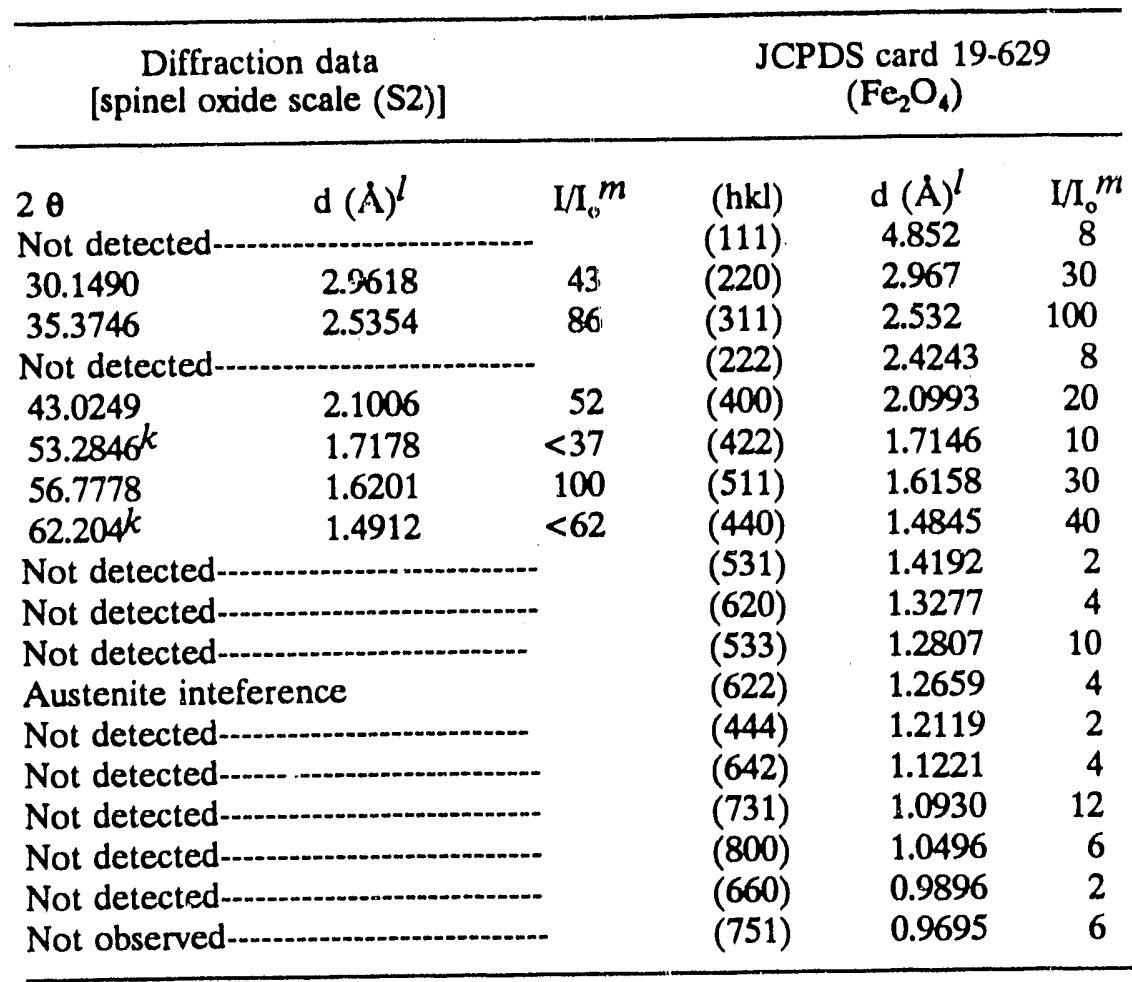

$a_{\mathrm{a}_{\mathrm{o}}}=3.59+\AA ;$ not (110) texture.

$b_{I_{0}}=9815 \mathrm{cpm}$. Probably represents metallic particles in the scale.

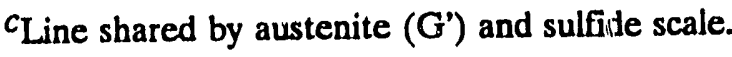

$d_{\mathrm{a}_{\mathrm{o}}}=8.94 \AA$; strained and large grain sixe.

$e_{\mathrm{I}_{0}}=8160 \mathrm{cpm}$; apparently not textured.

$f_{\mathrm{a}_{\mathrm{o}}}=3.586 \AA$; some (110) texture.

$\mathrm{gI}_{\mathrm{o}}=5139 \mathrm{cpm} ;$ probably represents the substrate alloy.

$h_{\mathrm{I}_{\mathrm{o}}}=3540 \mathrm{cpm}$; evidence for some (104) texture.

$i_{\text {Lines shared by sesquioxide and sulfide scale. }}$

$j_{\mathrm{I}_{0}}=1411 \mathrm{cpm}$.

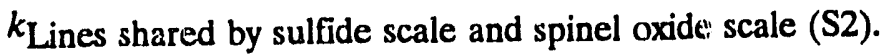

$l_{\mathrm{a}_{\mathrm{o}}} \sim 8.41 \AA$; spinel is highly textured.

${ }^{\prime} \mathrm{I}_{\mathrm{o}}=1252 \mathrm{cpm}$. 
are obtained for $\mathrm{NiS}_{1.03}$ and $\mathrm{Fe}_{3} \mathrm{O}_{4}$, the former possibly being weak because it occurs only in part as a crystalline phase and the latter being weak because most of this phase has spalled away from its site at the external surface.

Analyses by X-ray diffraction applied to specimens that had been exposed for times longer than $2 \mathrm{~h}$ revealed that other phases might also form in this environment. For such specimens, the additional structures found included those having the structural types of $\mathrm{FeO}, \mathrm{FeS}$, and $\mathrm{MnFe}_{2} \mathrm{O}_{4}$, the latter two of these being homologous. with other monosulfides and spinels, respectively.

\section{DISCUSSION}

In this section of the report, the findings of this experimental research program are discussed with respect to the observations and inferences drawn by others from either similar or allied studies.

\subsection{THERMOCHEMICAL CONSIDERATIONS}

The atmospheres utilized in this investigation, as well as their relation to both the usual thermodynamic parameters associated with the $310 \mathrm{~S}$ material constituents and the coal gasification regime, are illustrated in the thermochemical diagram of Fig. 24. This diagram was constructed for the temperature of $900^{\circ} \mathrm{C}$ using thermochemical data for the lowest oxidation state and, therefore, the most stable oxides and sulfides of interest. ${ }^{8-11}$ The range of oxygen and sulfur potentials representing the coal gasification regime, taken from Ref. 12, was then superimposed upon that diagram. Finally, the sulfur and oxygen potentials for the atmospheres used in this work are entered onto the diagram as the letters "A," "B," and "C," corresponding to their potentials as calculated for cases $\mathrm{A}, \mathrm{B}$, and $\mathrm{C}$, respectively, in the Appendix.

It is seen that the test atmospheres used in this research surround, but do not intercept, those of the coal gasification regime. The tests conducted in air cannot be represented, as their sulfur potential is zero. The "lean" sulfidizing atmospheres start at relatively low sulfur pressures (a), and as the specimen reacts with the gaseous dissociation products of $\mathrm{CaSO}_{4}$, thereby consuming oxygen, the gas composition within the capsule is altered to one of higher sulfur pressure $(b)$. For the case of the "rich" sulfidizing atmosphere, the gas composition within the capsule starts at point $(c)$; however, its variation with the course of reaction has not been adidresed hore. 


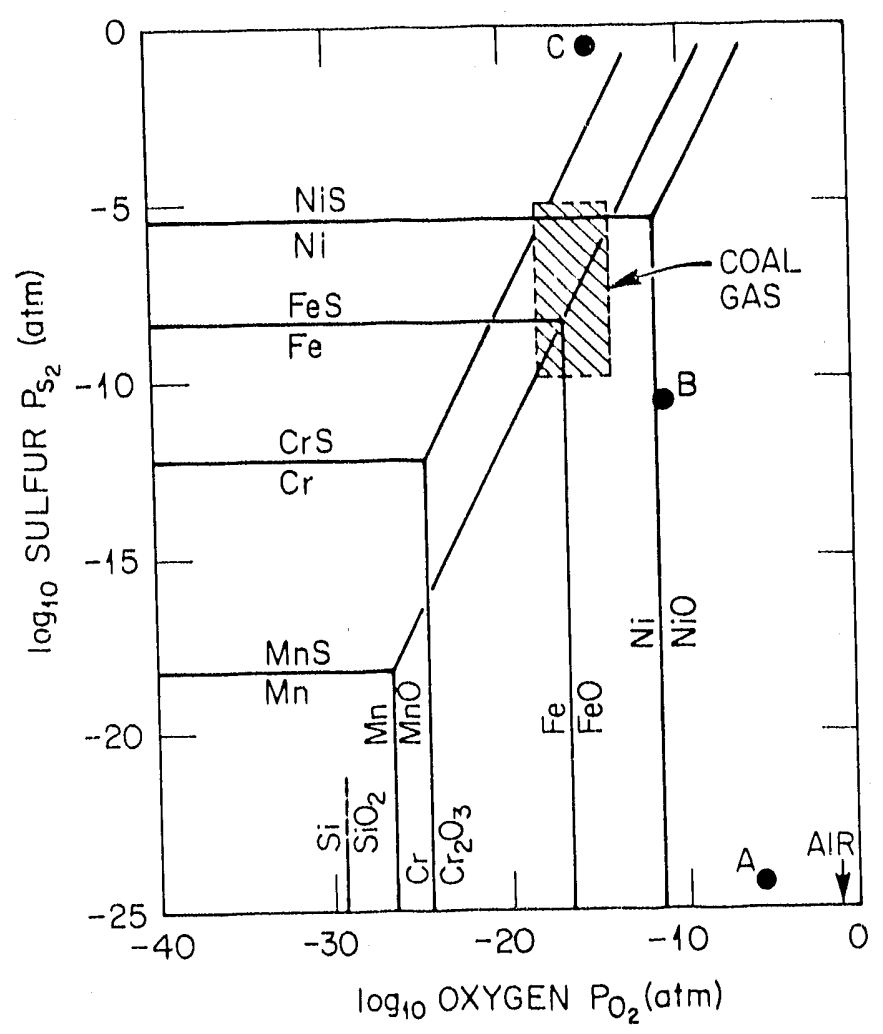

Fig. 24. Thermochenuical diagram at $900^{\circ} \mathrm{C}$ for the constituents of $310 \mathrm{~S}$ illustrating their critical oxygen and sulfur potentials, the atmospheres used in the research, and the gas potentials associated with the coal gasification regimen.

The diagram also illustrates that, from a thermodynamic point of view, the relative affinities of the constituent metals for oxygen and sulfur are essentially parallel; i.e., among them, manganese is most reactive and nickel is least reactive with either oxidant. The diagram is, of course, simplified in that it is constructed on the basis of pure elemental metals and reactants without consideration of their actual chemical activities in the $310 \mathrm{~S}$ alloy. The thermodynamically predicted high reactivity of manganese has been reflected here in its ubiquitous presence in the oxidic reaction products; however, the extremely high mobility of manganese necessary for its kinetic participation in these reactions cannot be explained simply by this energetic consideration.

Another important aspect of thermochemical considerations, which bears upon the interpretation of the results of these experiments, is the potential for the formation of liquid phases, especially in those cases where the "rich" sulfidizing atmosphere has been employed. It is well known that the metai suificies, as a ciass of niatcrials, have lower melting points than their 
inspected for their potential to liquify during the exposures used here. In Table 22 are presented the approximate melting points of the metal sulfides of interest to this system, as well as some selected eutectic temperatures for binary metal-metal sulfide systems. ${ }^{13}$

Table 22. Melting temperatures of selected metal sulfides and eutectic temperatures ${ }^{13}$

\begin{tabular}{lr}
\hline Sulfide or eutectic & Melting or eutectic point, ${ }^{\circ} \mathrm{C}$ \\
\hline \multicolumn{3}{c}{ Melting monosulfides } \\
$\mathrm{NiS}$ & 810 \\
$\mathrm{FeS}$ & 1195 \\
$\mathrm{MnS}$ & 1325 \\
$\mathrm{CrS}$ & 1550 \\
$\mathrm{TiS}$ & 2100 \\
& \\
$\mathrm{Ni}-\mathrm{Ni}_{3} \mathrm{~S}_{2}$ & \\
$\mathrm{Fe}-\mathrm{FeS}$ & 645 \\
$\mathrm{Mn}-\mathrm{MnS}$ & 985 \\
\hline
\end{tabular}

It is seen that nickel sulfide and its eutectic with nickel, if they form at the $900^{\circ} \mathrm{C}$ reaction temperature used in this work, will be liquid. There is, of course, the possibility of higher order sulfide eutectics, with correspondingly lower melting points, also forming as liquids with the test conditions used here. Good evidence has been presented above that, in the "rich" sulfidizing atmosphere, a nickel or similar sulfide did form as a liquid during reaction. While this sulfide was detected at the external surface of some scales and upon the upper portion of the inner suite of scale layers in others, its origin was most probably deep within the scaling system. This is so because the outermost scale layers are oxides and typically barren of nickel. Thus, the sulfide may have been extruded outward, through the vein network discussed in reference to Figs. 20 and 21, driven by the volumetric expansion of the forming nickel sulfide beneath the scale.

It is noted that, if one produces environments even more harsh than that associated with the "rich" atmosphere used here, then the corrosion process will become even more accelerated. 
For example, by producing sulfur pressures near $10^{-7}$ atmosphere in the absence of oxygen, one may produce microstructures similar to that shown in Fig. $19\left(900^{\circ} \mathrm{C}\right)$, in that internal sulfidation occurs at temperatures as low as $650^{\circ} \mathrm{C}$ in this steel..$^{14}$

\subsection{DEFORMATION CONSIDERATIONS}

The deformations that we have observed in this work must necessarily have arisen from the generation of stresses that occurred either during the high-temperature exposures or during the transient heating or cooling operations. In the discussion which follows, it is presumed that the majority of the stress-related effects occurred at elevated temperatures.

The mechanisms for stress relaxation in oxides growing upon metallic substrates have been reviewed by Stringer ${ }^{15}$ and Kofstad. ${ }^{16}$ Among the isothermal stress-generating mechanisms that have been proposed are:

1. pre-oxidation and pre-treatment effects involving impurities or "inherited" stresses;

2. volumetric changes based upon the Pilling-Bedworth ratio;

3. scale or transformation reactions involving dilatation;

4. oxygen dissolution in metals, with lattice expansion;

5. compositional changes in the oxide or metal near their common interface;

6. epitaxial stresses involving the scale and its substrate;

7. oxide growth within the scale, including specifically grain-bounjary oxidation;

8. vacancy injection into the metal; and

9. specimen geometry effects, especially with consideration of a coherent metal-scale interface (versus voids).

Among the isothermal stress-relaxation mechanisms that have been proposed are:

1. detachment of the scale near the metal-oxide interface, resulting in spalling;

2. elastic fracture or cracking of the scale layer;

3. recrystallation of the scale compounds;

4. plastic deformation and/or creep of the scale; and

5. deformation of the substrate metal or alloy.

A specialized mechanism involving vacancy injection coupled with interfacial dislocations has recently been proposed by Pieraggi and Rapp. ${ }^{17}$ It provides for the following features: (1) lateral compressive stresses in the scale layer, (2) lateral tensile stresses in the metallic 
substrate, and (3) maintenance of the metal-scale interface in its natural recession during oxide growth. These macroscopic effects are similar in kind to those provided in an earlier model of oxide growth within the scale layer at grain boundaries. ${ }^{7,18}$ No firm conclusion may be drawn as to which of all the stress generation models is most correct; however, much of what has been observed in this work may be rationalized qualitatively on the basis of the Pieraggi-Rapp mechanism.

The application of this mechanism to type $310 \mathrm{~S}$ steel is supported by our observation of a nominally coherent metal-oxide interface as shown in Fig. 7 and by void areas (condensed injected vacancies), especially on the alloy grain-boundary network as seen in Fig. 13(a). The linear dilitation of flat specimens in proportion to their degree of oxidation (Tables 4 and 13) and the earing of scale layers as shown in Fig. 19 are the types of deformation expected from the predicted stress state. The closure of "ells" depends upon the maintenance of the metal-oxide interface under the constraint that the retreating convex interface decreases in area, while that of the concave interface increases. Thus, to maintain both scale and interfacial continuities, the "ell" must necessarily close (Table 4) as the result of oxide formation by cation diffusion.

The lack of observed dilatation for specimens exposed to the "rich" sulfidizing atmosphere is consistent with their attendant liquid sulfide formation, as it is not possible to transmit large tractive forces across an interface containing liquid. It is the grossly different deformational behavior exhibited by the specimens exposed in air and those exposed in the "lean" sulfidizing environment that requires further explanation.

It was found that the deformation of specimens subjected to oxidation in air was very much larger than that observed when the specimens were exposed to the "lean" sulfidizing atmosphere. This occurred in spite of the fact that only oxides formed in both cases, and while a lesser amount of oxide was present in the "lean" sulfidizing environment, the deformations found there were less than they would have been had the deformation been proportional to the total amount of scale formation. It is believed that a primary cause of this apparently anomalous behavior is associated with phenomena that lead to the inclusion of metallic particles in the scale of the specimens exposed to the lean atmosphere (Fig. 17), an occurrence not seen in air. A second factor that may have diminished the deformation of these specimens is the fact that they do not, at least initially, form compact scales; rather, the open-bladed structures exemplified by Figs. 15 and 16 occur, and the generation of lateral stresses is, therefore, not expected in the outer reaches of these scales. Conversely, the scales formed in air are compact, and cooperative tractions may be large (as has been shown, for example, in Table 4 and Fig. 9). A further discussion of the "metal inclusion" effect will be presented below. 


\subsection{STRUCTURAL AND KINETIC CONSIDERATIONS}

It is clear that the air-formed scales are bilayered in their nature, having a distorted sesquioxide proximal to the alloy, which is chemically similar to $\mathrm{Cr}_{2} \mathrm{O}_{3}$ and that exhibits some tendency for (110) texture. This scale layer is evidently highly stressed initially, as if by epitaxial forces, as its lattice parameters change during the initial few hours of its development. Upon this inner layer develops a spinel of an $(\mathrm{Mn}, \mathrm{Cr})_{3} \mathrm{O}_{4}$ type, which initially has a very large lattice parameter $(8.55 \AA)$ that, at later times, undergoes a solid-state reaction to produce two spinels of lattice parameters 8.46 and $8.50 \AA$. It is suspected that such reaction is another possible evidence for stress alteration within the scale (generation or mitigation of stress depending upon detailed mechanism).

For those specimens oxidized in the "lean" sulfidizing atmosphere, the dominant crystal structures differ somewhat from those formed in air. 'The scale is again fundamentally bilayered; however, the underlying scale layer is a nearly undistorted form of $\mathrm{Cr}_{2} \mathrm{O}_{3}$, stress relief perhaps having been achieved through the creation of the blade-like structures cited earlier. The overlying spinel scale layer, which apparently nucleates upon the inner layer, is of a generally smaller lattice parameter $(8.45 \mathrm{~A})$ and corresponds closely to a compound of the type $\mathrm{Mn}_{1.5} \mathrm{Cr}_{1.5} \mathrm{O}_{4}$. Thus, while similar in general type, the scale layers formed in air and those formed in the "lean" sulfidizing atmosphere exhibit some distinct topographic and structural differences, differences that are probably also reflected in the state of stress in these scales. Another investigator has found that the $310 \mathrm{~S}$ alloy also exhibits the "spinel over $\mathrm{Cr}_{2} \mathrm{O}_{3}$ oxide" scale sequence in coal gasification atmospheres; ${ }^{19}$ however, the spinel cited is $\mathrm{MnCr}_{2} \mathrm{O}_{4}$, a compound not currently listed in the JCPDS file. That investigator also has identified the oxide phase cited in the grain-boundary network of this alloy as a manganese-iron silicate, in very good agreement with the findings here regarding the filamentary network shown in Fig. 11(b).

This bilayered scale structure with the internal silicate (or silica) evidently remains stable for a relatively long time, the tests conducted here indicating low parabolic rates of thickening for times of up to approximately $400 \mathrm{~h}$ in the "lean" atmosphere. Indeed, a parallel behavior is exhibited by this alloy in high-BTU coal gasification atmospheres where the scale remains protective for up to $3,000 \mathrm{~h}$ before its breakdown occurs. ${ }^{19}$ That time of exposure, also at temperatures near $900^{\circ} \mathrm{C}$, is approximately 10 times longer than the tests conducted in this work; unfortunately, it is also 3 to 10 times shorter than the target design life of certain coal gasifier components. Thus, the focus of future research must shift to the determination of why and how such breakdown occurs, in order that it may be prevented. The balance of this discussion will 
focus upon those types of scales that are initially protective, as have been produced here by the "lean" atmosphere exposures and which appear to be closely related to those produced in actual coal gasification applications.

It has been found that, for scales formed on materials such as $310 \mathrm{~S}$ to remain protective in actual application, the oxygen pressure in the gaseous phase must exceed approximately $10^{3}$ times the equilibrium dissociation pressure of the protective chromia scale product. ${ }^{20}$ This pragnatic limitation is recognized as a more qualitative statement of the fact that the activity of sulfur must not reach the critical value for compound nucleation in the region of the alloy-oxide interface, there being no simplistic relationship between that activity and the activity of gases at the gas-oxide interface. ${ }^{21}$ Thus, the problem of preventing scale breakdown in the long term must focus upon the quality of the protective oxide barrier with respect to sulfur transport, a kinetic consideration driven by the thermodynamic potentials involved and most probably modulated by the scale structure and/or its state of stress. For the case of iron-based alloys, relatively little is known regarding the relationship between scale microstructure and reaction kinetics. ${ }^{22}$ However, for alloys such as $\mathrm{Fe}-25 \mathrm{Cr}$, it is believed that fine chromia grain sizes lead to faster rates of reaction. ${ }^{23}$ This binary alloy probably reacts initially in a manner similar to the $310 \mathrm{~S}$ steel. A relatively fine grain size was exhibited by the chromia scale layer developed in air on this steel, Fig. 8, which may also be representative of that formed in the "lean" sulfidizing atmosphere. Methods of developing coarser oxide grain sizes for the protective scale layer may, thus, be a fruitful area for future research.

While only trace amounts of sulfur were detected by EDS for the specimens exposed to the "lean" sulfidizing atmosphere, it is believed that sulfur does play a major role in the evolution of the scale microstructure, much the same as a catalyst might. It is well known that sulfur can permeate the protective oxide scales formed on many otherwise corrosion-resistant alloys, where it subsequently becomes associated with the alloy grain-boundary network and subsequently alters the initially tormed scale layer. ${ }^{24}$ Because, in alloys such as $310 \mathrm{~S}$, the depletion zone beneath the scale is relatively rich in nickel and poor in chromium (which is utilized in the initial scale formation), a condition is established that promotes nickel sulfide formation, finally leading to a breakaway reaction. ${ }^{25}$ The presence of sulfur in the alloy grain boundaries was not confirmed in this work; however, the presence of nickel or an associated eutectic sulfide was established for the case of the rich sulfidizing environment.

It is believed that certain of the observations found in this work may be related to the ultimate breakdown of the protective layer. Thus, the metallic particles found embedded in the scale of the specimens oxidized in the "lean" sulfidizing atmosphere, Fig. 17, are belicved to 
represent the remnants of alloy grains which have been encapsulated as the scaling proceeds. As these embedded particles are absent in specimens exposed to sulfur-free air, it is postulated that they represent the remnants of alloy grains that have been encircled first by sulfide and later by oxide. This concept of particle formation infers that sulfur may have been transported through the oxide layers in sufficient quantity to react with the depleted alloy substrate along its grain boundaries.

As the particles are enriched in the less-reactive elements, iron and nickel, their continued reaction is limited so long as the oxide matrix in which they are embedded remains intact. However, should the oxide be disrupted in any manner, these particles would continue to oxidize in a state where they are thermally insulated from their substrate. As the heat of reaction cannot easily escape the region of the metallic particles, their temperature would ultimately rise (especially as they become smaller in dimension). ${ }^{26}$ Given a large volume concentration of relatively small particles so trapped in the insulating layer, the local temperature may rise rapidly and thus lead to the breakdown of an otherwise protective scale.

The precise mechanism by which sulfur traverses the scale remains an open question. It has been shown that, for the case of an $\mathrm{Fe}-25 \mathrm{Cr}$ alloy at $900^{\circ} \mathrm{C}$, the sulfur is associated with the grain-boundary network of the chromia scale and, incidentally, may decrease its rate of growth. ${ }^{27}$ If chromia thickens by the transport of the cations through grain-boundary short-circuit paths, sulfur could serve as a temporary blocking agent enhancing the barrier quality of the scale. Ultimately, however, the sulfur will proceed to the alloy-oxide interface, and the protective nature of the barrier will be lost. For the case of unalloyed iron, which had been completely oxidized and subsequently exposed to a sulfur-bearing gas, it was found that the sulfur was associated only with the grain-boundary network of the scale and that it had completely penetrated the oxide body in a matter of minutes at $900^{\circ} \mathrm{C}^{28}$ While the oxide present was different in kind from that formed on $310 \mathrm{~S}$, this observation is important in that it may indicate a general tendency for the transport of sulfur via oxide grain boundaries. Other mechanisms for the transport of sulfur through scale layers have been considered and included: its dissolution in the oxide phase followed by diffusive transport and its transport as a sulfur-bearing gaseous phase via undefined physical discontinuities in the scale. ${ }^{29}$ Obviously, further work will be required to first define the effective transport paths of sulfur and, second, to employ countermeasures for eliminating such paths in scales formed on engineering alloys in sulfidizing applications. 


\section{FUTURE WORK}

As is evident from the above discussion, work is needed in the area of potential methods for obviating the breakaway phenomenon in alloys of technical interest. One type of research that seems particularly fruitful is the certain identification of the mechanism by which sulfur traverses the scale layer. It is our opinion that the path of primary concern involves the grainboundary network of the scale and, therefore, it is suggested that this portion of the overall problem be addressed.

One method of securing this fundamental information involves using the "lean" sulfidizing atmosphere tests as described herein but with the late addition to the gaseous atmosphere of a sulfur species that differs in its isotopic distribution from that found in nature. The scales developed in such tests may then be analyzed using high-resolution secondary icn mass spectroscopy (SIMS) techniques to determine the precise sites at which sulfur is incorporated in the scale and at what stage in the evolution of scale development such incorporation occurs. This testing mode had been planned earlier but was not implemented during this reporting period due to time constraints. For these later specialized tests, a small lot of $\mathrm{CaSO}_{4}$ containing $55.99 \%$ of the stable isotope sulfur-34 was secured through the Isotope Distribution Center at Oak Ridge National Laboratory. This material was prepared by the Stable Isotope Enrichment Department from a special lot of sulfur and has the isotopic abundances indicated in Table 23.

Table 23. Relative sulfur abundance in special $\mathrm{CaSO}_{4}$ lot

\begin{tabular}{lrc}
\hline Isotope & $\begin{array}{c}\text { Analysis of } \\
\mathrm{CaSO}_{4}\end{array}$ & $\begin{array}{c}\text { Natural } \\
\text { abundance }^{30}\end{array}$ \\
\hline Sulfur-32 & $43.57 \%$ & 95.02 \\
Sulfur-33 & $0.42 \%$ & 0.74 \\
Sulfur-34 & $55.99 \%$ & 4.22 \\
Sulfur-36 & $<0.05 \%$ & 0.02 \\
\hline
\end{tabular}

It is hoped that, at some time in the future, the potentially informative research program utilizing this material may be initiated. 


\section{CONCLUSIONS}

Sheet specimens of type 310S stainless steel of known dimension and form were exposed to air, a "lean" and a "rich" sulfidizing atmosphere, at temperatures near $900^{\circ} \mathrm{C}$. Based upon the analyses of these specimens by various techniques, the following conclusions are drawn:

1. The scales formed in air and the "lean" atmosphere are protective and non-spalling while those formed in the "rich" atmosphere spall, react at rates 1,000 times greate' in their quasi-protective mode, and later exhibit a "breakaway" reaction.

2. Only those scales formed in air provide the cooperative, tractive, interfacial forces required to produce uniform dilatation and deformation of the substrate.

3. Evidence is presented that the scales formed in air or in the sulfidizing atmospheres at $900^{\circ} \mathrm{C}$ are highly stressed. While the stresses in air-formed scales may be long range, those formed in sulfur-bearing atmospheres may be localized.

4. The scales produced on specimens exposed to the "lean" sulfidizing environment appear to mock those produced in actual coal gasification applications.

5. Two-layer scales are formed both in air and in the "lean" atmosphere, the inner layer being a sesquioxide and the outer layer being a spinel. However, the structural details of the scales formed in these two atmospheres are grossly different.

6. The metallic particles found embedded in the scale layers of those specimens exposed to the "lean" sulfidizing atmosphere may be indicative of a stage in scale evolution that is a precursor to the breakdown process of the protective scale.

7. Scales formed in the "rich" atmosphere are very complex, having a minimum of six scale layers and subscale product formation. Liquid sulfides are present at temperature and may permeate the inner suite of layers via their vein-like network.

8. Alloys containing high concentrations of nickel, such as $310 \mathrm{~S}$, are contraindicated for sulfidation applications due to their potential to form disruptive liquid sulfides at relatively low temperatures.

9. The control of protective oxide grain size may prove to be a fruitful approach in the future development of sulfidation-resistant alloys.

10. The testing method employing the "rich" sulfidizing atmosphere may be one that can be employed as an inexpensive and rapid screening method for determining the sulfidation resistance of new alloys as they are developed. 


\section{ACKNOWLEDGMENTS}

This report results primarily from the 1987-1988 sabbatical research opportunity afforded one of the authors. It could not have been completed without the assistance of, and interaction with, many of the personnel of the Metals and Ceramics (M\&C) Division. For their assistance in facilitating this work administratively, the authors thank V. J. Tennery, G. M. Slaughter, J. R. DiStelano, and K. Newport. For his helpful technical discussions in the area of sulfidation, the authors thank J. V. Catheart. For their assistance in analytical and support services, the authors thank R. S. Crouse, B. C. Leslie, G. C. Marsh, J. W. Nave, and T. A. Nolan. For their assistance in the fabrication and exposure of specimens for this research, the authors thank J. J. Campbell, in. Howell, and E. J. Lawrence.

\section{KEFERENCES}

1. P. H. Ableson, "Energy Futures," Am. Sci. 75, 584-93 (1987).

2. H. S. Hsu, A Review of the Development and Breakdown of Protective Oxide Scales on Alloys Exposed to Coal-Derived Amospheres, ORNL-6323, Martin Marietta Energy Systems, Inc., Oak Ridge National Lab., 1986.

3. N. Birks, G. H. Meier, and F. S. Pettit, "High-Temperature Corrosion Resistance," J. Met. 39, 28-31 (1987).

4. R. H. Kane, "Alloy Selection for High-Temperature Corrosives," Process Industries Conrosion, ed. B. J. Moniz and W. I. Pollock, National Association of Corrosion Engineers, Houston, 1986.

5. ASM Metols Reference Book, 2nd ed., American Society for Metals, Materials Park, Ohis), 1983.

6. Oak Ridge National Laboratory, Analytical Chemistry Division, Analysis No. $88(0125-111,1988$.

7. J. S. Wolf, "An Investigation of the Effect of Specimen Geometry on the Oxidation of Nickel at Elevaled Temperatures," Ph.D. thesis, University of Florida, 1965.

8. K. K. Kelly, "Contributions to the Data on Theoretical Metallurgy," Vol. VII, The Thermodynamic Properties of Sulfur and its Inorganic Compounds, Burcau of Mines, Bull. 406, 1937. 
9. J. P. Coughlin, "Contributions to the Data on Theoretical Metallurgy," Vol, XII, Hetas" and Free Energiess of Formution of Inorganic Oxides, Burcalu of Mincs, Bull. 542, 1954.

10. S. R. Shatynski, "The Thermochemistry of 'Transition Metal Sullides," Oxid. Met. 11 , $307-20(1977)$.

11. F. Gesmundo, C. De Asmundis, and C. Boltino, "High-Temperature Corrosion ol" Manganese in Pure $\mathrm{SO}_{2}, "$ Oxid. Met. 14, 15-29 (1980).

12. T. C. Tiearney und K. Natesan, "Metallic Corrosion in Simulated Low-Btu Coal-Gasification Atmospheres," J. Mater. Energy Syst. 1, 13-29 (1980).

13. S. Mrowec and K. Przybylski, "Defect and Transport Properties of Sulfides and Sulfidation of Metals," High Temp. Mater. Processes 6, $1-79$ (1984).

14. P. I. Williams, R. G. Faulkner, L. W. Pinder, and D. J. Lees, "The Inlluence of Alloy Diffusion Processes on the Corrosion of Ferritic and Austenitic Stainless Steels," Corros. Sci. 27, 595-613 (1987).

15. J. Stringer, "Stress Generation and Relief in Growing Oxide Films," Corros. Sci. 10, $513-43(1970)$.

16. P. Kolstad, High Temperature Corrosion, Elsevier Applied Science, New York, 1988.

17. B. Pieraggi and R. A. Rapp, "Stress Generation and Vacancy Annihilation During Scale Growth Limited by Cation-Vacancy Diffusion," Acta. Metall. 36, 1281-89 (1988).

18. F. N. Rhines and J. S. Wolt, "The Role of' Oxide Microstructure and Growth Stresses in the High-Temperature Scaling of Nickel," Metall. Trans. 1, 1701-10 (1970).

19. R. A. Perkins, "Development of Alloys for Use in Coal Derived Gases," pp. 345-53 in High Temperature Corrosion, NACE-6, National Association of Corrosion Engineers, Houston, 1983.

20. K. Natesan, "High-Temperature Corrosion in Coal Gasification Systems," Corrosion 41, $646-55(1985)$.

21. F. S. Pettit, J. A. Goebel, and G. W. Goward, "Thermodynamic Analysis of the Simultaneous Altack of Some Metals and Alloys by T'wo Oxidants," Corros. Sci. 9, 9(1.3-1.3 (1969).

22. K. Ishiguro and T. Homma, "Thin Oxide Films on a Ferritic and an Austenitic Alloy," pp. 28 -34 in High Temperature Corrosion, NACE-6, National Association of Corrosion Enginecrs, Houston, 1983.

23. M. J. Graham, "Thin Oxide Film Formation on Mctals," pp. 139-44 in High Temperature Corrosion, NACE-6, National Association of Corrosion Enginecrs, Houston, 1983. 
24. J. Stringer, A. J, Minchencr, D. M. Lloyd, and H. R. Hoy, "In-Bed Corrosion of Alloys in Atmospheric Fluidized Bed Combustors," Pp. 433-47 in Proceedings of the Sixth International Conference on Fluidized Bed Combustion, Vol, 2, U.S. DOE, 1980.

25. R. C. Lobb and H. E. Evans, "Observations on the Elfect of Low Sultur Activity on the Oxidation of Chromium-Depleted Zones in a Stainless Steel," Oxid. Met. 15, 371-84 (1981).

26. J. S. Woll, Exploratory Development on Oxidation Behavior of Titanium Alloys under High Heating Rates, AFML_-TR-74-265, April 1975.

27. Y. K. Kim, K. Przyblski, and G. J. Yurek, "Segregation of Sulfur to Grain Boundaries In Chromia and Alumina Scales," pp. $259-81$ in Fundamental Aspects of High Temperature Corrosion II, Electrochemical Society, Pennungtoon, N.J., 1986.

28. F. C. Yang and D. P. Whittle, "Sulfur Diffusion in Oxide Grain Boundaries," Corros. Sci. 23, 285-90) (1983).

29. P. Singh and N. Birks, "Penetration of Sulfur through Preformed Protective Oxide Scales," Oxid. Met. 19, 37-52 (1983).

30. D. E. Gray, ed., American Institute of Physics Handbook, 3rd ed., McGraw-Hill, New York, 1972. 


\section{APPENDIX \\ GAS PRESSURE ESTIMATES FOR CAPSULE TESTS INVOLVING THE DISSOCIATION OF CALCIUM SULFATE WITH ANI) WITHOUT ELEMENTAL SULFUR PRESENT}

The purpose of this Appendix is to describe an approach used to calculate the gas pressures generated in evacuated and sealed capsules containing one or two gas-producing reagents. The reagents considered are: (1) anhydrous calcium sulfate alone and (2) anhydrous calcium sulfate in combination with elemental sulfur. The particular situation(s) being modeled are those wherein the reagent(s) and a metallic specimen are within an evacuated quartz capsule, which is subsequently to be heated to some constant temperature. It is assumed that: (1) there is no physical contact between the reagent(s) and the metal and (2) the activities of all condensed phases are unity.

The gases evolved from the heating of calcium sulfate involve two dissociation reactions, which are sequential:

$$
2 \mathrm{CaSO}_{4} \rightarrow 2 \mathrm{CaO}+2 \mathrm{SO}_{2}+\mathrm{O}_{2} ; \mathrm{G}_{\mathrm{Ol}} ; \mathrm{K} 1
$$

and

$$
2 \mathrm{SO}_{2} \quad-->\mathrm{S}_{2}+2 \mathrm{O}_{2} ; \mathrm{G}_{\mathrm{O} 2} ; \mathrm{K} 2
$$

For those cases where solid sulfur is present in the initial capsule charge, gaseous sulfur will be produced by the single reaction:

$$
2 \mathrm{~S} \quad->\mathrm{S}_{2} ; \mathrm{G}_{03} ; \mathrm{K} 3 \text {. }
$$

Two types of cases will be discussed here, one being for the situation where the metallic specimen is absent or non-reactive and the second for the case where the specimen reacts with the gaseous dissociation products.

\section{Case A. Non-Reactive System (large $\mathrm{CaSO}_{4}$ supply; no sulfur)}

For this case, the dissociations will eventually lead to the production of equilibrium gas pressures. As the tempe, ature dependence of $\left(\mathrm{G}_{\mathrm{O} 1}\right)$ and, therefore, (K1) are known, the equilibritu constant may be expressed as:

$$
\mathrm{K} 1=\left(\mathrm{P}_{\mathrm{O} 2}\right)\left(\mathrm{P}_{\mathrm{SO}_{2}}\right)^{2}=4\left(\mathrm{P}_{\mathrm{O} 2}\right)^{3}=\exp \left(-\mathrm{G}_{\mathrm{O} 1} / \mathrm{RT}\right)
$$


from which first $\left(\mathrm{P}_{\mathrm{O} 2}\right)$ and subsequently $\left(\mathrm{P}_{\mathrm{SO} 2}\right)$ may be determined as, for this step, the value of $\left(\mathrm{P}_{\mathrm{SO} 2}\right)$ is twice that of $\left(\mathrm{P}_{\mathrm{O} 2}\right)$.

Some small fraction $(f)$ of that initially formed $\mathrm{SO}_{2}$ dissociates in accordance with the second reaction to produce: sulfur vapor at a pressure of $\mathrm{f}^{*}\left(\mathrm{P}_{\mathrm{SO} 2}\right)$ and oxygen gas at a pressure of $2 \mathrm{f}^{*}\left(\mathrm{P}_{\mathrm{SO} 2}\right)$. As the temperature dependence of $\left(\mathrm{G}_{\mathrm{O} 2}\right)$ and $(\mathrm{K} 2)$ are also known, the equilibrium constant may be written as:

$$
\mathrm{K} 2=\left(\mathrm{P}_{\mathrm{S} 2}\right)\left(\mathrm{P}_{\mathrm{O} 2}\right)^{2} /\left(\mathrm{P}_{\mathrm{SO} 2}\right)^{2}=4\left(\mathrm{f}^{3}\right)\left(\mathrm{P}_{\mathrm{SO} 2}\right)
$$

from which the value of $(f)$ may be calculated, as $\left(\mathrm{P}_{\mathrm{SO} 2}\right)$ is essentially invariant during the second dissociation step, values of $(f)$ typically being less than $10^{-6}$ for temperatures at or below $1000^{\circ} \mathrm{C}$.

Applying this approach, the relevant equilibrium gas pressures at $900^{\circ} \mathrm{C}$ are found to be:

$$
\begin{aligned}
& \left(\mathrm{P}_{\mathrm{SO} 2}\right)=3.40 \times 10^{-6} \mathrm{~atm}, \\
& \left(\mathrm{P}_{\mathrm{O} 2}\right)=1.70 \times 10^{-6} \mathrm{~atm}, \text { and } \\
& \left(\mathrm{P}_{\mathrm{S} 2}\right)=5.00 \times 10^{-25} \mathrm{~atm} .
\end{aligned}
$$

It is seen that the primary dissociation controls the pressures of $\mathrm{SO}_{2}$ and $\mathrm{O}_{2}$, while the secondary dissociation controls the pressure of $\mathrm{S}_{2}$ for this case. This is so because the second dissociation fraction $(f)$ is of very small magnitude.

\section{Case B. Reactive System}

For the case of a reactive system, the behavior of the gas pressures with time is obviously governed primarily by kinetic considerations. This situation is addressed in two stages, the first dealing with thermodynamic limits for systems in equilibrium and the second dealing with a method of estimating the gas pressures for a dynamic system.

\section{Case B1. Equilibrium Considerations}

We have shown above that the inner scale layer formed on type 310S stainiess steel, in either air or the lean sulfidizing atmosphere, is essentially $\mathrm{Cr}_{2} \mathrm{O}_{3}$ and that chromium sulfides are not evident. One limiting circumstance may be described by setting the oxygen pressure equal to that dictated by the equilibrium between chromium metal (representing the $310 \mathrm{~S}$ alloy) and oxygen. That pressure at a temperature of $900^{\circ} \mathrm{C}$ is illustrated in Fig. 24 of the main text. Applying this approach, the relevant equilibrium gas pressures at this temperature may be calculated from the known values of the equilibrium constants. Those pressures are found to be: 


$$
\begin{aligned}
& \left(\mathrm{P}_{\mathrm{SO} 2}\right)=9.85 \times 10^{+3} \mathrm{~atm}, \\
& \left(\mathrm{P}_{\mathrm{O} 2}\right)=2.03 \times 10^{-25} \mathrm{~atm}, \text { and } \\
& \left(\mathrm{P}_{\mathrm{S} 2}\right)=9.85 \times 10^{+32} \mathrm{~atm} .
\end{aligned}
$$

This limiting set of pressures is not realistic with respect to the capsule tests that the authors have conducted; however, they do illustrate the dramatic increases in the sulfidizing gas pressures due to decreasing the oxygen pressure.

A second limiting circumstance may be described by examining the equilibrium resulting from the intimate contact of calcium sulfate with the chromium metal. In this instance, the oxygen and sulfur pressures (activities) are set equal to those dictated by the equilibria between chromium metal, oxygen, and sulfur as illustrated in Fig. 24 of the main text. Applying the same approach as was used above, the effective equilibrium pressure of $\mathrm{SO}_{2}$ may also be calculated. Those pressures at a temperature of $900^{\circ} \mathrm{C}$ are:

$$
\begin{aligned}
& \left(\mathrm{P}_{\mathrm{SO} 2}\right)=4.66 \times 10^{-19} \mathrm{~atm}, \\
& \left(\mathrm{P}_{\mathrm{O} 2}\right)=2.03 \times 10^{-25} \mathrm{~atm}, \text { and } \\
& \left(\mathrm{P}_{\mathrm{S} 2}\right)=6.62 \times 10^{-23} \mathrm{~atm} .
\end{aligned}
$$

While the sulfidizing gas pressures are considerably smaller than those of the previous example, this limiting set of pressures is also not realistic with respect to the capsule tests that the authors have conducted. Rather, they represent the expected activities at the interface between chromium metal and a coherent overlayer of $\mathrm{CaSO}_{4}$.

What are desired are the pressures of the species in the gas phase, which is addressed next.

\section{Case B2. Kinetic Considerations (large $\mathrm{CaSO}_{4}$ supply)}

For this case, the dissociations will eventually lead to the production of steady-state gas pressures. In order to carry out the estimation of these gas pressures, under the condition that the specimen is fixing only the oxygen, one must assume that the dissociations occur at infinite velocity:

As with case $A$, the first dissociation produces both $\mathrm{SO}_{2}$ and $\mathrm{O}_{2}$; however, the $\mathrm{O}_{2}$ is consumed rapidly by the specimen as $\left(\mathrm{P}_{\mathrm{O} 2}\right)$ is greater than the dissociation pressure of the metal oxide being formed. As a consequence of this pumping action, the value of $\left(\mathrm{P}_{\mathrm{SO} 2}\right)$ must rise in order to maintain the equilibrium constant for the first reaction at a fixed value; as:

$$
\mathrm{K} 1=\left(\mathrm{P}_{\mathrm{O} 2}\right)\left(\mathrm{P}_{\mathrm{SO} 2}\right)^{2}
$$


However, the rising pressure of $\mathrm{SO}_{2}$ must necessarily cause the values of both $\left(\mathrm{P}_{\mathrm{O} 2}\right)$ and $\left(\mathrm{P}_{\mathrm{S} 2}\right)$ to increase in order to maintain the value of the equilibrium constant for the second reaction fixed as:

$$
\mathrm{K} 2=\left(\mathrm{P}_{\mathrm{S} 2}\right)\left(\mathrm{P}_{\mathrm{O} 2}\right)^{2} /\left(\mathrm{P}_{\mathrm{SO} 2}\right)^{2}
$$

These pressure increases do not proceed without limit for two reasons. Firstly, as $\left(\mathrm{P}_{\mathrm{SO} 2}\right)$ increases, its degree of dissociation must decrease in accordance with:

$$
\mathrm{K} 2=4\left(\mathrm{f}^{3}\right)\left(\mathrm{P}_{\mathrm{SO} 2}\right) \text { or } \mathrm{f}=(\mathrm{K} 2 / 4)^{(1 / 3)}\left(\mathrm{P}_{\mathrm{SO} 2}\right)^{(-1 / 3)} \text {, }
$$

and, secondly, the value of (K1) must remain constant. It follows that:

$$
\left(\mathrm{P}_{\mathrm{O} 2}\right)\left(\mathrm{P}_{\mathrm{SO} 2}\right)^{2}=\mathrm{K} 1
$$

from the first dissociation, and

$$
\left(\mathrm{P}_{\mathrm{O} 2}\right)=2\left[(\mathrm{~K} 2 / 4)^{(1 / 3)}\right]\left(\mathrm{P}_{\mathrm{SO} 2}\right)^{(2 / 3)}
$$

from the second.

Upon substitution of the second of these equations into the first, one obtains the following value for the steady-state pressure:

$$
\left(\mathrm{P}_{\mathrm{SO} 2}\right)=\left[\mathrm{K} 1 /(2 \mathrm{~K} 2)^{(1 / 3)}\right]^{(3 / 8)}
$$

Applying this approach, the relevant equilibrium gas pressures at $900^{\circ} \mathrm{C}$ are found to be:

$$
\begin{aligned}
& \left(\mathrm{P}_{\mathrm{SO} 2}\right)=5.93 \times 10^{-4} \mathrm{~atm}, \\
& \left(\mathrm{P}_{\mathrm{O} 2}\right)=5.60 \times 10^{-11} \mathrm{~atm}, \text { and } \\
& \left(\mathrm{P}_{\mathrm{S} 2}\right)=2.80 \times 10^{-11} \mathrm{~atm} .
\end{aligned}
$$

It is seen that the secondary dissociation (K2) now controls the pressures of $\mathrm{O}_{2}$ and $\mathrm{S}_{2}$, while the primary dissociation (K1) controls the pressure of $\mathrm{SO}_{2}$ for this case. The estimation method used here is believed to provide a realistic set of gas pressures for the case of the "lean" sulfidizing atmosphere as used in these tests.

Added note: The results provided by this method of estimation may also be approximated by means of a "mental experiment" in which: (1) the gas pressures of case A are present at temperature in the closed capsule, (2) the metallic specimen is inserted and allowed to consume 
some percentage of the oxygen present, (3) the metallic specimen is withdrawn and pressures are recalculated, and (4) the insertion-consumption-withdrawal processes are repeated. The gas pressures calculated by this iterative technique converge toward those cited above.

\section{Case C. Non-Reactive System (large $\mathrm{CaSO}_{4}$ and sulfur supplies)}

This case addresses only that particular situation wherein the reagents are admixed in stoichiometric proportions with respect to the production of $\mathrm{SO}_{2}$; i.e., the case where the mass of $\mathrm{CaSO}_{4}$ in the charge is approximately 8.5 times that of sulfur. For the non-reacting system, the sulfur pressure is essentially predetermined by three system parameters: the mass of sulfur in the charge, the temperature of the capsule, and the volume of the capsule $(42 \mathrm{ml})$.

The pressure of $\mathrm{SO}_{2}$ may be determined by first summing the following reactions:

$$
\begin{aligned}
& 4 \mathrm{CaSO}_{4} \rightarrow-4 \mathrm{CaO}+4 \mathrm{SO}_{2}+2 \mathrm{O}_{2} ; 2 \mathrm{G}_{\mathrm{O} 1} \\
& \mathrm{~S}_{2}+2 \mathrm{O}_{2} \rightarrow 2 \mathrm{SO}_{2} ;-2 \mathrm{G}_{\mathrm{O} 2} \\
& 2 \mathrm{~S} \quad->\quad \mathrm{S}_{2} ; \mathrm{G}_{03},
\end{aligned}
$$

to give

$$
4 \mathrm{CaSO}_{4}+2 \mathrm{~S} \rightarrow 4 \mathrm{CaO}+6 \mathrm{SO}_{2} ; \mathrm{G}_{4}
$$

and then solving the equilibrium relation:

$$
\mathrm{P}_{\mathrm{SO} 2}=\exp \left(-\mathrm{G}_{4} / 6 \mathrm{RT}\right)
$$

The oxygen pressure in this case will be that calculated from the equilibrium dissociations of $\mathrm{SO}_{2}$ and $\mathrm{CaSO}_{4}$ for those temperatures in the range of interest.

Applying this approach, the relevant equilibrium gas pressures at $900^{\circ} \mathrm{C}$ are found to be:

$$
\begin{aligned}
& \left(\mathrm{P}_{\mathrm{SO} 2}\right)=7.40 \times 10^{-2} \mathrm{~atm}, \\
& \left(\mathrm{P}_{\mathrm{O} 2}\right)=3.60 \times 10^{-15} \mathrm{~atm}, \text { and } \\
& \left(\mathrm{P}_{\mathrm{S} 2}\right)=3.57 \times 10^{-1} \mathrm{~atm} .
\end{aligned}
$$

It is seen that the addition of elemental sulfur strongly enhances the sulfur pressure, while decreasing the oxygen pressure, as compared to the cases where $\mathrm{CaSO}_{4}$ is the lone reagent. The pumping action of a reactive specimen will not sensibly alter this situation, so long as the supply of reagents is large. 
For the three cases discussed above, it is emphasized that: (1) the $\mathrm{SO}_{2}-\mathrm{SO}_{3}$ equilibrium has been neglected and (2) kinetic effects have, in no way, been taken into account. For a more complete discussion of equilibria in metal-oxygen-sulfur systems, the reader is referred to the work of others.

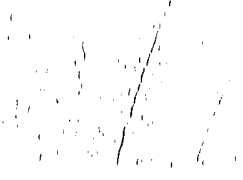

"P. Sarrazin and A. Skalli, "Corrosion of Metals in Multicomponent Gas Atmospheres: Generalization of the Use of Phase-Stability Diagrams," Oxid. Met. 30, 107-24 (1988). 


\section{INTERNAL DISTRIBUTION}

1-2. Central Research Library

3. Document Reference Section

4-5. Laboratory Records Department

6. Laboratory Records, ORNL-RC

7. ORNL Patent Section

8-10. M\&C Records Olfice

11. R. A. Bradley

12. P. T. Carlson

13-17. O. B. Cavin

18. D. F. Craig

19-23. J. H. DeVan

24. E. L. Fuller

25. C. R. Hubbard

26. R. R. Judkins

27. J. R. Keiser
28. R. C. Martin

29. H. E. McCoy

30. B. F. Myers

31. G. M. Slaughter

32. R. A. Strehlow

33. V. J. Tennery

34. P. F. Tortorelli

35. D. F. Wilson

36-40. J. S. Wolf

41. Y. A. Chang (Consultant)

42. H. W. Foglesong (Consultant)

43. J. J. Hren (Consultant)

44. M. L. Savitz (Consultant)

45. J. G. Simon (Consultant)

46. K. E. Spear (Consultant)

\section{EXTERNAL DISTRIBUTION}

47-48. AIR PRODUCTS AND CHEMICALS, P. O. Box 538, Allentown, PA 18105
S. W. Dean
S. C. Weiner

49. ALBERTA RESEARCH COUNCIL, Oil Sands Research Departent,

P.O. Box 8330, Post.ll Station F, Edmonton, Alberta, Canada T6H5X2

$$
\text { L. G. S. Gray }
$$

50-51. ALLISON GAS TURBINE DIVISION, P.O. Box 420, Indianapolis, IN 46206-0420

P. Khandelwal (Speed Code W-5)

R. A. Wenglarz (Speed Code W-16)

52. ARGONNE NATIONAL LABORATORY, 97(0) S. Cass Avenue, Argonne, IL $6(1) 439$

K. Natesan 
53. ARGONNE NATIONAL LABORATORY-WEST, P.O. Box 2528, Idaho Falls, ID 83403-2528
S. P. Henslee

54. AVCO RESEARCH LABORATORY, 2385 Revere Beach Parkway, Everett, MA 02149

R. J. Pollina

55-56. BABCOCK \& WILCOX, 1562 Beeson Street, Alliance, OH 44601

T. I. Johnson

T. Modrak

57. BABCOCK \& WILCOX, Domestic Fossil Operations,

20 South Van Buren Avenue, Barberton, $\mathrm{OH} 44023$

M. Gold

58. BABCOCK \& WILCOX, Lynchburg Research Center, P.O. Box 11165, Lynchburg, VA 24506

H. Moeller

59. BATTELLE-COLUMBUS LABORATORIES, 505 King Avenue, Columbus, $\mathrm{OH} 43201$

I. G. Wright

60-62. BRITISH COAL CORPORATION, Coal Research Establishment, Stoke Orchard, Cheltenham, Glochester, England, GL52 4RZ
M. Arnold
C. Bower
A. Twigg

63. BRITISH GAS CORPORATION, Westfield Development Centre, Cardenden, Fife, Scotland KY50HP

J. E. Scott

64. BROOKHAVEN NATIONAL LABORATORY, Department of Applied Science, Upton, Long Island, NY 11973

T. E. O'Hare

65-66. CANADA CENTER FOR MINERAL \& ENERGY TECHNOLOGY, 568

Booth Street, Ottawa, Ontario, Canada K1A OG1

R. W. Revie

M. Sahoo 
67. COMBUStION ENGINEERING, 1000) Prospect Hill Road, Windsor, CT 06095
D. A. Canonico

68. CONSOLIDATION COAL COMPANY, 4000 Brownsville Road, Library, PA 15129

S. Harding

69.71. ELECTRIC POWER RESEARCH INSTITUTE, P.O. Box 10412, 3412

Hillview Avenue, Palo Alto, CA 94303

W. T. Bakker

J. Stringer

R. H. Wolk

72. EUROPEAN COMMUNITIES JOINT RESEARCH CENTRE, Petten

Establishment, P.O. Box 2, 1755 ZG Petten, The Netherlands

M. Van de Voorde

73. FLUIDIZED BED TECHNOLOGIES, P.O. Box 4469, Chattanooga, TN 37405

R. Q. Vincent

74. FOSTER WHEELER DEVELOPMENT CORPORATICN, Materials

Technology Department, John Blizard Research Center,

12 Peach Tree. Hill Road, Livingston, NJ 07039

J. L. Blough

75. GAS RESEARCH INSTITUTE, 8600 West Bryn Mawr Avenue, Chicago, IL 60631

H. S. Meyer

76. GENERAL ELECTRIC COMPANY, 1 River Road, Bldg. 55, Room 115, Schenectady, NY 12345

R. W. Haskell

77. IDAHO NATIONAL ENGINEERING LABORATORY, P.O. Box 1625, Idaho Falls, ID 83415

D. W. Keefer

78. IOWA STATE UNIVERSITY, Materials Science and Engineering Department, 110 Engineering Annex, Ames, IA 500(0)1

K. M. Vedula 
79. LAWRENCE BERKELEY LABORATORY, University of California, Berkeley, CA 94720

A. V. Levy

80. LAWRENCE LIVERMORE LABORATORY, P.O. Box 808, L.325, Livermore, CA 94550

W. A. Steele

81. MOBIL RESEARCH \& DEVELOPMENT CORPORATION,

P.O. Box 1026, Princeton, NJ 08540

R. C. Searles

82. NATIONAL MATERIALS ADVISORY BOARD, National Research Council, 2101 Constitution Avenue, Washington, DC 20418

K. M. Zwilsky

83-84. NEW ENERGY AND INDUSTRIAL TECHNOLOGY DEVELOPMENT

ORGANIZATION, Sunshine 60 Bldg., P.O. Box 1151, 1-1, Higashi-

Ikebukuro 3-chrome, Toshima-Ku, Tokyo, 170, Japan

H. Narita

S. Ueda

85. RISOE NATIONAL LABORATORY, P.O. Box 49, DK-4000, Roskilde, Denmark

A. Olsen

86. SHELL DEVELOPMENT COMPANY, P.O. Box 1380, Houston, TX 77251-1380

L. W. R. Dicks

87. SOUTHWEST RESEARCH INSTITUTE, 6620 Culebra Road, P.O. Drawer 28510, San Antonio, TX 78284

F. F. Lyle, Jr.

88-89. TENNESSEE VALLEY AUTHORITY, 1101 Market Street, Missionary Ridge, Chattanooga, TN 37402-2801

C. M. Huang

A. M. Manaker

90. TEXAS EASTERN TRANSMISSION CORPORATION, P.O. Box 2521, Houston, TX 77252

D. H. France 
91. THE MATERIALS PROPERTIES COUNCIL, INC., United Engineering Center, 345 E. Forty-Seventh Street, New York, NY 10017

M. Prager

92. THE TORRINGTON COMPANY, Advanced Technology Center, 59 Field Street, Torrington, CT 06790

W. J. Chmura

93. UNIVERSAL ENERGY SYSTEMS, INC., 4401 Dayton-Zenia Road, Dayton, OH 45432

V. Srinivasan

94-95. UNIVERSITY OF CALIFORNIA AT BERKELEY, Berkcley, CA 94720

J. A. C. Humphrey, Dept, of Mechanical Engineering

E. R. Parker, Dept. of Materials Science and Mineral Engineering

96. UNIVERSITY OF TENNESSEE AT KNOXVILLE, Materials Science and Engineering Department, Knoxville, TN 37996

C. D. Lundin

97. UNIVERSITY OF TENNESSEE SPACE INSTITUTE, Tullahoma, TN 37388

J. W. Muchlhauser

98. WESTERN RESEARCH INSTITUTE, 365 N. 9th Street, P.O. Box 3395, University Station, Laramie, Wi 82071

V. K. Sethi

99. WESTINGHOUSE ELECTRIC CORPORATION, Research and Development Center, 1310 Beulah Road, Piltsburgh, PA 15235

S. C. Singhal

100. WESTINGHOUSE HANFORD COMPANY, P.O. Box 1970, W/A-65, Richland, WA 99.352

R. N. Johnson

101. DOE, OFFICE OF BASIC ENERGY SCIENCES, Materials Science Division, ER-131, GTN, Washington, DC 20545

J. B. Darby

112. DOE, OFFICE OF CONSERVATION AND RENEWABLE ENERGY, CE-12, Forrestal Building, Washington, DC 20545

J. J. Ebcrhardt 
103-110. DOE, MORGANTOWN ENERGY TECHNOLOGY CENTER, P.O. Box 880, Morgantown, WV 26505
R. A. Bajura
R. C. Bedick
D. C. Cicero
F. W. Crouse, Jr.
N. T. Holoombe
W. J. Huber
J. E. Notestein
J. S. Wilson

111. DOE, OFFICE OF FOSSIL ENERGY, Washington, DC 2.0585

J. P. Carr, FE-14

112. DOE, PITTSBURGH ENERGY TECHNOLOGY CENTER, P.O. Box 10940, Pittsburgh, PA 152.36
A. H. Baldwin
G. V. McGurl
R. Santore
T. M. Torkos

113-114. DOE OAK RIDGE FIELD OFFICE, P.O. Box 2008, Oak Ridge, TN 37831-6269

E. E. Hoffman

Deputy Assistant Manager for Energy Research and Development

115-124. DOE, OFFICE OF SCIENTIFIC AND TECHNICAL INFORMATION, P.O. Box 62, Oak Ridge, TN 37831

(For distribution by microfiche as shown in DOE/OSTI-4500, Distribution Category UC-330 (Transportation Systems), UC-103 (Fluidized Bed Combustion), UC-109 (Goal Gasification (Surface and Underground), and UC-114 (Coal-Based Instrumentation) 

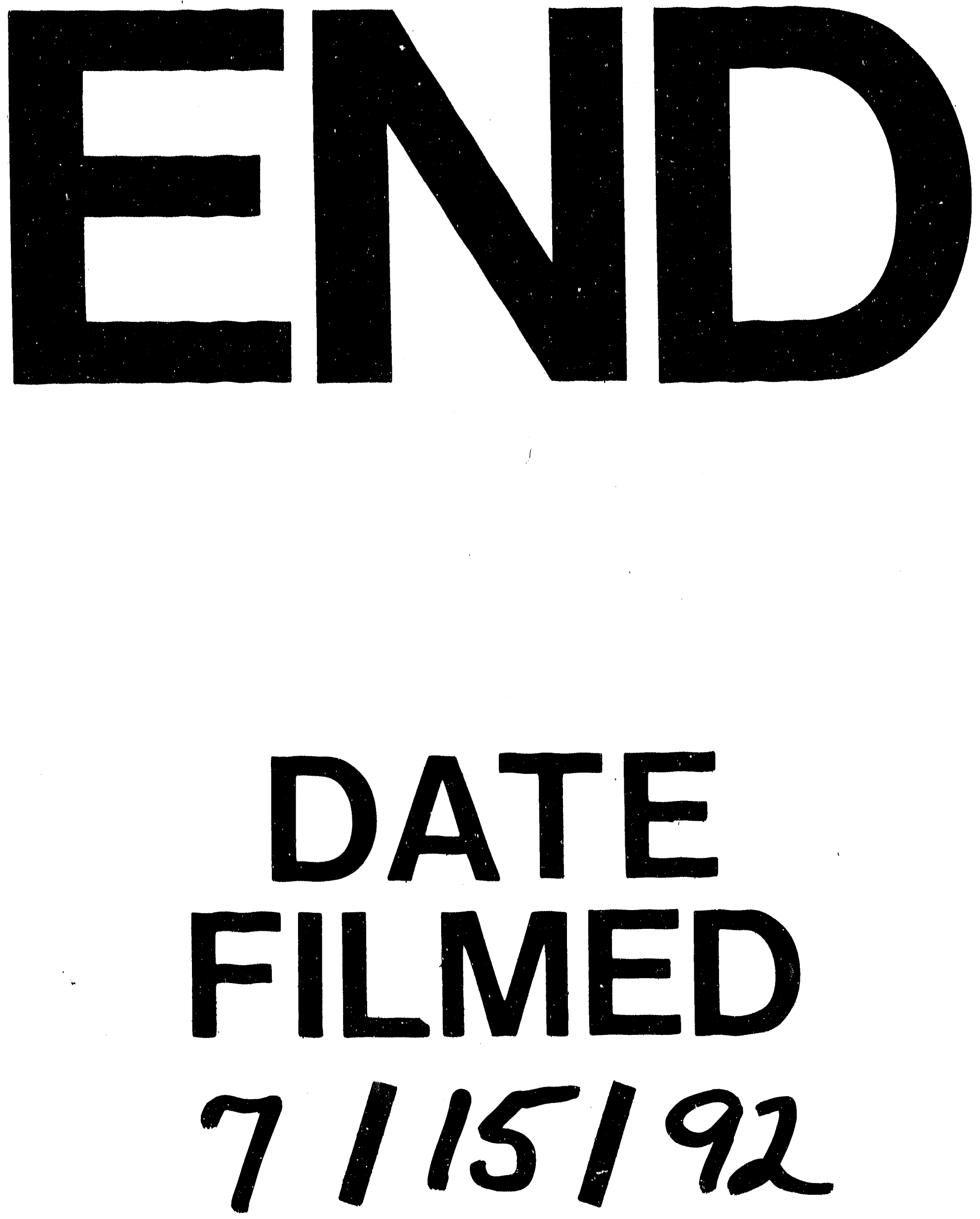


$$
\square
$$

